\title{
MULTI-LEVEL ANALYTIC NETWORK PROCESS MODEL TO MITIGATE SUPPLY CHAIN DISRUPTIONS IN DISASTER RECOVERY PLANNING
}

\author{
A Thesis \\ presented to \\ the Faculty of California Polytechnic State University, \\ San Luis Obispo \\ In Partial Fulfillment \\ of the Requirements for the Degree \\ Master of Science in Industrial Engineering
}

by

Martina U. Kroener

April 2016 
(c) 2016

Martina U. Kroener

ALL RIGHTS RESERVED 
TITLE:

AUTHOR:

DATE SUBMITTED:

CommitTee ChaiR:

COMmitTEe MEMBER:

COMmitTeE Member:
Multi-level Analytic Network Process Model to Mitigate Supply Chain Disruptions in Disaster Recovery Planning

Martina U. Kroener

April 2016

Reza Pouraghabagher, Ph.D.

Professor of Industrial Engineering

California Polytechnic State University

Jianbiao (John) Pan, Ph.D.

Professor of Industrial Engineering

California Polytechnic State University

Xuan Wang, Ph.D.

Assistant Professor of Industrial Engineering

California Polytechnic State University 


\title{
ABSTRACT
}

\author{
Multi-level Analytic Network Process Model to Mitigate Supply Chain \\ Disruptions in Disaster Recovery Planning
}

\author{
Martina U. Kroener
}

Over the past few decades, environmental changes have led to more frequent occurrences and greater intensities of natural disasters worldwide. In terms of globally connected supply chains, this has resulted in an enormous economical loss for corporations. Therefore, Business Continuity and Disaster Recovery (BC/DR) planning and management has become essential for businesses in order to protect their critical business flow. Yet there is a lack of systematic and transparent methodologies for companies to handle this problem.

Hence, this thesis introduces a novel approach to combine consecutive steps of the Disaster Recovery Planning (DRP) process within one application. The multi-criteria decision-making (MCDM) tool called the Analytic Network Process (ANP) is employed to identify critical products of a business and match them with optimal disruption mitigation strategies based on an evaluation of benefits, opportunities, costs, and risks (BOCR).

To validate the method developed in this thesis, a case study using historical data of a U.S. company (Company XYZ) is introduced. The results of the ANP mathematical modeling demonstrate that the developed methodology provides a valuable approach to analyze and confirm BC/DR planning decisions. Moreover, an expert of Company $\mathrm{XYZ}$ confirmed that the suggested solution established through this case study is in agreement with the preferable choice based on his expertise and professional decisionmaking.

Further research could extend the proposed methodology to other fields of BC/DR planning, such as IT Disaster Recovery Planning or Human Disaster Relief.

Keywords: Analytic Network Process, Business Continuity, Critical Products, Disaster Recovery, Mitigation Strategies, Supply Chain 
First, I would like to express my sincere gratitude to my advisor Professor Reza Pouraghabagher for the continuous support of my research, for his academic advice, patience, motivation, enthusiasm, and immense knowledge. His guidance helped me during all the time of research, writing of this thesis, and making decisions regarding my professional development.

Besides my advisor, I would like to thank the rest of my thesis committee: Prof. Dr. Jianbiao Pan, and Prof. Dr. Xuan Wang for their support with the model implementation and validation, their continuous encouragement, and insightful suggestions.

My sincere thanks also goes to the American and German Fulbright Program, which allowed me to participate in this Masters' degree program in Industrial Engineering at California Polytechnic State University. In particular, I want to thank Mrs. Laurie Stevens for the endless support of my academic and professional requests.

Last but not the least, I would like to thank my family and friends for supporting me in all my decisions, especially my dear friend Marissa for revising this thesis. 
LIST OF TABLES ...................................................................................... vii

LIST OF FIGURES.................................................................................. vii

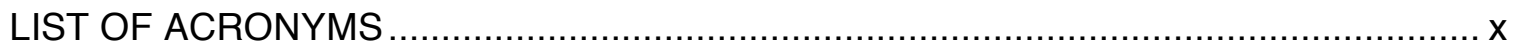

\section{CHAPTER}

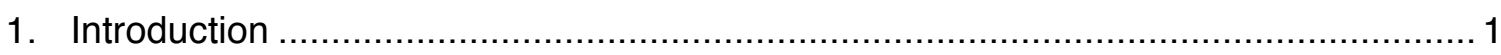

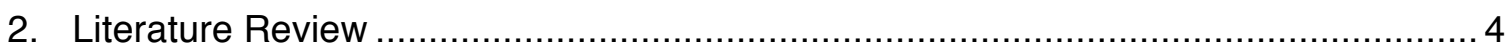

2.1 Great East Japan Earthquake Case Studies................................................. 4

2.2 Overview of Business Continuity and Disaster Recovery Practices........................ 5

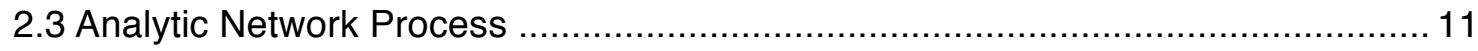

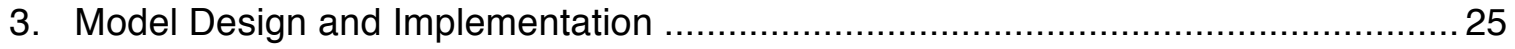

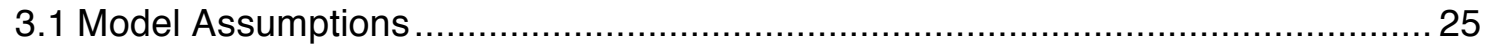

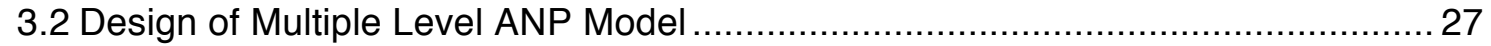

3.3 Implementation of Multiple Level ANP Model................................................... 31

4. Testing, Evaluation and Discussion .......................................................... 57

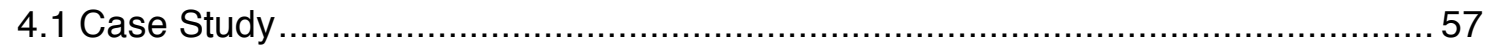

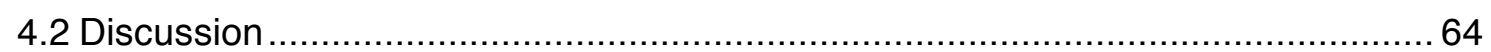

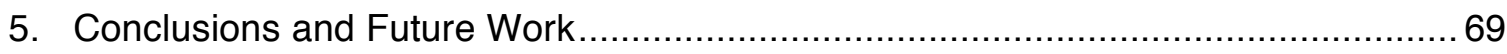

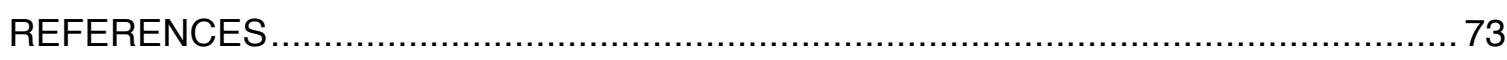

APPENDICES

A) Matrices of Product Selection ANP Model ............................................... 77

B) Limitmatrices for Benefits, Opportunities, Costs, and Risks............................. 79

C) Overview of Control Criteria and Decision Networks for each BOCR Merit ...........80

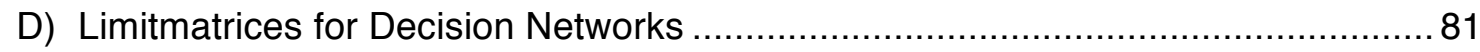

E) Table of Rating Standards used for BOCR-ANP Model ................................. 84

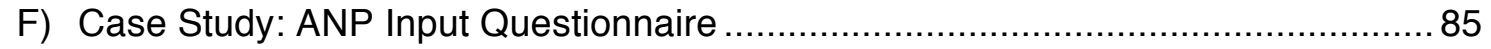

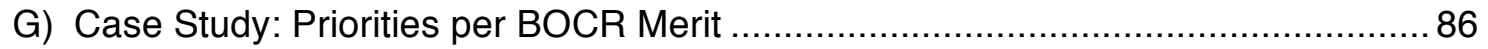

H) Case Study: Rating of Strategic Criteria vs. BOCR Merits ................................. 87

I) Case study: Super-/Limitmatrices for each BOCR Merit ................................. 88 


\section{LIST OF TABLES}

Table

Page

Table 1: Tactics for Managing Disruption Risks .............................................. 10

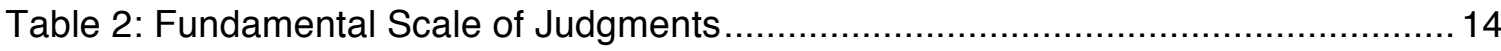

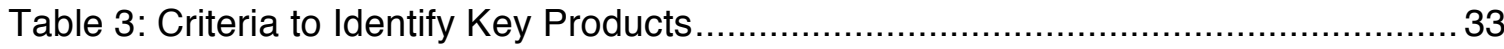

Table 4: Product Ranking Based on Obtained Priorities .......................................... 37

Table 5: Priorities Obtained for Criteria in each BOCR Merit........................................ 42

Table 6: Priorities Obtained for Disruption Mitigation Strategies per BOCR Merit ..........50

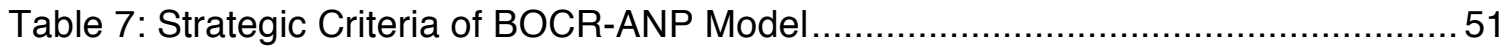

Table 8: Priority Rating of Strategic Criteria against BOCR Merits .............................55

Table 9: Synthesizing BOCR for each Alternative Using the Ideal Mode.......................56

Table 10: Final Ranking of Disruption Mitigation Strategies for Product B....................62 


\section{LIST OF FIGURES}

Figure

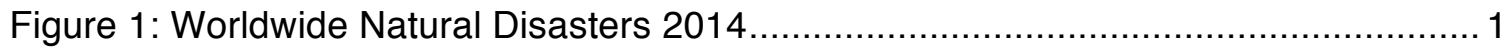

Figure 2: Risk Analysis and Business Continuity Process .................................... 6

Figure 3: From Business Continuity Management to Disaster Recovery Planning ........... 7

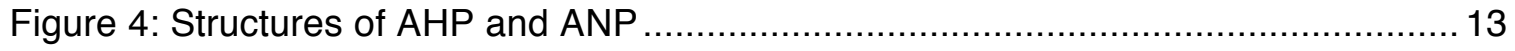

Figure 5: Network Structure with Generalized Supermatrix .................................. 17

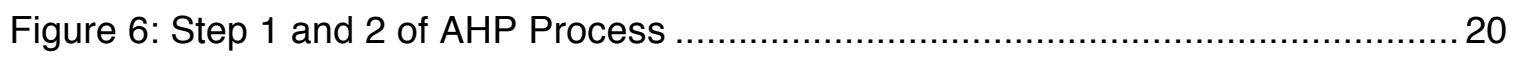

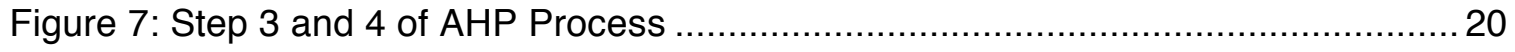

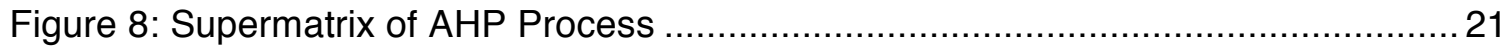

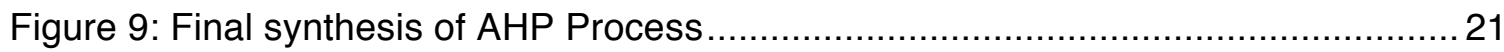

Figure 10: Flowchart for Multi-Level ANP Model Design........................................29

Figure 11: Implementation of ANP via Multiple Levels with SuperDecisions .................30

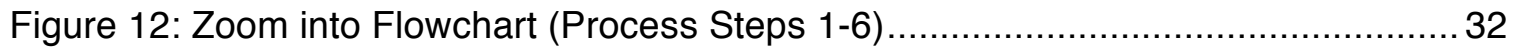

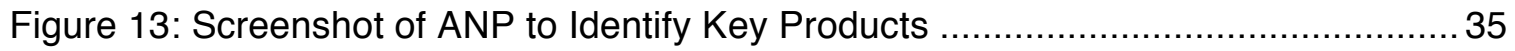

Figure 14: Pairwise Comparisons for Critical Products in SuperDecisions Software...... 36

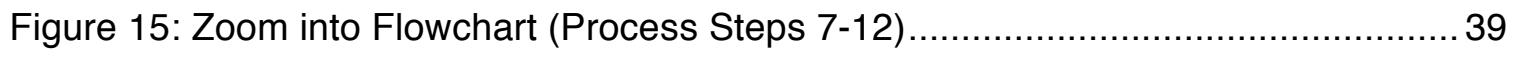

Figure 16: BOCR Control Criteria Hierarchies ................................................. 40

Figure 17: Pairwise Comparisons for Control Criteria of Benefits in SuperDecisions ..... 41

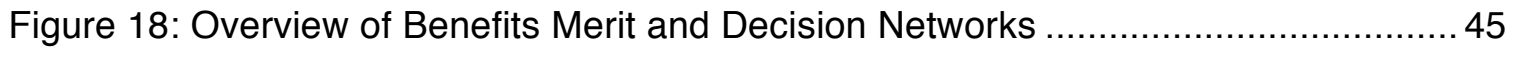

Figure 19: Overview of Opportunities Merit and Decision Networks ......................... 46

Figure 20: Overview of Costs Merit and Decision Networks ................................... 47

Figure 21: Overview of Risks Merit and Decision Networks ...................................... 48

Figure 22: Zoom into Flowchart (Process Steps 13-18) ............................................ 49 
Figure 23: Screenshot of Strategic Criteria Network

Figure 24: Priorities Obtained in Strategic Criteria Network .................................... 53

Figure 25: Data Gathering for Input of ANP Models ......................................... 57

Figure 26: Screenshot of "Key Product Selection" Network (Case Study) .....................58

Figure 27: Screenshot of Benefits Merit (Case Study) ........................................ 59

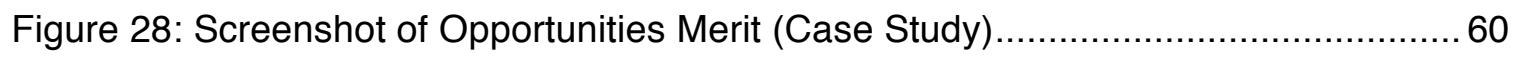

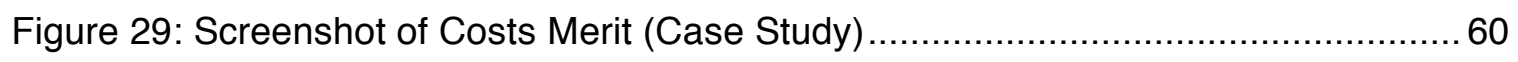

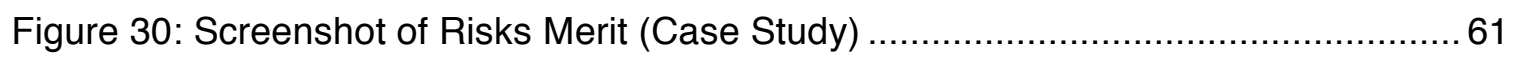

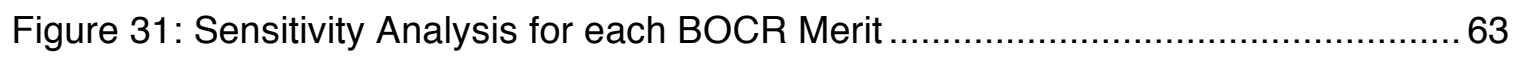




\section{LIST OF ACRONYMS}

$\begin{array}{ll}\text { AHP } & \text { Analytic Hierarchy Process } \\ \text { ANP } & \text { Analytic Network Process } \\ \text { BC/DR } & \text { Business Continuity / Disaster Recovery } \\ \text { BCM } & \text { Business Continuity Management } \\ \text { BCP } & \text { Business Continuity Planning } \\ \text { BIA } & \text { Business Impact Analysis } \\ \text { BOCR } & \text { Benefits, Opportunities, Costs, Risks } \\ \text { BOCR-ANP } & \text { ANP with Benefit, Opportunity, Cost, and Risk Merits } \\ \text { BOM } & \text { Bill of Materials } \\ \text { DEMATEL } & \text { Decision Making Trial and Evaluation Laboratory } \\ \text { DRM } & \text { Disaster Recovery Management } \\ \text { DRP } & \text { Disaster Recovery Planning } \\ \text { IPO } & \text { Input/Process/Output model } \\ \text { MCDM } & \text { Multi-criteria Decision-Making } \\ \text { SCM } & \text { Supply Chain Management }\end{array}$




\section{INTRODUCTION}

The occurrence and impact of natural disasters has risen over the last centuries, resulting in great human misery and enormous economic losses. In 2014 alone, there were more than 900 weather-related catastrophes, as shown in Figure 1, caused by earthquakes, storms, floods, and droughts. These disasters killed 6,900 people and created 97 billion U.S. dollars in overall losses and 30 billion U.S. dollars in insured losses (Munich Re, 2015).

NatCatSERVICE

Loss events worldwide 2014 Munich RE 禀

Geographical overview

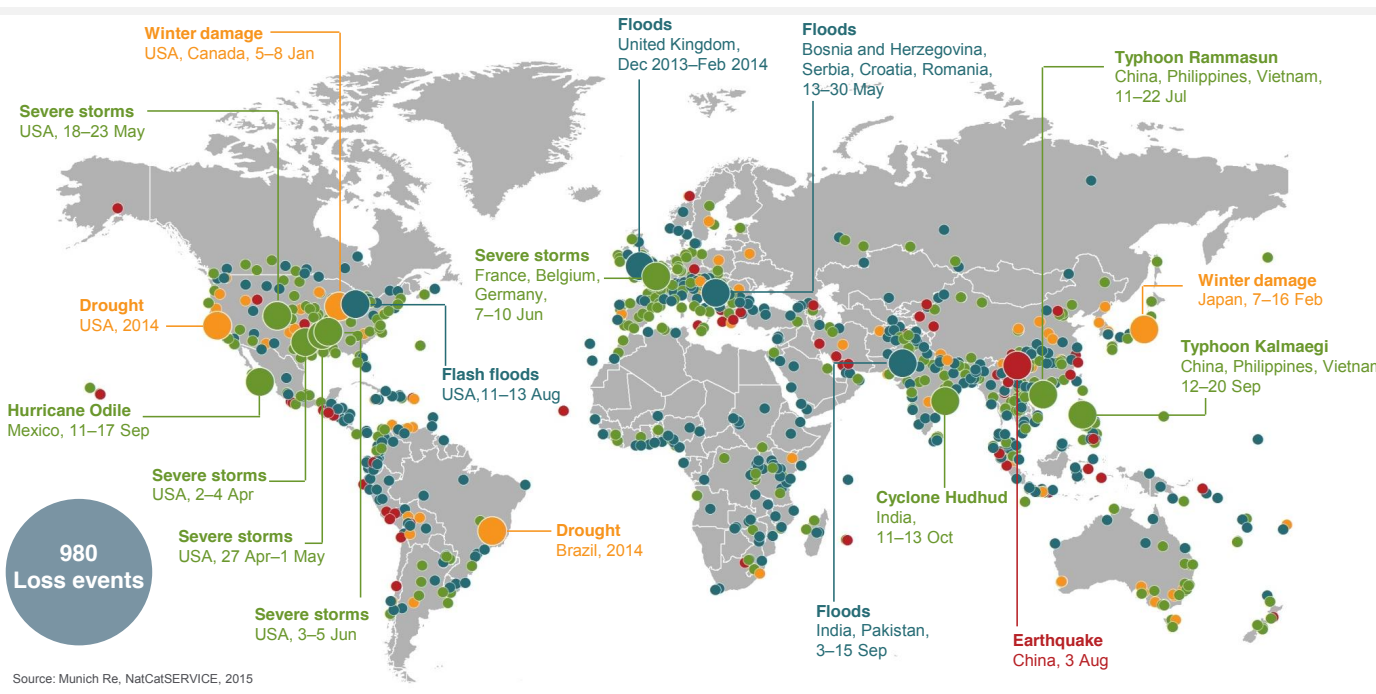

- Loss events

Selection of catastrophes Overall losses $\geq$ US $\$ 1,500 \mathrm{~m}$
- Geophysical events (Earthquake, tsunami, volcanic activity)

- Meteorological events (Tropical storm, extratropical storm,
convective storm, local storm)
- Hydrological events (Flood, mass movement)

- Climatological events (Extreme temperature, drought, wildfire)

๑ 2015 Münchener Rückversicherungs-Gesellschaft, Geo Risks Research, NatCatSERVICE - As at January 2015

Figure 1: Worldwide Natural Disasters 2014 (Source: Munich Re, NatCatSERVICE, 2015)

At the same time, companies have become more and more global by transferring parts of their production facilities to other countries and having supply chains worldwide. In this way, businesses are more vulnerable to supply chain disruptions and 
their unpredictable challenges. As an example, $25 \%$ of businesses impacted by a major disaster never resume their operations (Hewlett-Packard Development Company L.P., 2007). Therefore, it is essential that businesses invest in Business Continuity and Disaster Recovery (BC/DR) Planning and Management to proactively prepare for disruptions in their supply chains and production facilities.

During the last couple of years, researchers and organizations have intensified their research activities in the field of BC/DR planning. While most managers focus on protecting their businesses against reoccurring, low-impact disruptions of supply chains, researchers are trying to develop new methods to mitigate high-impact, lowlikelihood risks such as natural disasters. Both parties agree that an organization will never be able to restore all processes at the same time when a disaster hits the plant. Therefore, a business should identify its critical processes and products, and prioritize products for which business resilience practices will be implemented.

The intention of this research is to employ a unique approach of multi-criteria decision-making (MCDM) in the field of BC/DR planning for supply chains. The specific MCDM technique applied in this research is called Analytic Network Process (ANP), which allows analyzing and making complex decisions based on mathematical modeling. The proposed framework for this investigation is divided in two parts. The first ANP model ranks the products of a company with respect to multiple criteria. Based on the ranking, they are then categorized into critical and non-critical products. For these critical products, a second ANP model is employed to identify the optimal disruption mitigation strategy based on an evaluation of benefits, opportunities, costs, and risks. In order to implement this extensive network model, decision-making software employing the Analytic Network Process, called SuperDecisions, will be utilized. 
This thesis is divided into four chapters following this introductory first chapter. Chapter 2 will provide a review of disaster planning and mitigation procedures and expand the focus on the ANP decision-making tool. The third chapter describes the design and implementation of a multiple layer ANP model to identify critical products of a company and match these with optimal disruption mitigation strategies based on an assessment of benefits, opportunities, costs, and risks. Chapter 4 illustrates a case study applying data from a field expert, followed by a thorough discussion of the proposed model and method. The last chapter offers conclusions of the proposed and validated ANP framework and makes recommendations for future research. 


\section{LITERATURE REVIEW}

This chapter reviews case studies of the Great East Japan Earthquake to demonstrate the impact of natural disasters on global corporations and their supply chains. Thus, the author was able to draw the conclusion that there is a lack of effective tools for companies in the field of Business Continuity and Disaster Recovery Planning for supply chains. Moreover, this chapter shall give an overview of general $\mathrm{BC} / \mathrm{DR}$ practices and techniques to illustrate at which planning stage the proposed research method is introduced. Special attention shall be given to the general Analytic Network Process decision-making tool, which will be described in detail in the last section of this chapter.

\subsection{Great East Japan Earthquake Case Studies}

One of the most devastating natural disasters ever recorded was the Great East Japan Earthquake in 2011. It affected economies across the globe, especially impacting the Japanese economy. The manufacturing and chemical industries suffered losses particularly from the collapse of infrastructure and power supply systems, resulting in heavy financial losses for individual companies and the closing of businesses (Abe \& Ye, 2013). The production interruption triggered a domino effect, compromising the production lines of businesses not only in the immediate geographical impacted area, but also their supply chain partners in other parts of Japan, as well as worldwide. Abe and Ye (2013) state specifically that Thailand, the Philippines, and Indonesia recorded a large production decline in the automotive and electrical part sector after the earthquake in Japan. Even large global corporations, like Toyota and some of their tier-one suppliers did not fully recover until a couple of months after the disaster (Matsuo, 2014). 
In Toyota's case, the disaster did not directly damage their manufacturing and assembly plants, but nevertheless Toyota had to shut down their domestic sites for nearly two weeks after the earthquake due to missing materials and parts from suppliers (Matsuo, 2014). One of Toyota's main problems stemmed from an unclear supply chain. Toyota ran out of raw materials and components for critical products without knowing exactly which suppliers could continue to deliver. Although Toyota was able to identify all of their main suppliers (first and second tier), they could not distinguish suppliers of critical parts further down the supply chain due to a lack of visibility in their extensive supply chain. As a result, Toyota faced production shortages until approximately three months after the earthquake (Matsuo, 2014). After the disaster, a thorough analysis of Toyota's supply chain identified three weak links accounting for the loss of efficiency in the production system. The losses in productivity could have been prevented with the systemization of well-formulated plans and the implementation of strategies for disaster recovery in response to weather-related natural events. The Toyota case study illustrates that even large companies can be impacted heavily by disruptions including natural disasters. Thus, it is essential that businesses proactively plan for disruptions in their supply chains and production facilities, in addition to developing recovery strategies to mitigate negative long-term impacts. The next section expands on practices employed in BC/DR planning and management and develops an approach to mitigate supply chain disruptions with the help of proactive decision-making models.

\subsection{Overview of Business Continuity and Disaster Recovery Practices}

Although disasters cannot be prevented, companies can prepare and mitigate the effects of natural disasters on their businesses. The case studies of the Great East Japan Earthquake demonstrate the significance of thorough Supply Chain Manage- 
ment (SCM), including the identification of supply chain risks and proactive planning for supply chain disruptions.

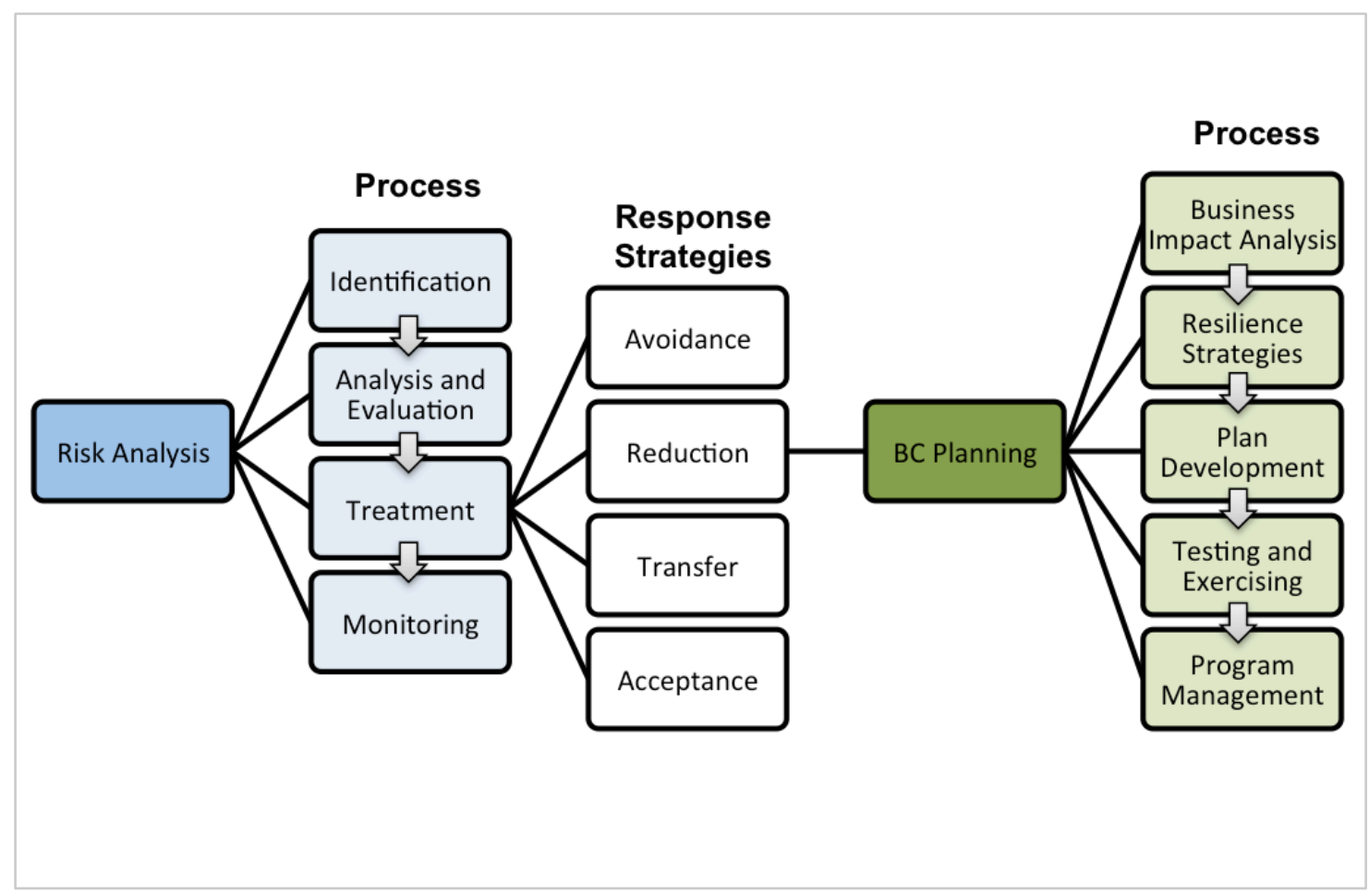

Figure 2: Risk Analysis and Business Continuity Process (Source: World Continuity Congress, 2011)

In order to begin to explain Business Continuity and Disaster Recovery Management practices, definitions are required. Often, the terms "business continuity" and "disaster recovery" are used interchangeably and thus lead to confusion. Figure 2 illustrates the general risk analysis process, which managers use in their organizations. First, risks are identified and analyzed, and then matching response strategies are developed. Business Continuity Planning $(\mathrm{BCP})$ is introduced as a specific part of a risk reduction treatment. In general, Business Continuity Management $(\mathrm{BCM})$ is a management process with the goal to plan, implement, and continually improve a management system that prepares for any disruptive events that could potentially harm an organization (ISO 22301:2012, 2012). Business Continuity Management (BCM) methods 
require the involvement of the whole organization, including middle and upper management, and the use of a general crisis management process to prepare and react to business threats. Evans and Elphick (2005) describe four stages as a general sequence recommended for crisis management, introduced as the "4 R's": Reduction, Readiness, Response, and Recovery. Following these four stages, an organization can establish tailored mitigation and contingency strategies to overcome potentially negative long-term effects.

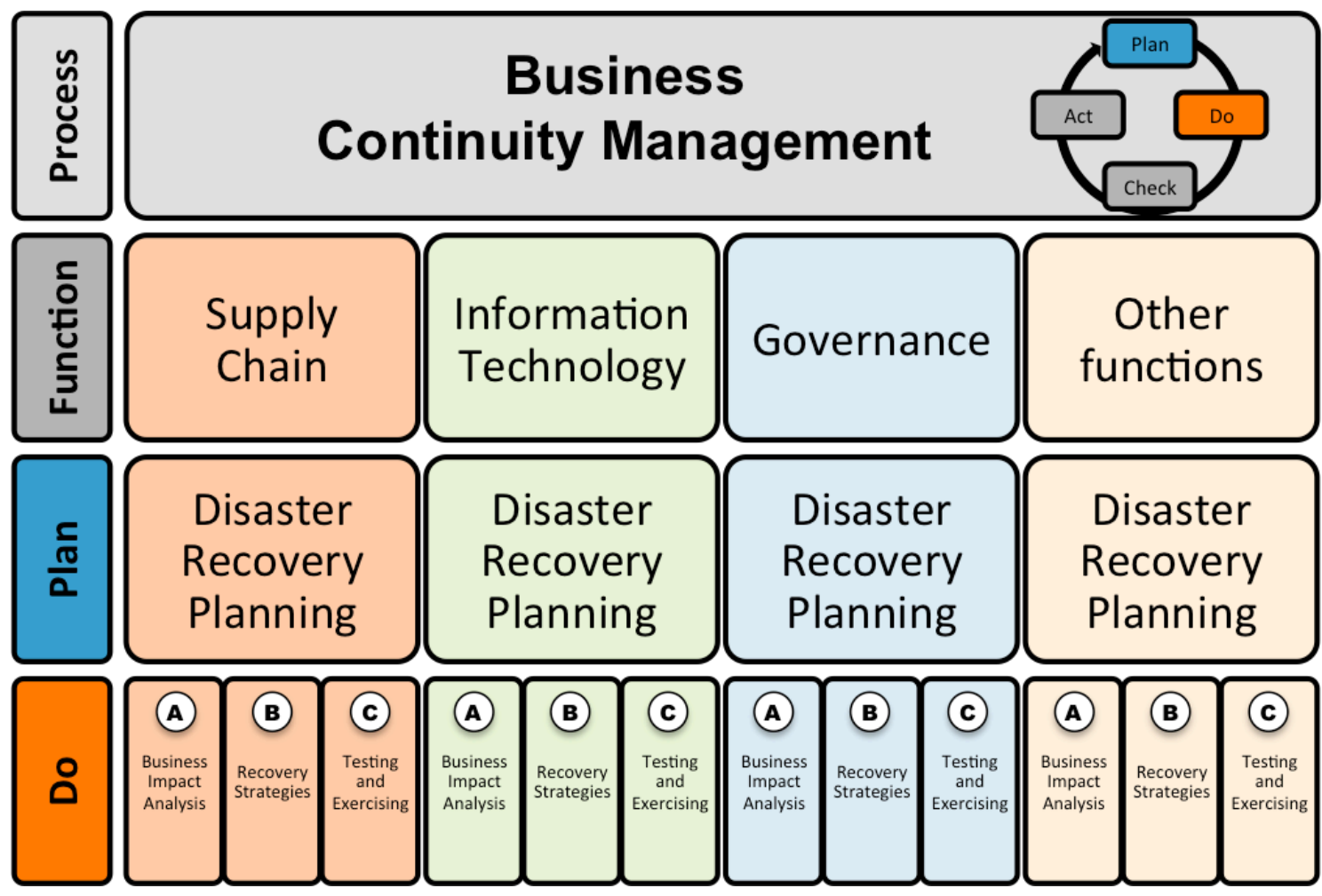

Figure 3: From Business Continuity Management to Disaster Recovery Planning

Disaster Recovery Planning (DRP), represents the planning phase of Disaster Recovery Management (DRM), which is a specific part of the BCM (Sahebjamnia, Torabi, \& Mansouri, 2015). As Figure 3 illustrates, an organization develops multiple DRP's to successfully mitigate and overcome any disasters harming the success of their particular business units or functions. This thesis focuses on Disaster Recovery 
Planning for supply chains. The next section will describe the DRP process in more detail.

In general, the goal of applying DRP to supply chains is to evaluate all potential scenarios and risks that could lead to a disruption or delay of material, cash flow, or information (Wieland \& Wallenburg, 2012). The DRP process is carried out through several iterations of business impact analysis (Step A in Figure 3), development of recovery strategies (Step B in Figure 3), and implementation and testing of the procedures (Step C in Figure 3).

Business Impact Analysis (BIA) describes the methodology of identifying all risks that could potentially trigger a supply chain breakdown (Torabi, Rezaei Soufi, \& Sahebjamnia, 2014). These risks are then evaluated by their impact and likelihood. In general, disruptions caused by natural disasters are often classified as low-likelihood risks with high impacts on the supply chain network. Organizations typically develop plans to reduce supply chain risks and mitigate negative impacts that are more likely to occur, and hence create a higher risk for the company. Companies often overlook disastrous events that could severely harm their business operations, but are not likely to occur on a regular basis. As a result, the challenge for managers is to protect their business against high frequency, low-impact risks while also developing strategies to successfully mitigate low-likelihood, high-impact disruptions for their most important products and processes (Chopra \& Sodhi, 2004).

Focusing on the BIA (Step A in Figure 3) of supply chains, Torabi et al. (2014) developed a novel approach for prioritizing critical business products and processes. This prioritization systematic is necessary since a business is never able to recover all their products and processes at the same time after a disaster strikes. Torabi et. al 
(2014) divided the BIA into three steps: (1) Identification of key products, (2) Identification of critical processes, and (3) Development of continuity measures for key products and critical functions. A main difference between Torabi et al.'s approach and previous research was that their process was based on a specific multiple criteria decisionmaking tool called Analytic Network Process (ANP).

ANP allows identifying critical products and processes based on multiple criteria instead of only one criterion such as revenue. Using ANP as a decision-making tool in DRP has a couple of advantages for organizations. First, decision-making models based on ANP are relatively easily to develop and to employ (Taslicali \& Ercan, 2006) and are therefore ideal business solutions. Additionally, ANP decision-making takes a wide array of factors into account instead of basing the choice on one aspect, or solely relying on the intuition of managers. Since supply chain disruptions caused by natural disasters are less likely to occur but result in a high-impact on organizations, a tool for hypothetical decision-making is required. The ANP method represents a powerful application to model complex decision-making environments, which are usually influenced by a mix of tangible and intangible factors. As a result, the ANP method is employed in this thesis and will therefore be discussed in detail in the next section of this literature review.

Referring back to Figure 3 , the next step following the BIA is the identification and implementation of recovery strategies in response to supply chain disruptions. In general, strategies to reduce and prepare for disruptions are called mitigation strategies; whereas, contingency strategies describe tactics after a disaster strikes. Tomlin (2006) introduces six widely used mitigation and contingency strategies (Table 1) for managing supply chain disruption risks. 
Table 1: Tactics for Managing Disruption Risks (Based on Tomlin, 2006)

\begin{tabular}{ll}
\hline Category & Tactic \\
\hline Financial mitigation & Business interruption insurance \\
Operational mitigation & Inventory \\
& Sourcing \\
Operational contingency & Rerouting \\
& Demand management \\
\hline
\end{tabular}

Another approach of tackling disruption risks, referred to as "passive acceptance," fits neither the category of mitigation nor contingency strategies. It describes a company that does not choose to invest in recovery practices and agrees to risk an interruption of their operations. This tactic is obviously the preferred choice when companies are hesitant to invest, but it is important to acknowledge possible effects and costs of low-likelihood but high-impact risks such as weather-related disasters (Chopra \& Sodhi, 2004). In general, the implementation of recovery strategies is expensive as Tomlin (2006) states, and therefore should only be considered for key products and processes of a company.

The previous literature research revealed that there is a missing link in the Disaster Recovery Planning process between the Business Impact Analysis (Step A) and the selection of appropriate Recovery Strategies (Step B), as shown in Figure 3. As a result, the intention of this research is to employ a novel approach in multi-attribute decision-making by combining two ANP models in an effort to:

1. Identify critical products of a company or business unit based on multiple criteria. 
2. Analyze and find the optimal disruption mitigation strategy for a critical product based on the assessment of benefits, opportunities, costs, and risks of a set of strategies.

Input for both ANP models are measures and strategies found through the literature review of this thesis. The product selection ANP model employs measures suggested by Torabi et al. (2014). In the second ANP model, various supply chain disruption mitigation strategies defined by Tomlin (2006) shall be evaluated in this investigation. This proposed research statement represents a unique approach since there has been no former work identified which extends BIA steps with the succeeding DRP process step of implementing recovery strategies. Additionally, the suggested investigation requires the combination of two separate Analytic Network Processes into one comprehensive, multiple level ANP model. For the extensive calculations required in the multi-level ANP model, ANP decision-making software will be employed. The next chapter describes the working mechanics of the Analytic Network Process in more detail.

\subsection{Analytic Network Process}

\section{Introduction}

The Analytic Network Process (ANP) and its more specific form, called the AnaIytic Hierarchy Process (AHP), are methods in multi-criteria decision-making. Whereas the ANP allows non-linear relationships and feedback between elements to structure a decision problem, the AHP consists solely of linear connections. In general, MCDM techniques are used to determine the best alternative based on individual preferences

of decision-makers rather than objective measurements. Using personal preference 
means that the outcome for one person applying the decision-making method will be completely different from another person's outcome that reflects their individual goals and judgment (Saaty, 2009).

ANP and AHP are methods of relative measurement and intangibles, which assist in making complex decisions based on the perception and experience of decisionmakers and experts. Thomas L. Saaty developed the Analytic Network Process as a broader form of the Analytic Hierarchy Process allowing non-linear relationships and interdependencies such as cycles (mutual outer dependencies) and loops (inner dependencies) between elements of a network (Saaty \& Vargas, 2013).

The general approach of both decision-making methods is based on the same principles. For this purpose, rationality as well as intuition is taken into account when the best option from a number of alternatives are evaluated with regard to several criteria. Therefore, a decision-maker is needed to carry out simple pairwise comparisons of criteria with respect to alternatives and vice-versa. The judgments are then turned into overall priorities for ranking alternatives. Finally, Saaty noted that intuitive judgments may lead to inconsistencies, which need to be minimized before a final synthesis is made (Saaty \& Vargas, 2001).

\section{Building the Structure: Hierarchy or Network?}

Figure 4 shows a hierarchy model on the left side, which provides the simplest form of structuring decision problems. The goal of a decision problem is stated on the first level (followed by criteria used for evaluation) and alternatives on the next lower level of the hierarchy. The arrows indicate the way comparisons are carried out. Criteria are pairwise compared with respect to the goal to establish the importance of each criterion; then alternatives are pairwise compared with regard to each criterion. On the 
right side of Figure 4, a network model is shown where elements are freely arranged and connected to each other, instead of the AHP's linear structure (Saaty, 2009). Hence, ANP models allow simulating feedback loops and interdependencies between all elements, representing a more realistic scenario of complex decision-making.
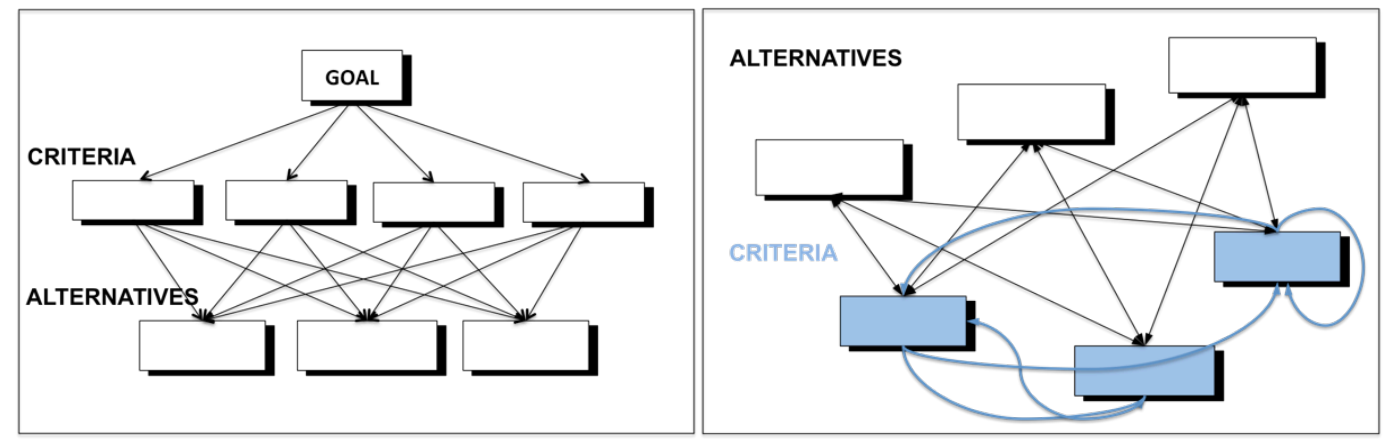

Figure 4: Structures of AHP and ANP (Source: Saaty and Vargas, 2001)

An essential characteristic of ANP is the way in which pairwise comparisons are conducted. Saaty introduces the term control criterion to describe an element, which serves as a common denominator when two elements are compared to each other. This signifies that all elements can be pairwise compared to each other when they have common feature towards a third element serving as basis. Thus, alternatives can be pairwise compared to a criterion, and criteria can be pairwise compared to a alternative. This was not possible with the AHP method where all elements were compared based on a top-down approach. To structure detailed ANP models wisely, Saaty introduces clusters, which refer to grouping of homogenous elements together, such as alternatives, criteria, and subcriteria. Determining the relationships between all elements leads to outer dependencies as well as inner dependencies between clusters of the ANP, as shown on the right hand side of Figure 4. 


\section{The Fundamental Scale for Making Comparisons with Judgments}

In order to obtain priorities, which resemble human decision logic most accurate, two measurement systems are used: absolute and relative measurement systems, with the intention of deriving ratio scales. For absolute measurements, rating standards are established and elements are compared once at a time against the standards. An example of a standard are grades from A to F with which each letter represents a specific numerous value (Saaty \& Vargas, 2001). Absolute measurements in AHP and ANP are used when certain ideals already exist and alternatives can be rated against them.

Table 2: Fundamental Scale of Judgments (Source: Saaty and Vargas, 2001)

\begin{tabular}{|c|c|c|}
\hline $\begin{array}{l}\text { Intensity of } \\
\text { importance }\end{array}$ & Definition & Explanation \\
\hline 1 & Equal importance & $\begin{array}{l}\text { Two activities contribute equally to } \\
\text { the objective. }\end{array}$ \\
\hline 2 & Weak & \\
\hline 3 & Moderate importance & $\begin{array}{l}\text { Experience and judgment slightly fa- } \\
\text { vor one activity over another. }\end{array}$ \\
\hline 4 & Moderate plus & \\
\hline 5 & Strong importance & $\begin{array}{l}\text { Experience and judgment strongly } \\
\text { favor one activity over another. }\end{array}$ \\
\hline 6 & Strong plus & \\
\hline 7 & $\begin{array}{l}\text { Very strong or demonstrated } \\
\text { importance }\end{array}$ & $\begin{array}{l}\text { An activity is favored very strongly } \\
\text { over another; its dominance demon- } \\
\text { strated in practice. }\end{array}$ \\
\hline 8 & Very, very strong & \\
\hline 9 & Extreme importance & $\begin{array}{l}\text { The evidence favoring one activity } \\
\text { over another is of the highest possi- } \\
\text { ble order of affirmation. }\end{array}$ \\
\hline $\begin{array}{l}\text { Reciprocals } \\
\text { of above }\end{array}$ & $\begin{array}{l}\text { If activity } i \text { has one of the above } \\
\text { nonzero numbers assigned to it } \\
\text { when compared with activity } j \text {, } \\
\text { then } j \text { has the reciprocal value } \\
\text { when compared with } i \text {. }\end{array}$ & A reasonable assumption. \\
\hline
\end{tabular}


A more common approach, however, is the application of relative measurements. In this approach, two elements are compared with respect to a common property, and a ratio is assigned accordingly. Saaty and Vargas (2001) suggested a fundamental scale with integers between one and nine to express the nature of the preference between two elements with a quantitative judgment. Table 2 gives the quantitative and qualitative description for the intensities of importance.

Using the fundamental scale, a specific value representing the intensity of importance is assigned to element $i$ when compared to element $j$. Then, element $j$ automatically receives the reciprocal value when compared to $i$. Performing pairwise comparisons for all elements with respect to a common feature results in a consistent reciprocal matrix of judgments:

$$
A=\left(a_{i j}\right) \text { with } a_{i j}, a_{j i}=\frac{1}{a_{i j}} \text { and } a_{i i}=1 \text {, }
$$

where $i$ represents the row elements, $j$ the column elements of the matrix and $a_{i j}$ the importance of the $i$ th element compared to the $j$ th element (Chung, Lee, and Pearn, 2005). Saaty and Vargas (2001) discuss the significance of the comparison matrix for developing an estimate of the relative importance of all elements by deriving a local priority vector, which will from now on referred to as Eigenvector $w$. In general, the priority vector is obtained by solving the following equation (Chung et al., 2005):

$$
A * w=\lambda_{\max } * w
$$

where $A$ is a matrix of pairwise comparisons, $w$ is the eigenvector, and $\lambda_{\max }$ is introduced as the largest eigenvalue of $A$. The derivation of the eigenvector approach to obtain the relative importance of elements, as well as the procedures for how to approximate the eigenvector $w$ are extensively elaborated on in Saaty's comprehensive literature involving AHP and ANP from 2001, 2005, and 2009. 
The eigenvector solution emphasizes the relevance of consistency when making judgments. However, the way humans make decisions leads to inconsistencies, and with this solution the inconsistency of each comparison matrix can be measured as a percentage. Saaty and Vargas (2001) define a maximum value of $10 \%$ as acceptable. If the inconsistency ratio is higher than the upper limit, judgments should be revised; otherwise, false conclusions might be drawn. For details on the mathematical determination of the measurement of consistency and inconsistency, the reader can refer to Saaty's and Vargas' book from 2001: 'Models, Methods, Concepts and Applications of the Analytic Hierarchy Process." The employed ANP software in this thesis provides a function to monitor and reduce inconsistencies. It shall be indicated, that all computations throughout this project conform to the maximal inconsistency index of $10 \%$.

The following section describes how the eigenvector solution is used to obtain priorities for criteria and alternatives. For this purpose, Saaty's (2004) concepts of the "supermatrix," "clustermatrix," and "limitmatrix" are introduced.

\section{The Supermatrix Concept}

All priority vectors derived from the comparison matrix are entered as column vectors with respect to their control criterion into a new matrix called the supermatrix (Saaty, 2004). Saaty introduced the supermatrix concept to model relationships and interdependencies between elements in a system. Figure 5 shows a simplified network structure with its corresponding supermatrix in which:

- $\quad w_{21}$ is a vector that represents the impact of the goal on the criteria,

- $\quad W_{22}$ is a matrix that represents an inner dependence between criteria,

- $W_{32}$ is a matrix that represents the impact of detailed criteria on control criteria, 
- $W_{33}$ is a matrix that represents an inner dependence between subcriteria,

- $W_{34}$ is a matrix that represents the impact of criteria on each of the alternatives,

- $\quad I$ is the identity matrix (Chung et al., 2005).

Note that all fields where elements do not have influence on each other are filled with zeros.

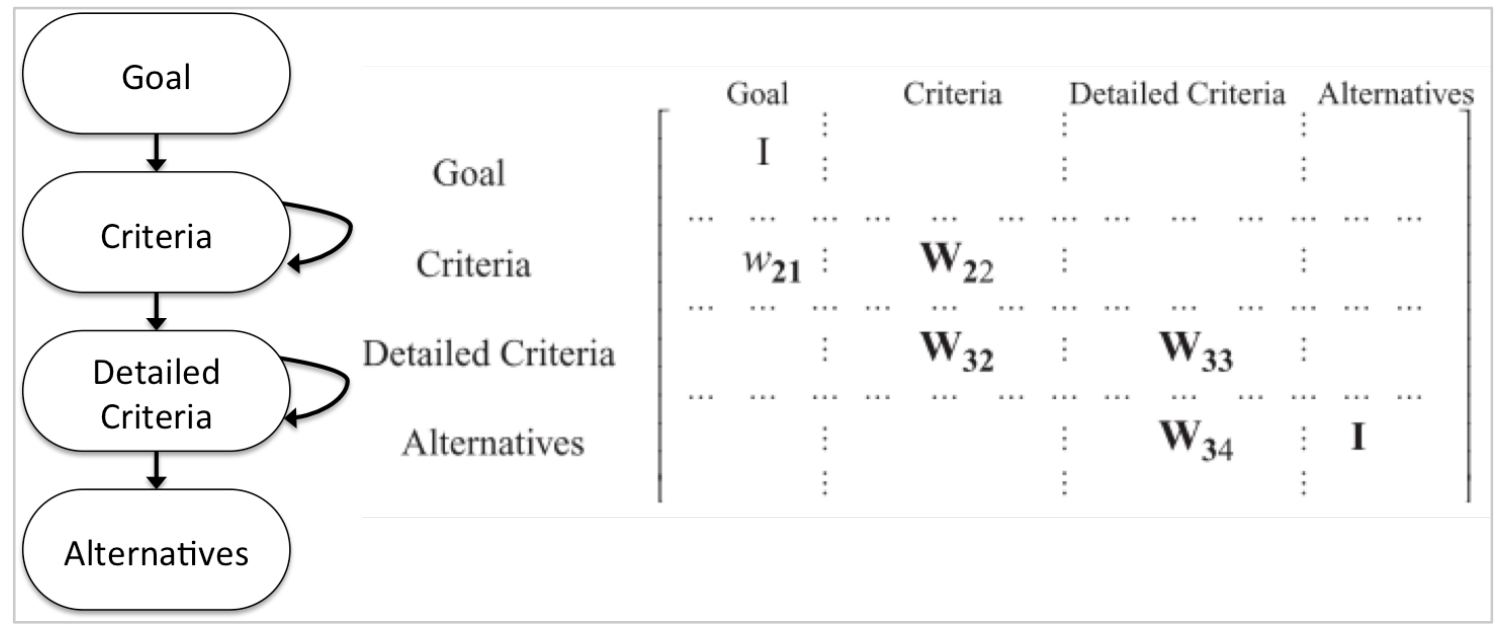

Figure 5: Network Structure with Generalized Supermatrix (Source: Chung et al., 2005)

For the Analytic Network Process, it is necessary to distinguish between two phases of the supermatrix: The unweighted and weighted supermatrix. When the supermatrix is obtained, its columns consisting of local priority vectors commonly sum up to a value greater than one. The reason for this are the interdependencies between clusters in a network structure. Spoken in mathematical terms, the supermatrix does not fulfill the requirement of stochasticity, which is necessary to obtain final priorities. Thus, the supermatrix is called an unweighted supermatrix and requires a weighting process that leads to unity in each column of the matrix (Chung et al., 2005). For a detailed mathematical explanation of the stochasticity specification, refer to Saaty's "Fundamentals of the Analytic Network Process - Dependence and feedback in decisionmaking with a single network" (2004). 
In order to reduce the supermatrix to a column stochastic matrix, Saaty (2004) suggests comparing all clusters with influence on each other in a pairwise manner with respect to a common property they share. Again, this results in multiple comparison matrices and eigenvectors can be derived to determine the influence of the clusters. A new matrix, called the clustermatrix, is developed by this approach, and for each column the eigenvector is multiplied by the elements of the respective block in the unweighted supermatrix. This results of weighting each column of the supermatrix is that it sums up to one. Hence, this new matrix is called the weighted supermatrix and fulfills the requirement of stochasticity, as mentioned earlier and described by Chung et al. (2005).

The final transformation to obtain global priorities is the determination of a limitmatrix through the exponentiation of the supermatrix by $(2 k+1)$, where $k$ is a randomly large number, until all columns of the limitmatrix display an equal number. This process can only be performed by software applications. To acquire the final priorities of the elements including the priority weights for all alternatives, each cluster is normalized (Saaty, 2004).

In the following section, the computational steps of solving an AHP problem will be described in detail with the example of a case study in SCM. In this case study, the eigenvector and supermatrix computations required for the employed AHP model were approximated. This demonstrates an effective example for gaining a better understanding of the previous theoretical paragraphs on the working mechanics of AHP and ANP.

\section{Computational Example of a Hierarchy Process Model}

Saaty and Vargas (2001) suggests several methods to obtain final priorities of alternatives through the supermatrix and limitmatrix transformations. An exact solution 
can only be acquired by using a software application, but there are ways to approximate the eigenvector solution. This can be especially helpful to solve simple hierarchy problems where software utilization would waste time and money. However, methods of approximation can falsify the results and therefore should be used with caution. One way to approximate the eigenvector solution is to normalize all columns of the comparison matrix and then average each row. This method shall be employed when calculating the final priorities in the following SCM case study.

Sapci and Pouraghabagher (2003) combine the Analytic Hierarchy Process with the Quality Function Deployment analysis to utilize customer expectations for supplier selection. The following example follows the approximation process for the synthesis of a hierarchical model without the intention of providing details of the researchers' supply chain expertise. For additional information, the reader can refer to "A systematic approach for selection of suppliers through an integration of Quality Function Deployment (QFD) and Analytical Hierarchy Process (AHP)" by Sapci and Pouraghabagher (2003).

The following computational steps were applied by Sapci and Pouraghabagher (2003) in order to employ the AHP method in their case study:

1. Compare each supplier in pairs to the selection criteria once at a time (Step 1 of Figure 6).

2. Normalize the matrix for each selection criterion (Step 2 of Figure 6).

3. Compare the selection criteria pairwise to each other based on the importance of each criterion (Step 3 of Figure 7).

4. Normalize the criteria comparison matrix (Step 4 of Figure 7).

5. Synthesize the overall matrix.

6. Prioritize the suppliers. 


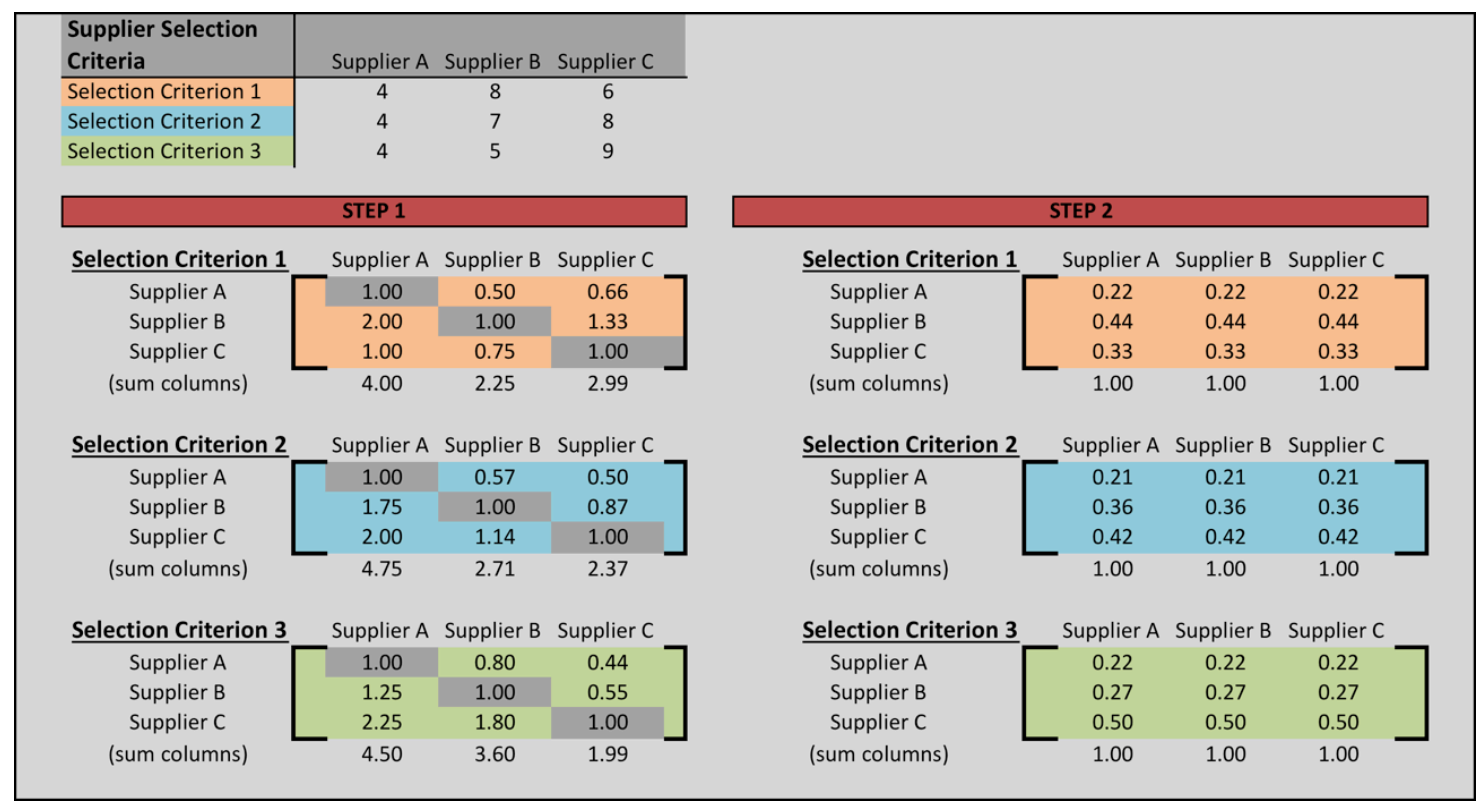

Figure 6: Step 1 and 2 of AHP Process (Source: Sapci \& Pouraghabagher, 2003)

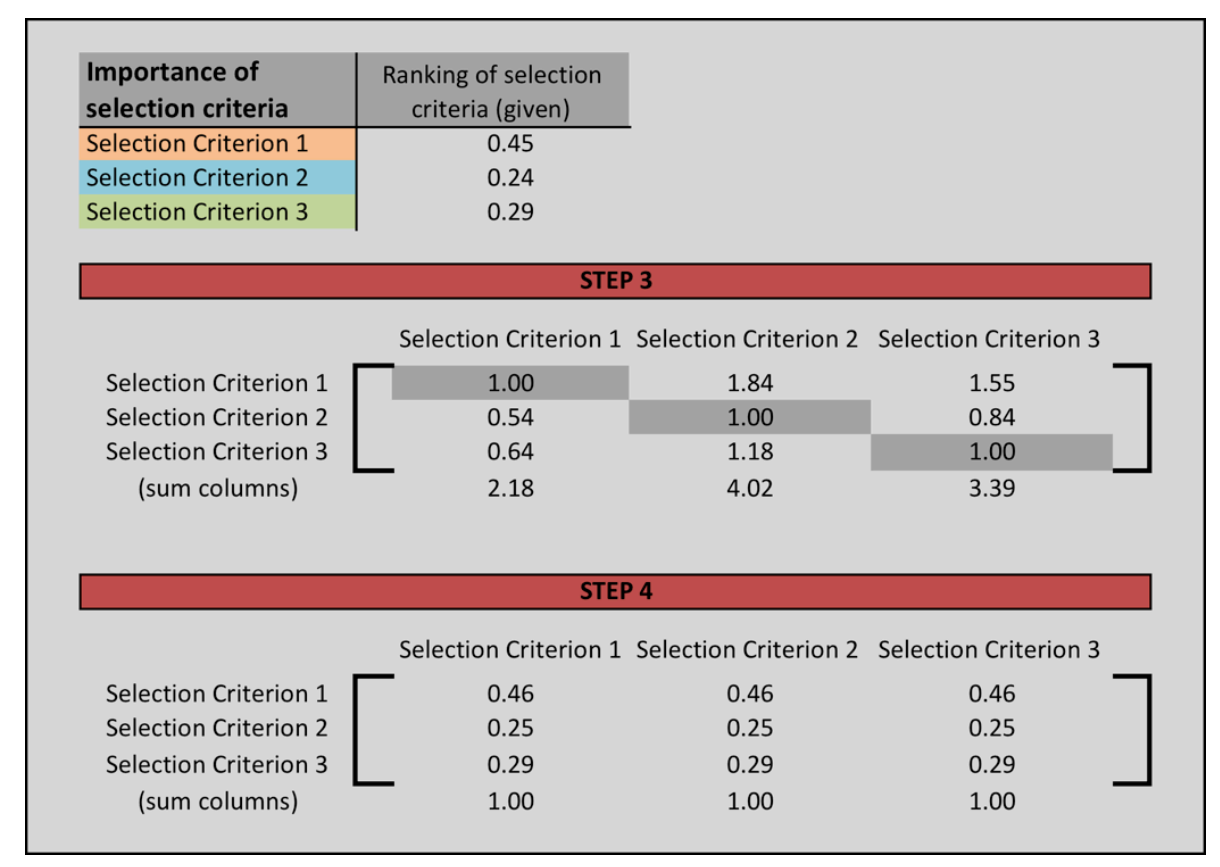

Figure 7: Step 3 and 4 of AHP Process (Source: Sapci \& Pouraghabagher, 2003)

The supermatrix is compiled throughout Step 5. The matrix shows the suppliers as rows and the selection criteria as columns. The priorities, which approximate the 
eigenvector solution, are established by taking the average of each of the normalized rows of the matrices in Step 2 and Step 4, resulting in the following matrix (Figure 8):

\begin{tabular}{l|ccc} 
Suppliers vs. SC & Selection Criterion 1 & Selection Criterion 2 & Selection Criterion 3 \\
\hline Supplier A & 0.22 & 0.21 & 0.22 \\
Supplier B & 0.44 & 0.36 & 0.27 \\
Supplier C & 0.33 & 0.42 & 0.50
\end{tabular}

Figure 8: Supermatrix of AHP Process (Source: Sapci \& Pouraghabagher, 2003)

Finally, Step 6 involves the multiplication of the matrix obtained during the prior step with the priority vector of the supplier selection criteria. Therefore, the overall priorities per supplier are shown in Figure 9.

\begin{tabular}{|c|c|c|c|c|c|c|c|c|c|}
\hline & $\begin{array}{c}\text { Selection } \\
\text { Criterion } 1\end{array}$ & $\begin{array}{c}\text { Selection } \\
\text { Criterion } 2\end{array}$ & $\begin{array}{c}\text { Selection } \\
\text { Criterion } 3\end{array}$ & & & & & & \\
\hline Supplier A & 0.22 & 0.21 & 0.22 & & Selection Criterion 1 & 0.45 & & Supplier A & 0.2193 \\
\hline Supplier B & 0.44 & 0.36 & 0.27 & $\mathbf{x}$ & Selection Criterion 2 & 0.24 & $=$ & Supplier B & 0.3766 \\
\hline Supplier C & 0.33 & 0.42 & 0.50 & & Selection Criterion 3 & 0.29 & & Supplier C & 0.4041 \\
\hline
\end{tabular}

Figure 9: Final synthesis of AHP Process (Source: Sapci \& Pouraghabagher, 2003)

The goal of the previous sections was to enhance the reader's understanding of the AHP and ANP by describing the mathematical principles and functionality in detail. In addition, an example was employed to illustrate the manual steps required for the approximation of final priorities for a relatively simple hierarchy model. In order to simplify mathematical complexity, prevent mistakes by approximating values, and develop more advanced models, Saaty published software to model AHP and ANP problems. The software is called SuperDecisions and was freely released by the Creative Decisions Foundation (http://www.superdecisions.com). The model design and implementation in this thesis will be performed with the SuperDecisions software to build the ANP structure and obtain final results. 
The next section will provide an overview of how the ANP method can be used to make decisions based on an assessment of benefits, opportunities, costs, and risks. This approach will be applied to the proposed framework of this project.

\section{ANP with Benefit, Opportunity, Cost, and Risk Merits (BOCR-ANP)}

When modeling real life scenarios in order to make decisions, it is necessary to compare alternatives based on positive and negative aspects. For example, when alternatives are compared to the extent of a priority in beauty or importance, the resulting values would be based on a positive scale. However, it might be necessary to make judgments depending on which alternative is most costly, leading to negative prioritization. In order to find the best overall solution, both positive and negative values have to be taken into account. Saaty (2009) developed a special form of the Analytic Network Process to meet these requirements. A multiple layer model consisting of subnets for benefits $(B)$, opportunities $(O)$, costs $(C)$, and risks $(R)$ networks will be introduced to find the best alternative of each category. The results will then be combined by a formula to account for the positive and negative priorities.

In order to model these fairly complex networks models, the SuperDecisions software will be utilized. The following description of employing a multiple layer ANP model with BOCR merits is based on the software application of SuperDecisions. In every layer, a significant step towards the final goal of obtaining overall priorities for alternatives is made. The layers are divided into a "strategic criteria network," "control criteria network," and "decision network." The first level introduces strategic criteria of a decision, which are essential to help the decision makers assess whether a particular decision should be made in terms of the overall goal and effected parties (Saaty, 2009). The next layer implements a hierarchy, or network, structure for each BOCR 
merit with multiple criteria to allow the decision-maker to evaluate all significant influences of a merit. Elements are compared pairwise with the goal of identifying the most beneficial, opportune, costly and risky alternatives. Priorities derived from the comparison matrix demonstrate which elements have the highest influence on the final decision. These elements are called control criteria, which serve as subnets for decision networks in the final layer of the BOCR model. A decision network contains the alternatives and criteria directly influencing them and thus builds the basis for obtaining the final priorities of alternatives. To synthesize every BOCR merit, the software application uses the local priorities of the decision networks and passes them to the next highest layer. There they are weighed by the priorities of the control criteria network and added up to finally emerge in a ranking of alternatives for each BOCR merit (Saaty, 2009).

Going back to the first layer in the model, the best alternative of every merit $(B O C R)$ is rated against the strategic criteria to find the final weight of each BOCR merit. These weights are introduced as "b" for the Benefits merit, "o" for the Opportunities merit, "c" for the Costs merit, and " $\mathrm{r}$ " for the Risks merit. The reason for using a rating system is to encourage giving each BOCR merit individual importance based on the subjective evaluation of strategic criteria. This approach helps to improve the decisionmaking model based on a real world scenario where cost considerations might be more relevant than potential benefits, opportunities, or risks.

The final answer for the best overall strategy is realized when positive priorities of the benefits and opportunities merits and negative priorities of the costs and risks merits are combined through a formula. Two formulas have been introduced in BOCRANP applications to account for negative priorities (Saaty, 2009): The multiplicative (ratio) and additive (total) formula. For the additive formula, the ratings of each merit 
$(b, o, c$, and $r)$ are multiplied with the ideal priorities obtained for every alternative $i$ in the specific merit $(B, O, C$, and $R)$. The multiplicative formula does not use the weights $(b, o, c$, and $r$ ) since they would cancel out when the obtained results are normalized.

$$
\begin{gathered}
\text { Additive formula }=\left(\left(b B_{i}+o O_{i}\right)-\left(c C_{i}+r R_{i}\right)\right) \\
\text { Multiplicative formula }=\frac{B_{i} * O_{i}}{C_{i} * R_{i}}
\end{gathered}
$$

In general, results gained with the additive formula represent the best alternative under long-term considerations, whereas the multiplicative formula suggests the best short-term solution (Saaty, 2009).

In conclusion, the BOCR-ANP approach helps to make decisions based on an evaluation of multiple criteria categorized into benefit, opportunity, cost, and risk merits. The objective of this research is to employ the BOCR-ANP approach to identify critical products of a company and match them with ideal supply chain disruption mitigation strategies. The next chapter will describe the design and implementation of the proposed research method. 


\section{MODEL DESIGN AND IMPLEMENTATION}

Referring back to the objective of this research, an Analytic Network Process model shall be developed to match key products of a company with optimal supply chain disruption strategies. For this purpose, the proposed framework is based on two main models organized in multiple levels. The initial network process ranks products of a company based on multiple criteria, assisting the analyst in selecting products that are critical for the organization. Then, for these key products, a BOCR-ANP model evaluates different disruption mitigation strategies based on an assessment of benefits, opportunities, costs, and risks. The following sections specify assumptions of the proposed research method, and describe its design and implementation in detail.

\subsection{Model Assumptions}

Before the proposed research method is described in more detail, assumptions need to be defined. Assumptions are necessary to obtain plausible results and interpret them correctly. In this research, assumptions made can be differentiated into inputspecific assumptions and process-specific assumptions. The following paragraphs further explain these two categories.

\section{Input-specific Assumptions}

In general, the typical user would be a manufacturing company which is prone to disruptions in their supply chain or production facilities and which needs a tool for product prioritization and disruption strategy matching. It shall be assumed that products can be compared to each other with regard to multiple criteria. This requires comparable product structures, also referred to as the bill of materials (BOM), and sourcing

practices. For example, the proposed method will not be significant for products con- 
sisting of hundreds of subassemblies, parts, or raw materials due to a high sourcing complexity, which cannot be modeled properly. In this research, an ideal test environment is assumed, characterized by a simple BOM structure. Good examples for such products and companies are be found in the steel forging or semiconductor industries.

When evaluating strategies based on the BOCR assessment, it shall be assumed that they are in general suitable and realizable for the specific product. The criteria used to compare the disruption mitigation strategies must be applicable to at least

one of the alternatives; otherwise, they shall be removed from the ANP model. Additionally, referring to the sourcing practices of raw materials and parts, only first-tier supply chain partners shall be considered when deciding on strategies for supply chain disruption mitigation.

\section{Process-specific Assumptions}

Process-specific assumptions refer to the decision-making methodology of the ANP and its consequences. A decision-maker expresses judgments in ANP through pairwise comparisons of criteria and alternatives using the fundamental scale from one to nine. This may lead to inconsistencies because human judgment is based on opinions and changes depending on the elements that are pairwise compared. This can be further explained by an example: a user determines element " $X$ " to be twice as important as element "Y," "Y" to be three times as important as "Z," but "X" only five times as important as "Z." This results in an inconsistency because the mathematical solution would automatically define "X" as six times more important than "Z."

Inconsistencies represent a necessity when modeling human decision-making since they express the human ability to learn and comprehend complexity. Nevertheless, large inconsistencies could lead to wrong decisions. One process-specific re- 
quirement is therefore that inconsistencies are kept at a minimum. Fortunately, when specific ANP software, such as SuperDecisions, is utilized, the inconsistencies in the ANP model are expressed and calculated through a value called the "Inconsistency Index." This value shall be kept at a maximum of $10 \%$; otherwise, pairwise comparisons need to be adjusted. For more details of the concept of inconsistency in ANP, the reader should refer to Saaty and Vargas (2001).

In general, a decision-maker carries out comparisons based on individual judgment and expertise. Therefore, the user should not only be knowledgeable about the theory and functionality of ANP but also about the company's capabilities. A lack of theoretical as well as practical competence could result in wrong conclusions. After all assumptions are made, the design for the suggested research method can be developed.

\subsection{Design of Multiple Level ANP Model}

This chapter will describe the design of the proposed research method based on a multiple-level ANP model. To refresh the intention of this thesis, the following paragraph summarizes the objectives and general approach for the suggested design.

In general, after a disaster paralyzes a company's production system or supply chain, the company will not be able to recover all processes simultaneously due to limited resources. As an integral step of BC/DR planning for supply chains, it is therefore crucial for companies to identify critical processes and products. Often, the importance of products is evaluated solely based on the generated revenue, while other important measures are neglected. Torabi et al. (2014) introduced a set of tangible and intangible measures that should be considered when ranking products in terms of their priority for 
recovery (Table 3). These measures will be defined as an input for the initial network model, which identifies the key products of a company.

After critical products of a company are identified, the following step in BC/DR planning involves the assessment of recovery strategies. Tomlin (2006) identified several tactics specifically for managing disruption risks in supply chains. He categorized them into financial and operational mitigation strategies, as well as operational contingency strategies. The question of which single strategy or combination of multiple strategies a company chooses to implement depends on the company's interest in BC/DR planning as well as their willingness to invest in it financially. Hence, an ANP model based on the evaluation of benefits, opportunities, costs, and risks shall be introduced to find the overall best supply chain disruption strategy from a set of strategies introduced by Tomlin (2006). As a result, combining the two described consecutive steps of BC/DR planning within one decision-making tool leads to a multiple-level ANP model.

The flowchart diagram (Figure 10) outlines all process steps for the proposed research framework. After the ANP has been designed, the model can be implemented with the ANP software, SuperDecisions. White rectangles in Figure 10 represent activities carried out by the decision-maker via the ANP software. The colored (blue, red, green, and orange) boxes depict ANP computations performed by the software. All process steps will be described in detail in the next chapter when the proposed design is implemented. In general, the flowchart in Figure 10 describes the logical sequence of steps required to set up the proposed ANP model. However, when the SuperDecisions software is employed to model the fairly complex ANP, the logic flow is interrupted. A 
software-specific requirement of SuperDecisions is that every judgment procedure requires its own layer or level in the software.

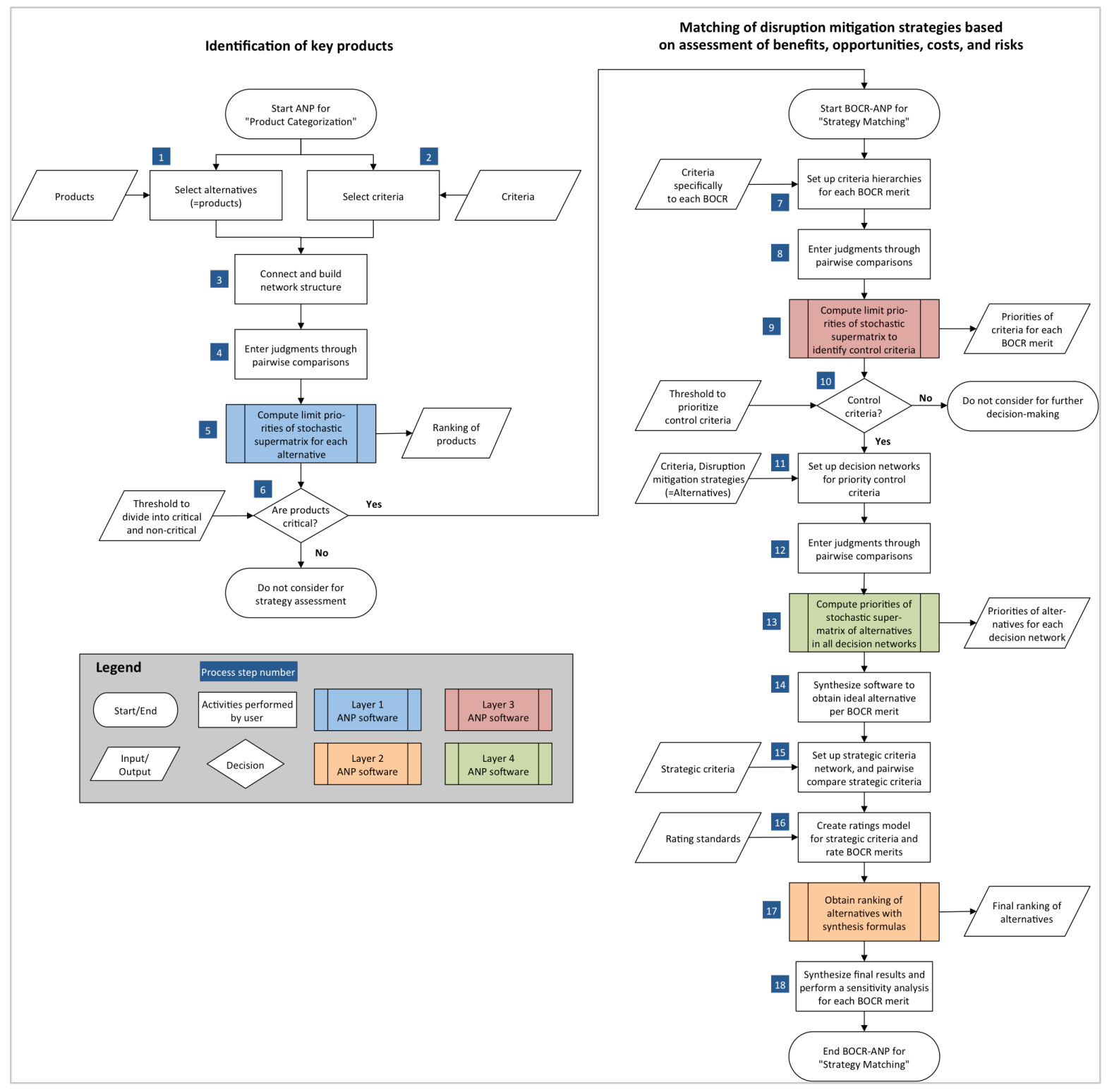

Figure 10: Flowchart for Multi-Level ANP Model Design

In this thesis, there are a minimum of four judgment procedures necessary in order to: 
- Identify critical products (compare to process step 4 in Figure 10)

- Select control criteria (process step 8 in Figure 10)

- Rank disruption mitigation strategies (process step 12 in Figure 10)

- Evaluate strategic criteria (process step 15 in Figure 10)

Thus, several layers are necessary to implement the proposed design with the SuperDecisions ANP software. In order to build and connect levels to each other in the ANP software, so-called "subnetworks" are introduced.

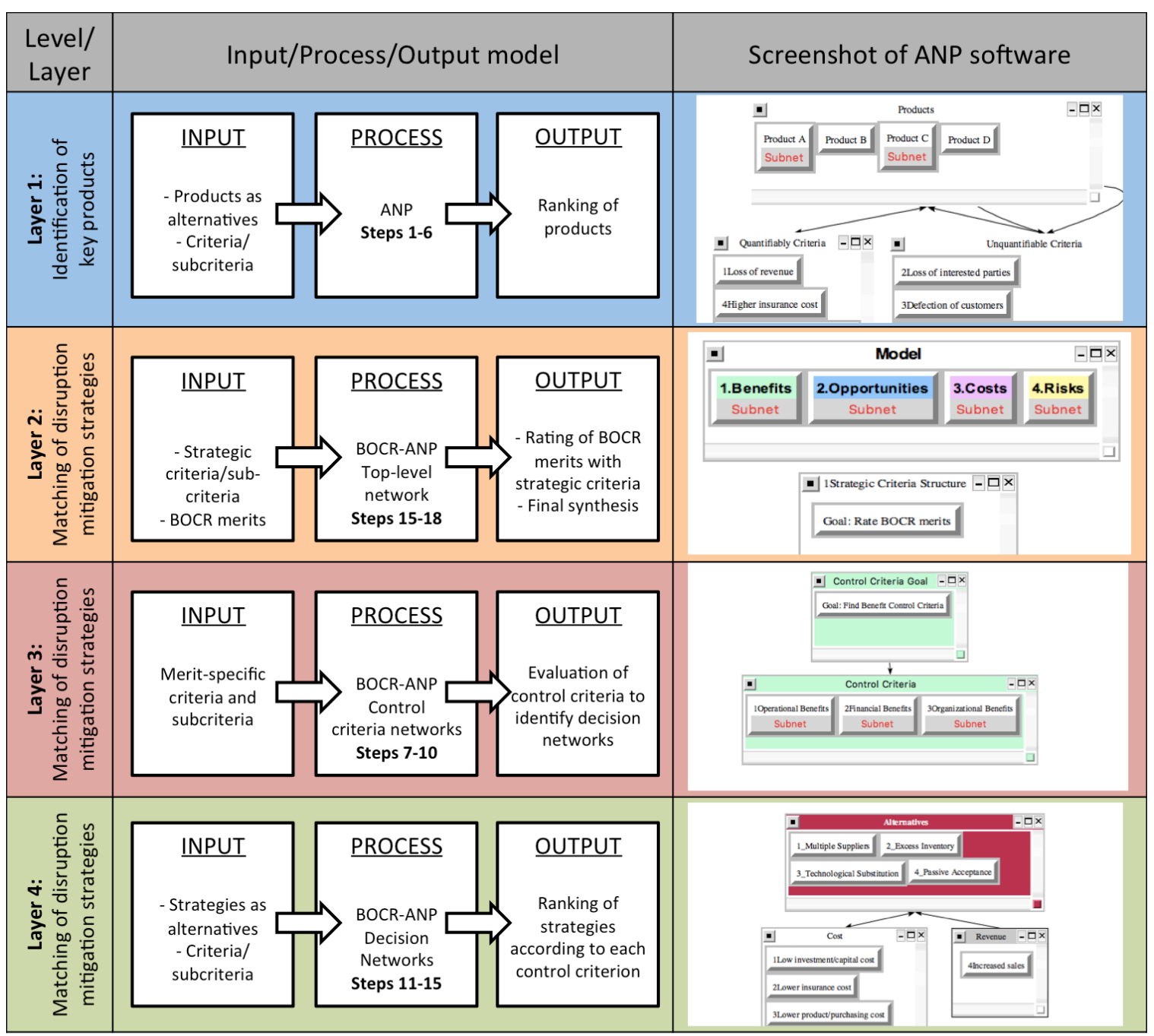

Figure 11: Implementation of ANP via Multiple Levels with SuperDecisions 
Figure 11 illustrates the setup and structure of the multiple level ANP suggested for this project. Level 1 is built upon a network process to identify critical products. Every key product is then connected to a subnetwork containing the four BOCR merits in Level 2. Again, each BOCR merit will be linked to a subnetwork containing control criteria networks assigned to each merit, representing Level 3 of the proposed model. Finally, significant control criteria are once again connected to subnetworks containing the decision networks in Level 4. In conclusion, the proposed ANP model will result in a multiple-level network consisting of a first-level, at least four second-levels (4 BOCR merits per key product), and many third- and forth-levels. Figure 11 illustrates each level, a description of the specific input, process, and output (IPO), as well as a software screenshot. The IPO connects the process steps of Figure 10 to each level implemented in the SuperDecisions software.

\subsection{Implementation of Multiple Level ANP Model}

This chapter will describe the implementation process of the proposed multiplelevel ANP model design. For this purpose, the ANP software "SuperDecisions" is employed to model all process steps, as illustrated earlier in the flowchart of Figure 10. Subsequently, sections of the flowchart are used to introduce the implementation of each process step in detail. In general, each process step will describe a detailed procedure of implementing the suggested ANP design so future users may employ and modify the methodology individually. It will then be explained how the design is implemented specifically for the scope of this thesis.

Figure 12 illustrates a section of the overall flowchart zoomed in to Process Steps one through six, which will be specified in the following paragraphs. 


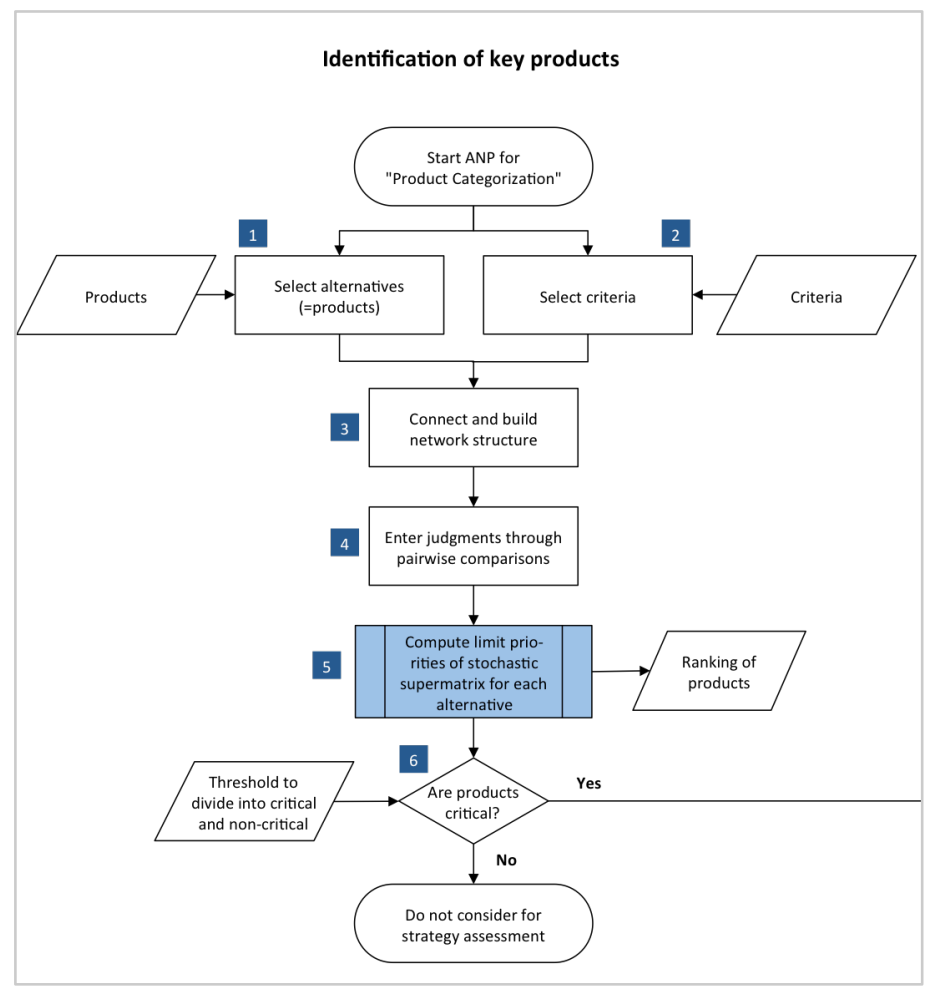

Figure 12: Zoom into Flowchart (Process Steps 1-6)

\section{Process Step 1}

In Process Step 1, alternatives for the ANP are selected. In this initial ANP model, the alternatives are the products of a company or business unit, which are in the end ranked. There is no limit to the quantity of products that can be input into the ANP framework. A requirement for input is, however, that the products can be compared to each other with respect to specific criteria that will be chosen in the subsequent process step. In this case, the input could be a list of products that are to be ranked. As an example in this thesis, there were four products selected, referred as to Product A, Product B, Product $C$, and Product D. 


\section{Process Step 2}

In Process Step 2, a decision-maker selects the criteria to rank products according to their recovery importance or priority when a company faces disruption to its supply chain. In this thesis, the criteria selected are based on Torabi et al.'s measures. Torabi et al. conducted interviews with BC/DR experts and studied literature in this field to come up with ten criteria to measure the importance of products (Torabi et al., 2014). Table 3 names these criteria and includes a short description of what they entail.

Table 3: Criteria to Identify Key Products (Source: Torabi et al., 2014)

1. Loss of revenue

\section{Criteria}

\section{Description}

Lost sales in the event of supply chain and production breakdown .

2. Loss of interested parties

3. Defection of customers Loss of customers' demands in the event of supply chain and production breakdown.

4. Higher insurance cost

5. Degree of damage on company's image and reputation

6. Influence on markets

7. Importance of product for the country

8. Influence on human resources

9. Rate of deviation from company objectives

10. Loss of technological level of company
High compensation costs in the event of supply chain and production breakdown.

Lack of manufacturing famous products will permanently damage reputation of company.

Degree of losing markets for products in the event of supply chain and production breakdown.

Regulatory obligations when a product has an important role in country.

Number of staff are fired or become unemployed in the event of supply chain and production breakdown.

Lack of manufacturing product influences company's objectives.

Ability of developing product will be lost in the event of supply chain and production breakdown. 


\section{Process Step 3}

With the alternatives and criteria selected in the two previous steps, the network structure of the ANP can be developed. First, the user categorizes criteria and alternatives in clusters. A cluster is, in general, a group of homogenous elements which can either be criteria or alternatives. As a next step, connections are made between elements that influence each other. These relationships, which are triggered by feedback and dependecies between specific elements, result in arrows between clusters on the software interface. As a general rule, when connecting the first element to the second element in the ANP software application, an arrow emerges pointing from the second element to the first. This represents the way comparisons are carried out later in the process. The following paragraphs describe how Process Step 3 will be implemented in this research.

To start with, alternatives and criteria must be arranged in clusters. For this purpose, three clusters are set up: one for the alternatives (products), one for quantifiable criteria (criterion no. 1, 4, and 8 of Table 3), and one for unquantifiable criterion (criterion no. 2, 3, 5, 6, 7, 9, and 10 of Table 3). Elements within these clusters need to be connected to each other. For a better understanding of the connections made in this research, Figure 13 shows a screenshot of the ANP structure. The grey Boxes, labelled from $\mathrm{A}$ to $\mathrm{C}$, represent clusters including alternatives and criterion, respectively. Following Figure 13, the connections between elements of the clusters will be described in more detail. 


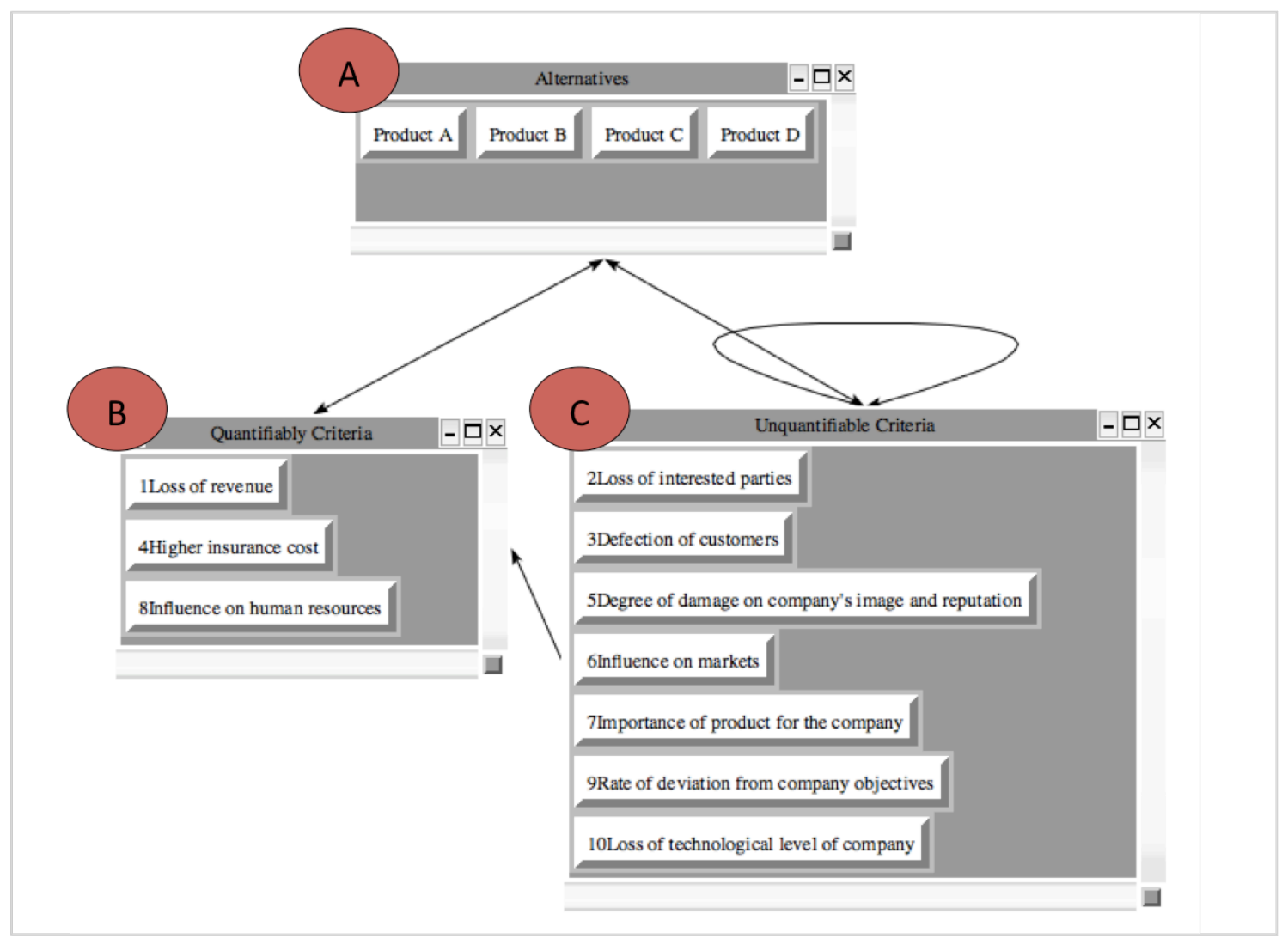

Figure 13: Screenshot of ANP to Identify Key Products

In the above shown network structure, the alternatives cluster (Box A) and each criterion cluster (Boxes B and C) are connected by double sided arrows. This implies that Products $A, B, C$, and $D(B o x A)$ are influenced by the elements in the "Quantifiable" cluster (Box B) and "Unquantifiable criteria" cluster (Box C), and viceversa. The arrow between the two criteria clusters (Box B and C) indicates that elements of Box B impact elements of Box C. More specifically, "1. Loss of revenue" (Criterion 1 of Table 3, Figure 13) affects the, "5. Degree of damage on company's image and reputation," (Criterion 5 of Table 3 and Figure 13) and, "Rate of deviation from company objectives," (Criterion 9 of Table 3 and Figure 13) respectively. The arrow making a loop in the "Unquantifiable Criteria" cluster (Box C) demonstrates an inner 
dependence between elements in this cluster. Again, Criterion 5 and 9 are affected by Criterion 2 and 3.

\section{Process Step 4}

After the network structure is set up, a decision-maker can conduct pairwise comparisons between criterion and alternatives with the goal of ranking the products. Comparisons originate from connected elements, as described in the previous process step; therefore, it is crucial that the network structure is set up correctly. In order to compare elements pairwise with respect to a commonality, the analyst applies Saaty's fundamental scale of one to nine. For further explanation of the functionality of ANP, please refer back to a detailed description of the ANP process in Chapter 2.3.

Figure 14 shows how comparisons can be conducted in the ANP software application. For example, Product $A$ is considered to be eight times more important than Product B with respect to Criterion "1. Loss of revenue." After comparisons are made, priority vectors for criteria and alternatives can be derived. This will be part of the next process step.

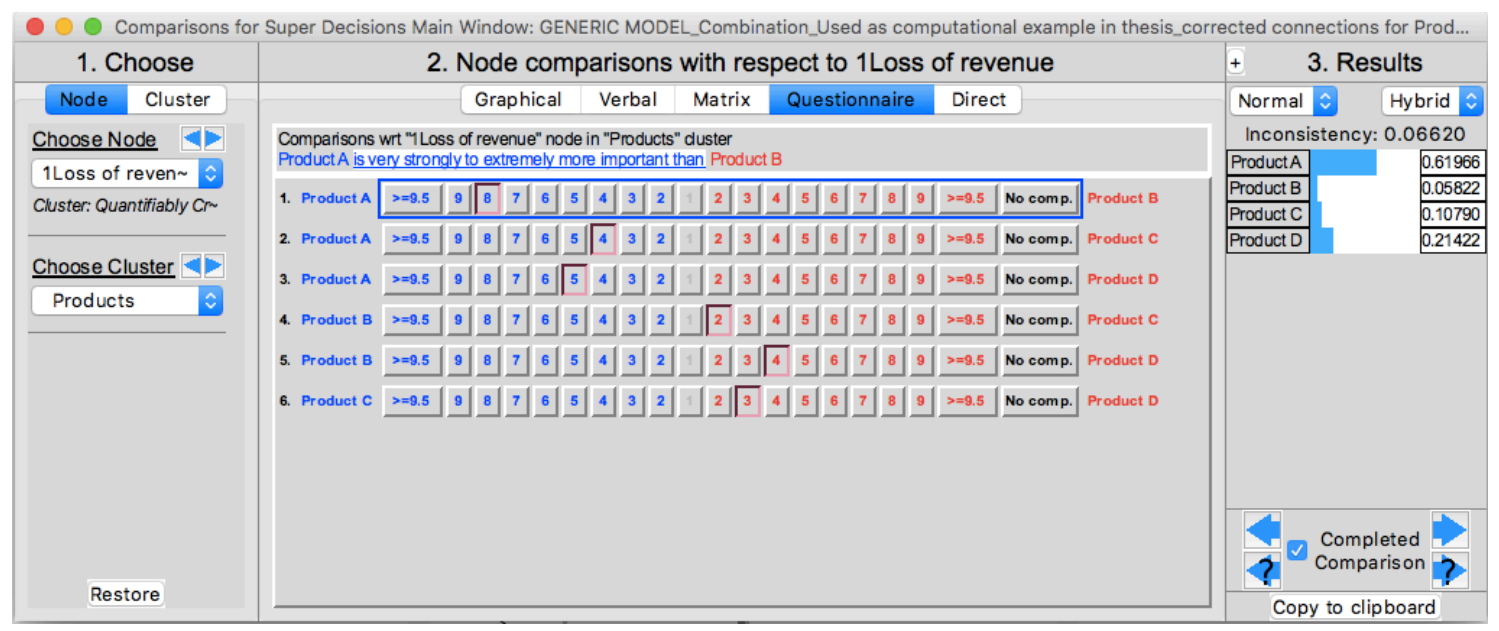

Figure 14: Pairwise Comparisons for Critical Products in SuperDecisions Software 
In this thesis, Products $A, B, C$, and $D$ are compared in pairs with every connected element in the quantifiable and unquantifiable criteria cluster. Since there is more than one criteria cluster in this network, clusters can be pairwise compared as well. In general, this is done when a difference in importance between the two clusters is demonstrated. In this specific example, quantifiable criteria are evaluated as twice as important as unquantifiable criteria.

\section{Process Step 5}

In Process Step 5, ANP software is employed to obtain the final priorities for each alternative. Computational steps include the weighting of priority vectors for criteria and alternatives with cluster priorities, and exponentiating the supermatrix to obtain the final limitmatrix. From there, the idealized priorities are normalized, and hence a ranking of products is synthesized. Again, these process steps were discussed in detail in Chapter 2.3, "Analytic Network Process."

In this investigation, outputs of the software calculations are shown in Table 4. Each product has an assigned "Ideal," "Normal," and "Raw" priority. In general, priorities obtained in SuperDecisions matrix are displayed in three ways. "Raw" values are derived directly from the limitmatrix, "Normal" values are "Raw" values normalized per cluster, and "Ideal" values are obtained by dividing the "Raw" or "Normals" by the largest value.

Table 4: Product Ranking Based on Obtained Priorities

\begin{tabular}{|llccc|}
\hline Name & Graphics & Ideals & Normals & Raw \\
Product A & & 0.7841 & 0.2776 & 0.1358 \\
Product B & & 0.4925 & 0.1744 & 0.0853 \\
Product C & & 1.0000 & 0.3541 & 0.1731 \\
Product D & & 0.5477 & 0.1939 & 0.0948 \\
\hline
\end{tabular}


Results of Table 4 emerge from the stochastic supermatrix and limitmatrix computed in the SuperDecisions software. The reader can refer to these matrices in Appendix A (p. 77).

\section{Process Step 6}

After ranking the alternatives in the previous process step, a decision-maker can now select the critical products. A requirement is the definition of a threshold value, which categorizes products as either critical or non-critical. This represents an essential step for proceeding to the next ANP model. For key products only, disruption mitigation strategies will be assessed regarding their benefits, opportunities, costs, and risks. Non-critical products will not be further considered in this ANP project.

In this research, a minimum value of $25 \%$ was set to categorize products as critical and non-critical. This means that all products that achieve a normalized priority higher than $25 \%$ will be considered as critical. Referring back to the results of the previous process step shown in Table 4, Product $A$ and Product $C$ are determined to be key products. Thus, for these two products a new ANP model will be created with the goal of finding optimal disruption mitigation strategies. Products B and D do not qualify for further considerations in the proposed decision-making process.

Figure 15 illustrates the flowchart for Process Steps seven through twelve. It is important to mention that all succeeding process steps in this implementation will be performed twice, since the previous step identified both Products $A$ and $C$ as critical. However, the process implementation will only be spelled out for the example of Product $A$. 


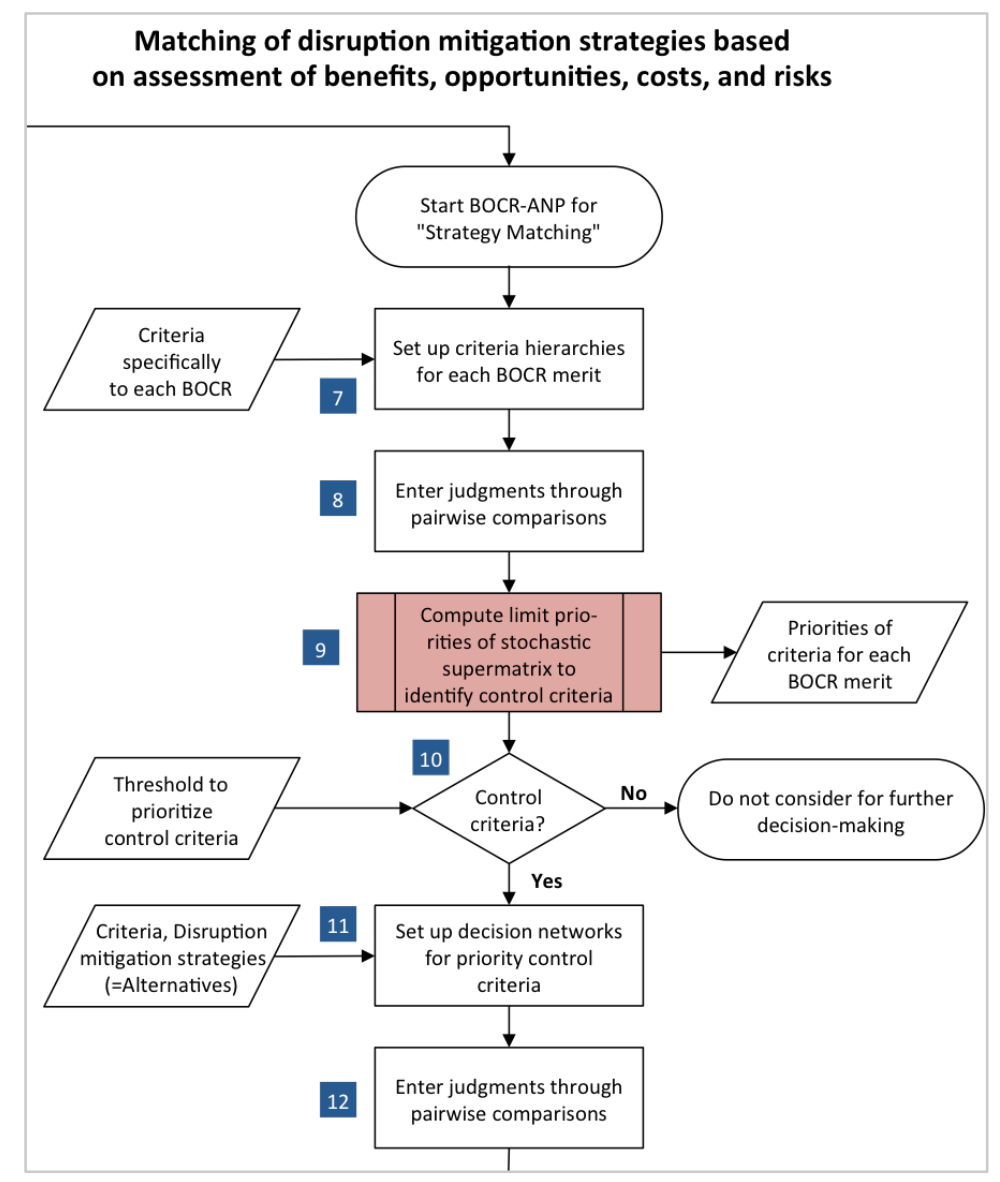

Figure 15: Zoom into Flowchart (Process Steps 7-12)

\section{Process Step 7}

A requirement for Process Step 7 is the start of a new ANP model with the goal of evaluating supply chain disruption mitigation strategies based on their benefits, opportunities, costs, and risks. Thus, Product $A$ is connected to a new subnetwork in order to implement the ANP structure. Process Step 7 includes the set-up of criteria hierarchies for each BOCR merit. For a detailed description of the working mechanics of the BOCR-ANP, the reader should refer back to Chapter 2.3.

The first step towards a BOCR-ANP model is the set-up of each BOCR merit subnetwork. A decision-maker usually structures the merits according to a hierarchy model including a goal node and multiple criteria/subcriteria specific to each BOCR 
merit. In general, the goal of every BOCR network is the identification of control criteria. Control criteria are defined as criteria, which strongly influence the final outcome. A requirement for a criteria input is that each criterion must be applicable to at least one of the alternatives but not necessarily to all of them. In this thesis, the following criteria, shown in Figure 16, were selected as inputs and connected to a goal node in each BOCR network.

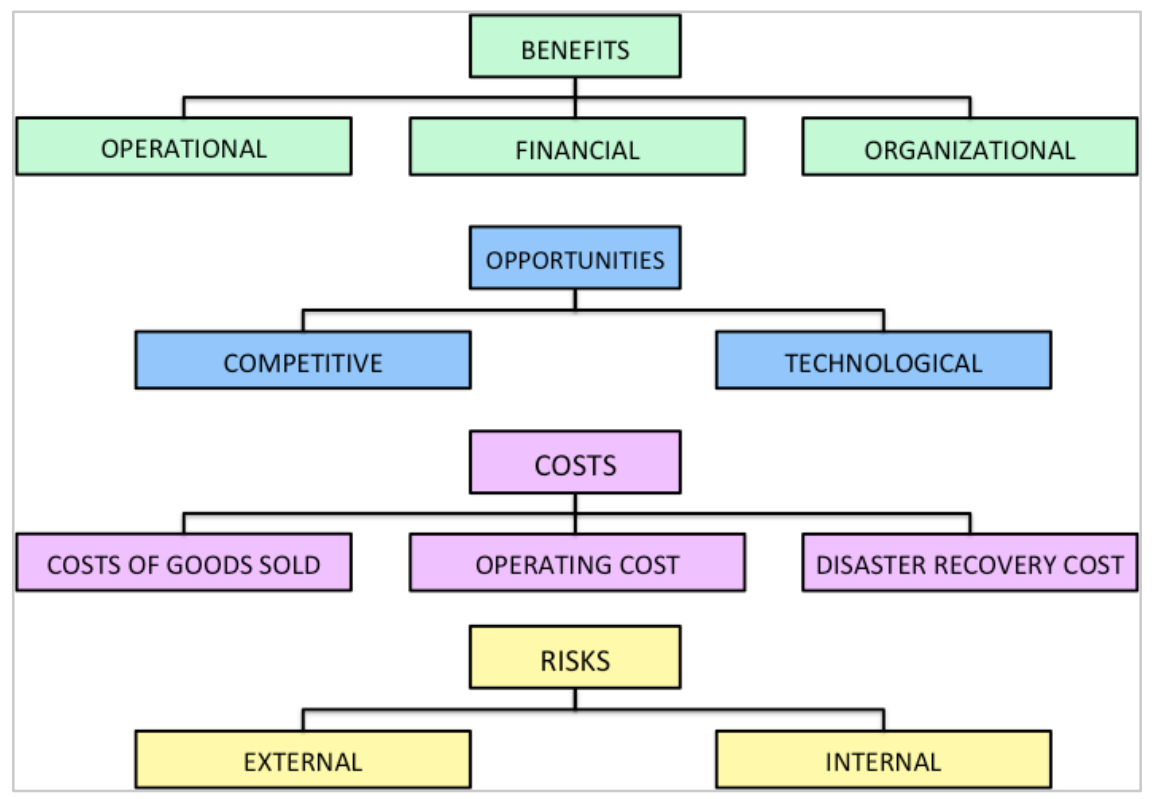

Figure 16: BOCR Control Criteria Hierarchies

\section{Process Step 8}

In each BOCR merit, a decision-maker pairwise compares criteria with respect to goals, which vary according to each merit. For example, for the benefits merit, the goal is to identify the most beneficial criteria when evaluating disruption mitigation strategies. Likewise, the goal of the other merits is to find the most opportune, costly and risky criteria respectively. Pairwise comparisons will then result in highest priorities for the most influential criteria (control criteria) of every merit. In general, the reason for identifying control criteria is for them to be connected to subnetworks in the following 
process steps. In these subnetworks, called decision networks, the alternatives will be finally compared with respect to multiple criteria influenced by each control criteria. As before, pairwise comparisons carried out in the SuperDecisions software are based on Saaty's and Vargas' (2001) fundamental scale. Figure 17 shows an example of pairwise comparisons run for the benefits merit with the goal of identifying the most beneficial criteria.

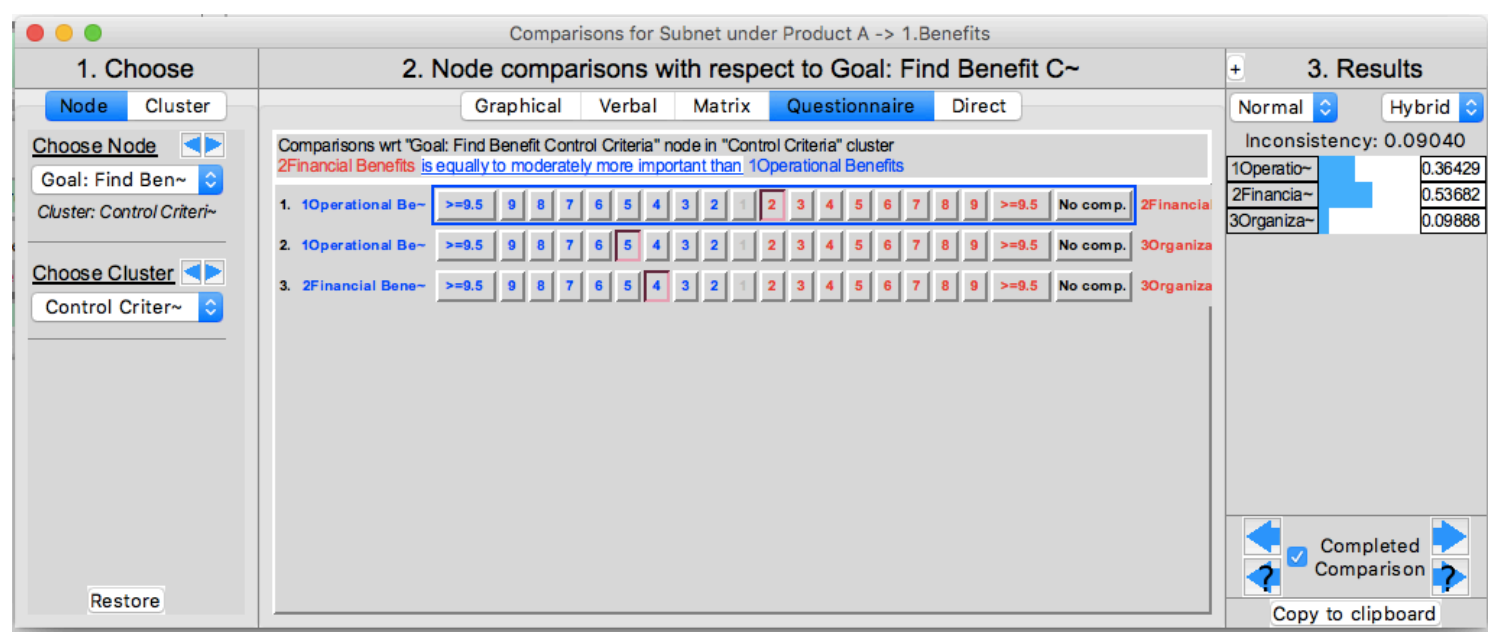

Figure 17: Pairwise Comparisons for Control Criteria of Benefits in SuperDecisions

\section{Process Step 9}

Again, in Process Step 9, the ANP software is employed to obtain the final priorities for each criterion. Computational steps include the weighting of priority vectors for criteria with cluster priorities and exponentiating the supermatrix, which results in the final limitmatrix. From there, the idealized priorities are normalized and hence a list of criteria with their priorities is synthesized. In this project, synthesis by the SuperDecisions software leads to the priorities, which were normalized per merit and are shown in Table 5. For computational details, please refer to Appendix B. The limitmatrices are individually shown for all BOCR merits. From there, priorities for all criteria can directly be derived. 
Table 5: Priorities Obtained for Criteria in each BOCR Merit

\begin{tabular}{llc}
\hline Merit & Control criteria & Local priorities \\
\hline Benefits & Operational benefits & 0.36 \\
& Financial benefits & 0.54 \\
\multirow{3}{*}{ Opportunities } & Organizational benefits & 0.10 \\
& Competitive opportunities & 0.33 \\
Costs & Technological opportunities & 0.67 \\
& Cost of goods sold & 0.16 \\
\multirow{2}{*}{ Risks } & Operating expenses & 0.11 \\
& Disaster recovery cost & 0.73 \\
& External risks & 0.80 \\
\hline
\end{tabular}

\section{Process Step 10}

After the priorities for all criteria of the BOCR merits are obtained, the decisionmaker needs to select control criteria. As stated earlier, the term "control criteria" refer to criteria, which influence the overall merit the most. As a general rule of thumb of ANP, criteria or subcriteria obtaining priorities smaller than $3 \%$ should not be further considered in the decision-making process. However, ANP users are able to determine individual threshold values based on their personal evaluation and expertise. If criteria are not determined to be control criteria, they will not further be considered in the decision-making process. The reason for this is that criteria with overall low priorities could impact the outcomes negatively, and this must be prevented.

In this investigation, the decision has been made that all criteria obtaining priorities equal or greater than $10 \%$ shall serve as control criteria. Referring back to Table 5 , all criteria qualify to the established threshold value in this research. Therefore, a subnetwork will be connected to each criterion containing decision network structures. 


\section{Process Step 11}

The next step includes setting up decision networks for each identified control criterion. In general, decision networks are structured in the same way as usual network models, consisting of criteria and alternatives. In this case, the alternatives are represented by different supply chain disruption mitigation strategies, and criteria are individual elements influencing the alternatives under each control criteria. Both sets of elements are connected to represent the relationships and dependencies between each other, and finally, pairwise comparisons are conducted.

In this thesis, all ten criteria of the BOCR merits (Table 5) were identified as control criteria. Consequently, ten decision networks need to be developed. Since the implementation of this process step demonstrates a main part of the proposed research design, the following paragraphs will describe the inputs (strategies and criteria) and setup of each control criteria under the respective BOCR merits in detail.

In all decision networks, the same strategies will be evaluated based on different criteria. For this project implementation, four strategies, widely used in BC/DR planning shall be compared. Two of the mitigation strategies are based on Tomlin's research (2006), referred to in more detail in Chapter 2.2 "Overview of Business Continuity and Disaster Recovery Practices." Subsequently, all strategies are described individually:

\section{- Strategy 1: Establish a Supplier Network}

Identify and collaborate with multiple suppliers for every key product to mitigate disruptions in case one supplier cannot deliver. It shall be assumed that it is possible to determine multiple suppliers for all critical products. 


\section{- Strategy 2: Carry Excess Inventory}

Build up inventory to overcome a certain period of delivery disruptions. This strategy is based on the assumption that there are no physical regulations that hinder a company from carrying extra inventory.

- Strategy 3: Invent/Research/Invest in Technological Substitution Identify new and/or different materials and/or technologies to produce critical products. For this alternative it needs to be assumed that substitution is a technologically feasible possibility and that the company has access to appropriate resources (funds, staff, and material).

\section{- Strategy 4: Passive Acceptance}

Accept the risk of supply chain disruptions and act only in response to disasters. This approach represents the category of "risk acceptance" and is either consciously or unconsciously chosen when there is little to no investment willingness. Although this alternative may not represent a proper disruption mitigation strategy, it might be a valid risk response tactic for some companies. Since this research model is based on a profound analysis of benefits, opportunities, costs, and risks, this strategy might achieve higher priorities than other alternatives.

These four strategies are included in a cluster for all the ten decision networks.

For each network, criteria were individually selected with respect to the control criteria. The following paragraphs describe the setup of the decision networks, which will be grouped according to their BOCR merit. 


\section{- Benefits Decision Network}

Figure 18 shows the three decision networks for operational, financial, and organizational benefits. In addition to alternatives, each subnetwork contains criteria specific to the corresponding control criteria.

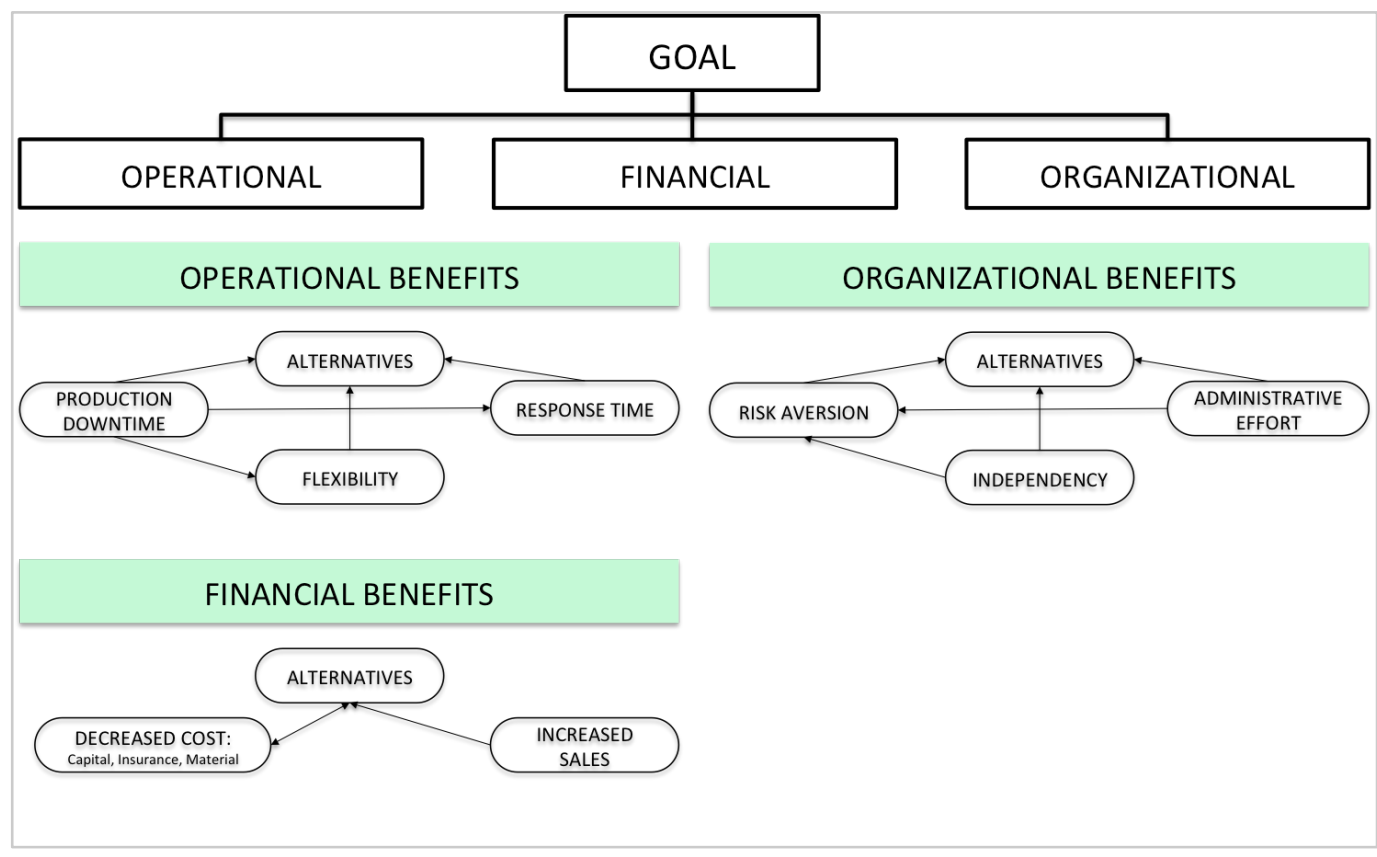

Figure 18: Overview of Benefits Merit and Decision Networks

For example, the "Operational Benefits" network includes "Flexibility," "Response time," and "Production downtime." The connections between "Production downtime" with respect to "Flexibility" and "Response time," stem from a higher probabilities of continuous production when the supply chain is characterized by a fast response time and high flexibility. The "Financial Benefits" network consists of two criteria clusters: "Decreased Cost" and "Increased Sales." Subcriteria of "Decreased Costs" are "Lower investment/capital cost," "Lower insurance cost," and "Lower product/purchasing cost." Thus the criteria are only 
compared with respect to the strategies. The decision network for "Organizational Benefits" contains three criteria clusters. "Risk aversion" influences "Independence," and "Administrative effort" due to the consequences of enacting a certain risk attitude. The relationship between these three clusters can be explained by the higher effort of avoiding disruption risks leading to a higher dependence on suppliers and an increased administrative effort.

\section{- Opportunity Decision Networks}

Figure 19 illustrates the opportunities merit with its two decision networks for "Competitive Opportunities" and "Technological Opportunities." The first decision network consists of two criteria clusters for "Supplier Relations" and "Sales Growth," including subcriteria for "Product Diversification" and "New Market Entry." The connection between these two clusters can be explained through an enhanced supplier relationship if the sales of a company increase. For example, an organization may be able to extend their total available market by choosing the technological substitution strategy. The "Technological Opportunities" network is characterized by the subcriteria: "Improved processes through skipping steps" and "New Product Introduction," which are only connected to the strategy cluster.

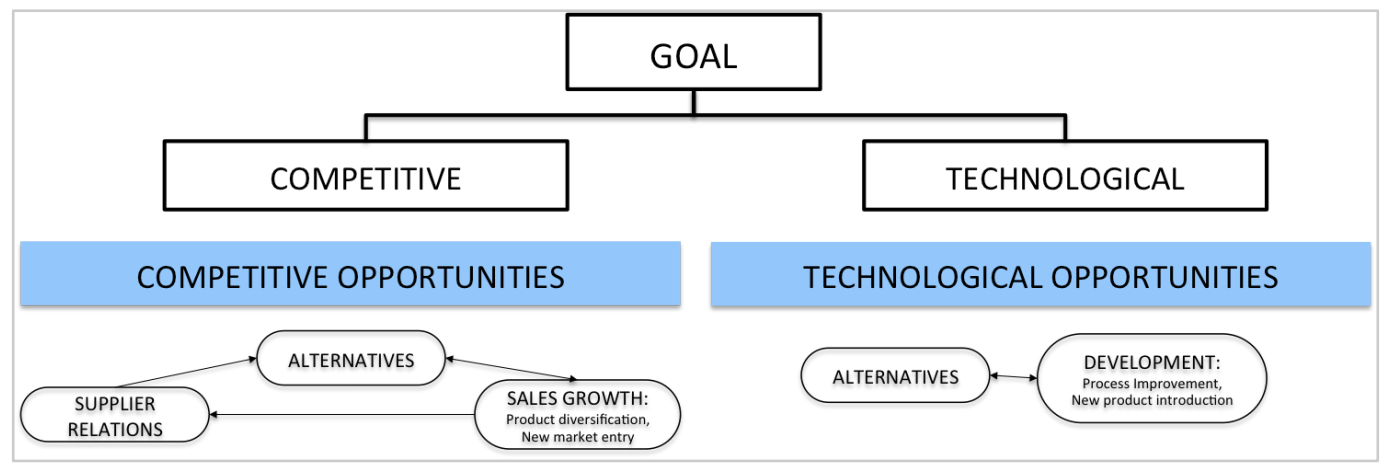

Figure 19: Overview of Opportunities Merit and Decision Networks 


\section{- Cost Decision Networks}

In this research, the costs decision networks are labeled as, "Costs of goods sold," "Operating Cost," and "Disaster Recovery Cost," as illustrated in Figure 20. The first decision network consists of the three clusters: material cost, labor cost, and overhead cost. Additionally, the material cost cluster includes two subcriteria for "Unit price increases" and "Material Handling." There is no connection between these three criteria clusters. The "Operating cost" decision network distinguishes "Product-based R\&D cost" and "Market-based R\&D cost" and compares them pairwise to the alternatives. The last decision network of the costs merit compares tangible and intangible disaster recovery costs with respect to the disruption mitigation strategies. Tangible costs are more specifically "Recovery costs" and "Unavailability costs;" whereas intangible costs would be caused by "Productivity loss" and "Future lost sales."

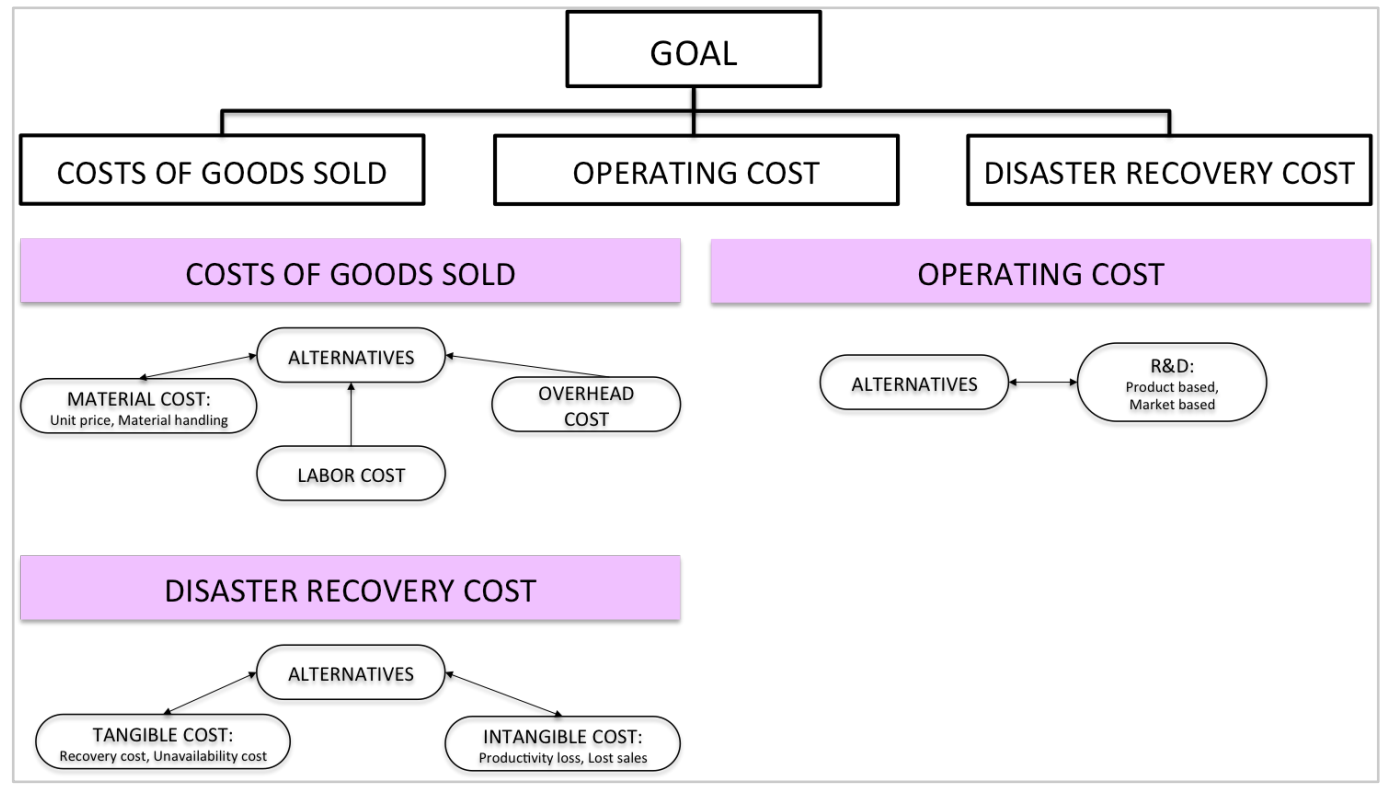

Figure 20: Overview of Costs Merit and Decision Networks 


\section{- Risk Decision Networks}

Figure 21 illustrates two decisions networks for the risks merit: external and internal risks. The external risks include a cluster for "Relations" with subcriteria "Customer relations" and "Supplier relations" and a cluster for "Reputation." The "Internal risks" decision subnetwork includes the criteria "Financial risk" and "Product Quality Decline." All criteria clusters of the risks merit are directly connected to the alternatives (disruption mitigation strategies). A summary of all the ten decision networks sorted by each BOCR merit can be found in Appendix C.

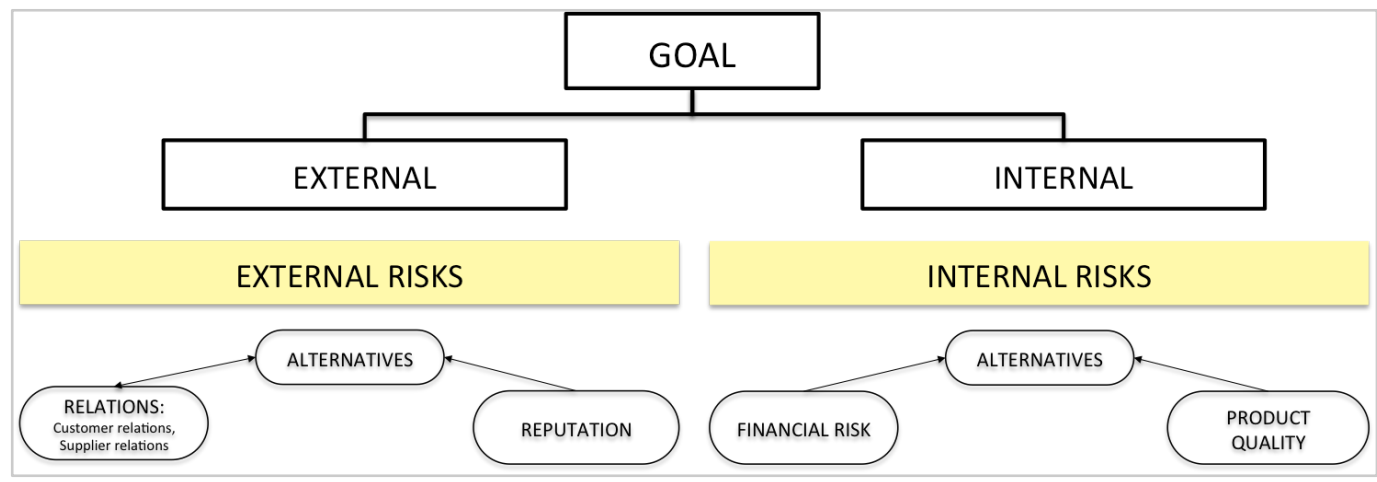

Figure 21: Overview of Risks Merit and Decision Networks

Process step 11 demonstrates a major phase of this thesis' proposed ANP model. With these decision networks, the analyst will be able to carry out pairwise comparisons with the goal to evaluate the different disruption mitigation strategies.

\section{Process Step 12}

After all decision networks have been set up, a decision-maker can conduct pairwise comparisons according to all connected elements. Again, when making comparisons, the decision-maker has to keep the overall goal of the decision network in 
mind. For example, for the decision networks of the benefits merit, the objective is to identify the most beneficial disruption mitigation strategy. Likewise, for decision networks in the opportunity/cost/risk merit, the most opportune/costly/risky alternative must be ranked highest. Pairwise comparisons are run the same way as described in previous stages, such as in Process Steps 4 and 8.

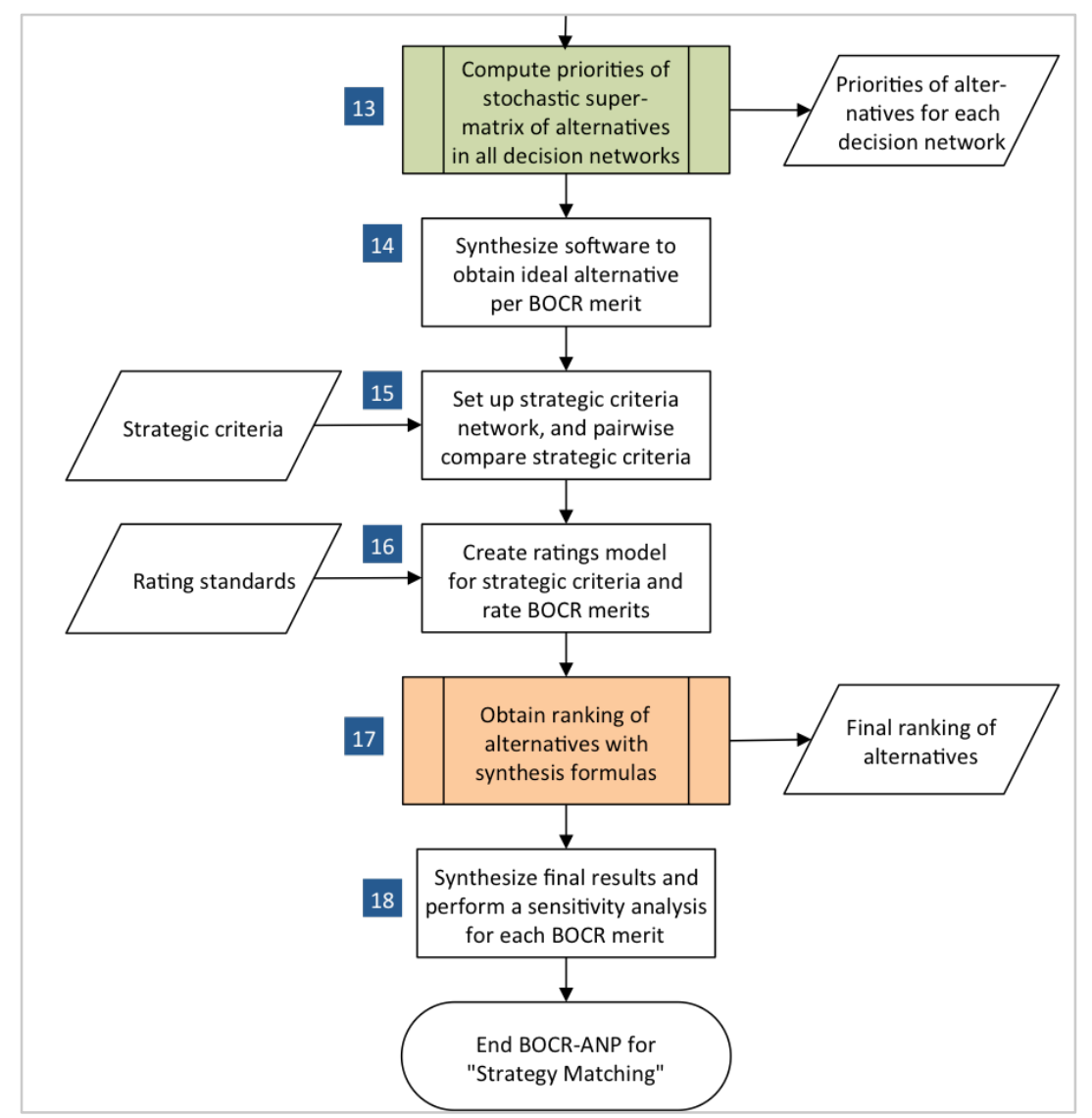

Figure 22: Zoom into Flowchart (Process Steps 13-18)

Figure 22 highlights the succeeding Process Steps $13-18$, which will be described in the following paragraphs.

\section{Process Step 13}

Again, in Process Step 13, the ANP software is employed to obtain the alternatives' priorities for each decision network. Computational steps include the weighting of 
priority vectors for alternatives with cluster priorities, and exponentiating the supermatrix to obtain the final limitmatrix. Limitmatrices are retrieved for all of the ten decision networks, and from there, priority vectors for the disruption mitigation strategies can be derived. The limitmatrices are listed in Appendix D according to their BOCR merit.

\section{Process Step 14}

Based on the priority vectors for the alternatives of each decision network, the ANP software synthesizes a ranking per BOCR merit. For this purpose, each alternative is weighted by the importance of the respective control criteria, and are then added together per BOCR merit. To better illustrate the output of Process Step 14 in this research, Table 6 shows the overall priorities of each alternative per BOCR merit. Overall, the "Excess inventory" strategy demonstrates to be the most beneficial strategy, whereas the strategy of a "Technological substitution" provides the most opportunities. On the contrary, the most costly and risky option is "Passive acceptance."

Table 6: Priorities Obtained for Disruption Mitigation Strategies per BOCR Merit

\begin{tabular}{|c|c|c|c|c|}
\hline \multirow{2}{*}{ Strategy } & Benefits & Opportunities & Costs & Risks \\
\hline & Ideals Graphic & Ideals Graphic & Ideals Graphic & Ideals Graphic \\
\hline 1. Multiple Suppliers & 0.7291 & 0.3587 & 0.2876 & 0.4860 \\
\hline 2. Excess Inventory & 1.0000 & 0.2104 & 0.2999 & 0.3854 \\
\hline 3. Technological Substitution & 0.6919 & 1.0000 & 0.3921 & 0.8274 \\
\hline 4. Passive Acceptance & 0.9177 & 0.1092 & 1.0000 & 1.0000 \\
\hline
\end{tabular}

\section{Process Step 15}

Process Step 15 reveals a new level for this proposed thesis model, introducing the strategic network of the BOCR-ANP. Similar to the control criteria structures, the strategic criteria network consists of a goal as well as criteria and subcriteria. The goal of the strategic criteria network is to evaluate the relevance of disruption mitigation strategies and ultimately determine the best overall strategy for a specific product 
based on the assessment of benefits, opportunities, costs, and risks. The following paragraphs describe how the strategic criteria network is implemented in this research.

For this purpose, seven criteria were selected to assess the significance of disruption mitigation strategies. Table 7 categorizes these criteria into three groups and provides a short description for each criterion.

Table 7: Strategic Criteria of BOCR-ANP Model

\begin{tabular}{|c|c|c|}
\hline Cluster & Strategic criteria & Short description \\
\hline \multirow[t]{3}{*}{$\begin{array}{l}\text { External } \\
\text { influences }\end{array}$} & $\begin{array}{l}\text { Increased probability } \\
\text { of disasters (1) }\end{array}$ & $\begin{array}{l}\text { Quantity and severity of disasters statisti- } \\
\text { cally increased the last decades. }\end{array}$ \\
\hline & Globalization (2) & $\begin{array}{l}\text { Companies and their supply chains be- } \\
\text { come more global. }\end{array}$ \\
\hline & $\begin{array}{l}\text { Competitive behavior } \\
\text { (3) }\end{array}$ & Competitors invest in BC/DR strategies. \\
\hline $\begin{array}{l}\text { Internal } \\
\text { influences }\end{array}$ & $\begin{array}{l}\text { Growth/Long-term } \\
\text { orientation (4) }\end{array}$ & $\begin{array}{l}\text { Long-term plans of company might include } \\
\text { more global approaches for sourcing, sell- } \\
\text { ing or partnerships. }\end{array}$ \\
\hline \multirow[t]{3}{*}{ Consequences } & Profit (5) & $\begin{array}{l}\text { Disasters might have long-term impact on } \\
\text { profit. }\end{array}$ \\
\hline & Image (6) & $\begin{array}{l}\text { Corporate image might suffer due to lack of } \\
\text { precautions taken. }\end{array}$ \\
\hline & Stakeholders (7) & Abandonment of interested parties. \\
\hline
\end{tabular}

With reference to Table 7, each criteria shall be discussed further regarding its relevance to make a decision about investing in BC/DR practices. For example, the geographical location of a company as well as the location of supply chain partners shall be taken into account. Since some countries are especially prone to disasters, organizations in these countries show a higher willingness to invest in resilience. However, a company should also consider the overall increased probability and severity of disasters (Strategic Criterion 1, Table 7). Additionally, businesses face global interactions 
(Strategic Criterion 2) on a daily basis, which is another indicator for the need for a more elaborate disaster planning process. Proactive planning and investing in disruption mitigation strategies might lead to competitive advantages (Strategic Criterion 3), and thus companies should consider an investment. In summary, Criteria 1 through 3 are external influences triggering a company's investment in resilience practices.

Further, internal impacts exist that a company should consider when making decisions about BC/DR management. For instance, investing in a broader supplier network might lead to collaborations and change the long-term orientation and thus projected growth strategy of a company (Strategic Criterion 4). Eventually, consequences will be taken into account when deciding about an investment in disruption mitigation strategies. A production disruption due to a disaster might lead to a decrease in profit (Strategic Criterion 5), a negative influence on the company's reputation (Strategic Criterion 6), and lost interest of stakeholders (Strategic Criterion 7).

After choosing appropriate criteria, the network structure can be set up. Again, clusters are used to gather similar criteria, and connections between elements are made. Figure 23 shows a screenshot of the strategic criteria network of this project in the SuperDecisions software. There are two relationships that are noteworthy. The first one is an inner dependence in the "consequences" cluster, which stems from negative effects on concerned stakeholders (Strategic Criterion 7), on the profit (Criterion 5), and on the company image (Criterion 6 ) during a production interruption. The outer dependencies between the elements: "Growth/Long-term orientation" (Strategic Criterion 4) and "Image" as well as "Stakeholders" (Strategic Criteria 6 and 7) refer to a potential impact on the long-term development of a company, depending upon how the company is perceived by the public and by third parties. 


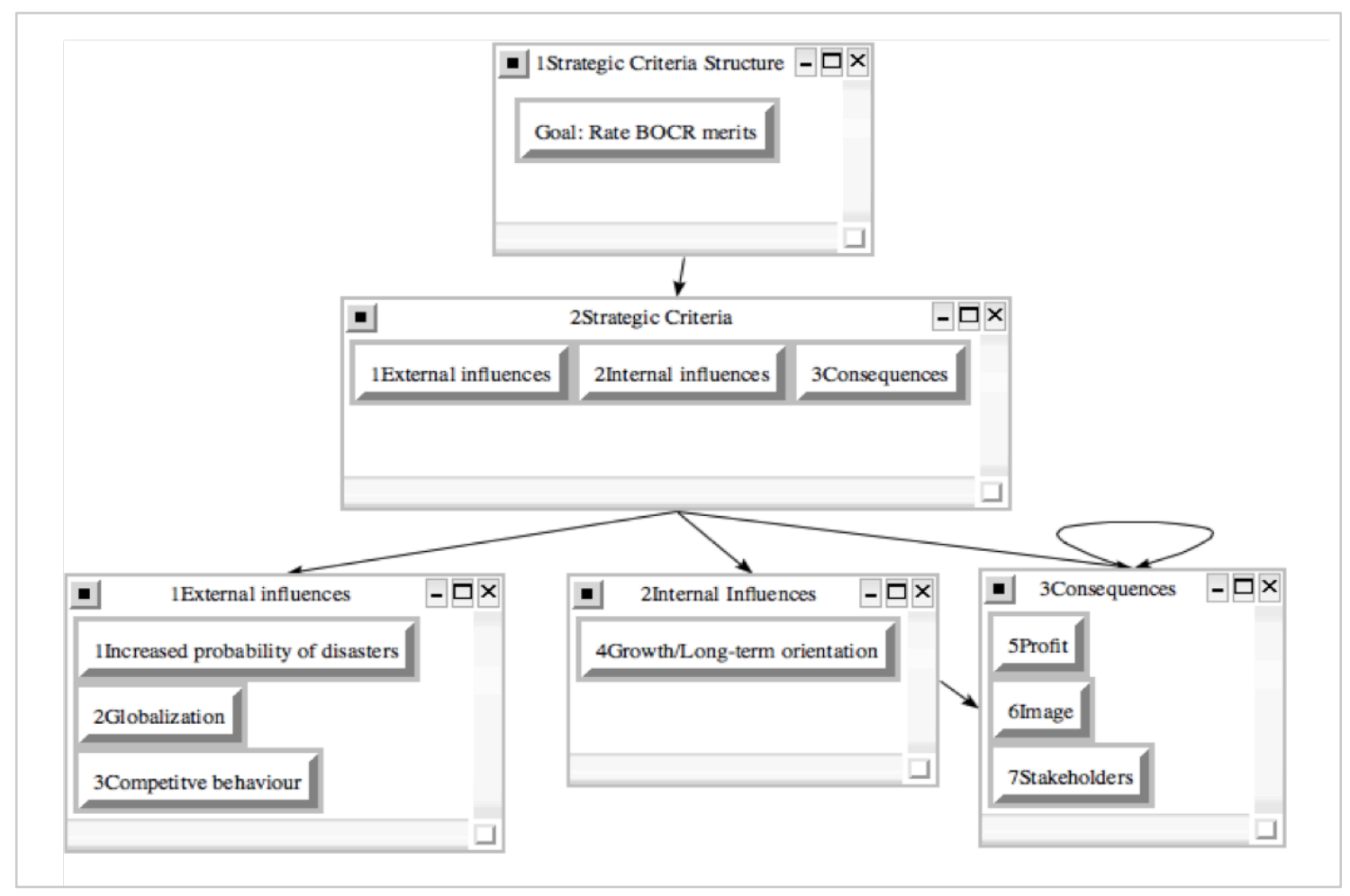

Figure 23: Screenshot of Strategic Criteria Network

As a next step, strategic criteria are pairwise compared against one another according to their connections. This leads to the priorities illustrated in Figure 24, which will be employed to individually rate the BOCR merits during next process step.

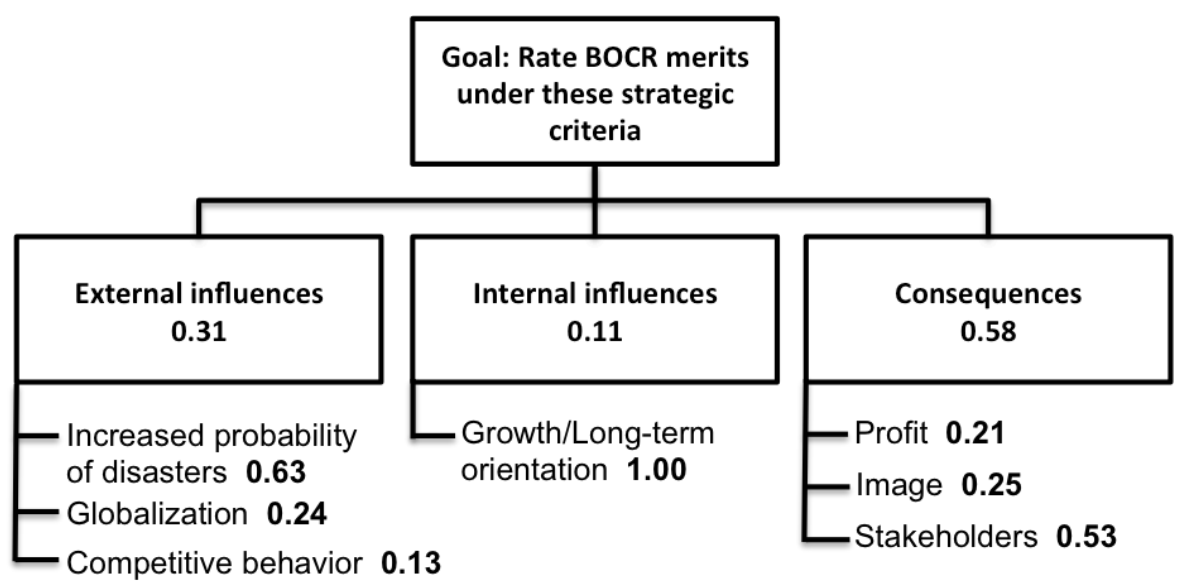

Figure 24: Priorities Obtained in Strategic Criteria Network 


\section{Process Step 16}

The goal of Process Step 16 is to rate the benefits, opportunities, costs, and risk merits of the BOCR-ANP model in this thesis. Initially, each of the four merits will contribute equally (25\% each) to the final result. This will not necessarily represent a realistic scenario where a user might prioritize cost considerations over possible benefits or opportunities. Therefore, each merit will be rated against strategic criteria to determine the overall importance of each merit. Rating standards will be applied to translate a qualitative judgment into a numeric value.

In this research, the BOCR merits are evaluated according to the strategic criteria introduced in the earlier process step (Table 7 and Figure 24). During the rating process, the analyst refers to the highest ranked alternative of each merit, as shown in Table 6 , and rates it against each strategic criteria. For example, when comparing the most beneficial alternative, "Excess inventory," to strategic criterion no. 3, "Competitive behavior," the following question is asked: "How beneficial is it to choose excess inventory with respect to the competitive behavior?"

In this example, the standard, "High," is assigned because carrying excess inventory, and thus ensuring a longer supply, could lead to a competitive advantage while competitors face production unavailability. This rating procedure is repeated for every criterion with respect to its merit. For this purpose, a numeric value assigned to the verbal rating standard (Appendix $E$ ) is multiplied by the strategic criteria priorities and summed. Finally, the obtained priorities are normalized for all merits. Table 8 shows the assigned rating values of the strategic criteria against the BOCR merits and the final normalized priorities per merit in this project. 
Table 8: Priority Rating of Strategic Criteria against BOCR Merits

\begin{tabular}{lcccc}
\hline & Benefits & Opportunities & Costs & Risks \\
\hline 1. Increased probability of disasters (0.11) & 0.00 & 0.00 & 0.00 & 0.00 \\
2. Globalization (0.04) & 0.00 & 0.00 & 0.00 & 0.00 \\
3. Competitive behavior (0.03) & 0.71 & 0.71 & 0.05 & 0.05 \\
4. Growth/Long-term orientation (0.06) & 0.71 & 0.71 & 0.05 & 0.05 \\
5. Profit (0.16) & 0.24 & 0.71 & 0.24 & 0.00 \\
6. Image (0.19) & 0.71 & 0.00 & 0.24 & 0.00 \\
7. Stakeholders (0.41) & 0.00 & 0.00 & 0.00 & 0.05 \\
\hline SUM(Strategic criteria priority * Rating) & 0.24 & 0.18 & 0.09 & 0.02 \\
Normalized Priorities & $\mathbf{0 . 4 5}$ & $\mathbf{0 . 3 4}$ & $\mathbf{0 . 1 7}$ & $\mathbf{0 . 0 4}$ \\
\hline
\end{tabular}

\section{Process Step 17}

Process Step 17 entails the final computations to obtain the overall priorities for all disruption mitigation strategies. Therefore, the "positive" priorities (of the benefits and opportunities merits) for each alternative are combined with the "negative" priorities (of the costs and risks merits) in a formula. Two formulas, introduced in Chapter 2.3, can be employed to counterbalance the conflicting priorities. Referring back to the ANP theory, the additive formula gives the best results based on long-term considerations, whereas the multiplicative formula is favorable concerning decisions influencing the near future.

In this thesis, both formulas were applied to come to a final conclusion. In both cases, Strategy Number 3, "Technological substitution," obtains the highest priority, whereas Strategy No. 4, "Passive acceptance," represents the worst option. The overall ideal priorities for each mitigation strategy are shown in Table 9. 
Table 9: Synthesizing BOCR for each Alternative Using the Ideal Mode

\begin{tabular}{|l|cccc|cc|}
\hline Strategy & $\begin{array}{c}\text { Benefits } \\
0.45\end{array}$ & $\begin{array}{c}\text { Opportunities } \\
0.34\end{array}$ & $\begin{array}{c}\text { Costs } \\
0.17\end{array}$ & $\begin{array}{c}\text { Risks } \\
0.04\end{array}$ & $\begin{array}{c}\text { Additive } \\
\text { formula }\end{array}$ & $\begin{array}{c}\text { Multiplicative } \\
\text { formula }\end{array}$ \\
\hline 1. Multiple suppliers & 0.73 & 0.36 & 0.29 & 0.49 & 0.65 & 0.88 \\
2. Excess inventory & 1.00 & 0.21 & 0.30 & 0.39 & 0.75 & 0.85 \\
3. Technological substitution & 0.69 & 1.00 & 0.39 & 0.83 & 1.00 & 1.00 \\
4. Passive acceptance & 0.92 & 0.11 & 1.00 & 1.00 & 0.37 & 0.05 \\
\hline
\end{tabular}

\section{Process Step 18}

By now all necessary ANP calculations have been conducted, and final results have been synthesized. As a final step, a sensitivity analysis shall be performed to validate the adequacy of the decision process. In general, the goal of a sensitivity analysis is to demonstrate how stable final results are to input changes. In the case of a BOCRANP, an input is defined as the priority of each of the BOCR nodes. After confirming the stability of the proposed decision-making model, the BOCR-ANP model ends. In the next chapter, the proposed multiple-level ANP model is applied to a case study to prove the applicability and effectiveness of this thesis research. 


\section{Testing, EVAluation AND Discussion}

This chapter describes the validation process for the generic research framework developed in this thesis through a case study using historical data of a U.S. semiconductor company. For confidentiality reasons, the company is referred as to "Company $\mathrm{XYZ"}$. The case study was conducted in collaboration with a BC/DR-expert of Company XYZ. In addition, this chapter compares the positive attributes of the proposed model with limitations of the generic method, and limitations encountered during the implementation process.

\subsection{Case Study}

For the case study, an expert in the field of BC/DR management with several years of experience in the semiconductor industry determined the input data and conducted comparisons through the proposed multi-layer ANP model. The data-gathering process was enforced in two steps, as shown in Figure 25.

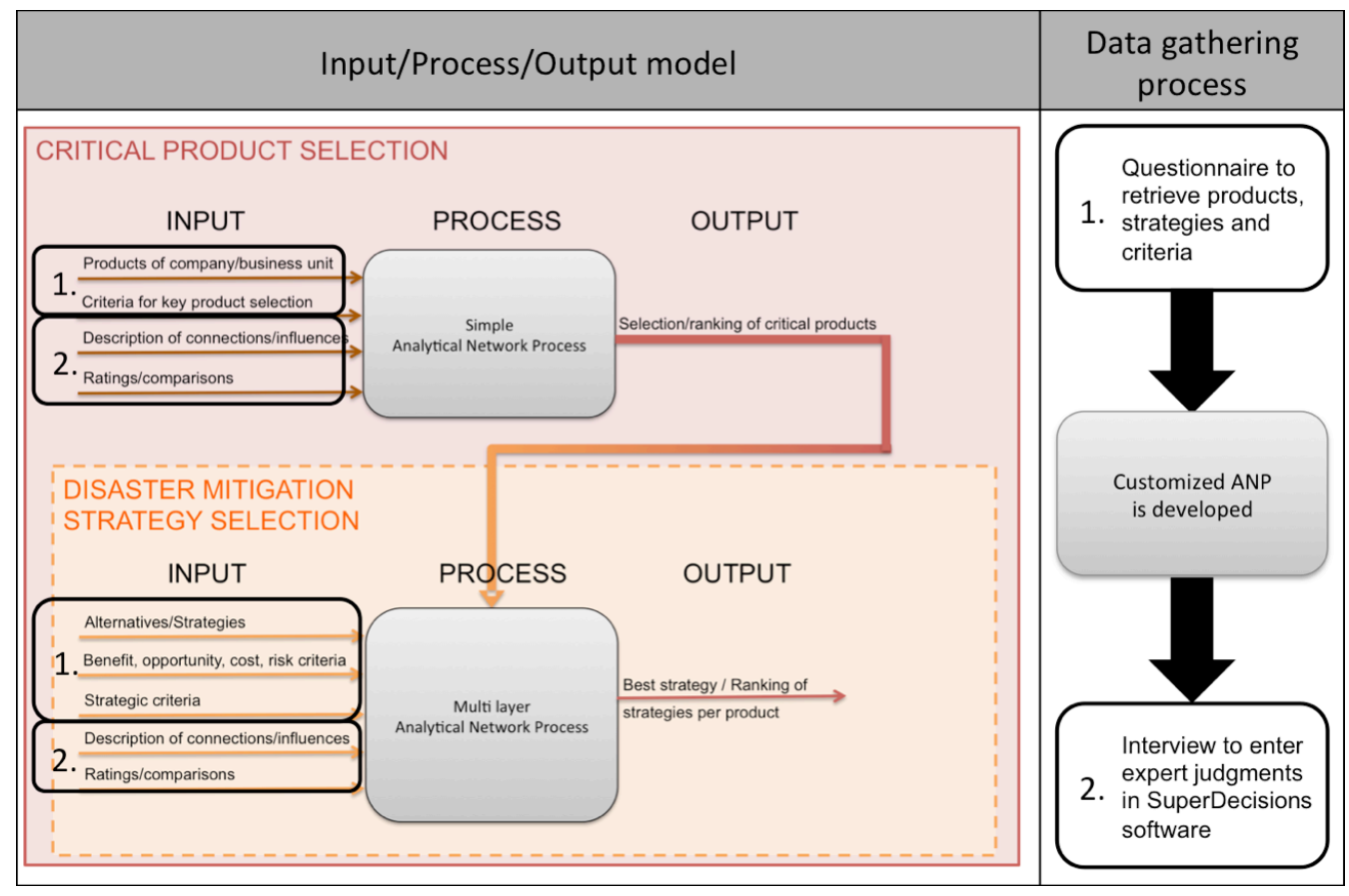

Figure 25: Data Gathering for Input of ANP Models 
First, the expert filled out a questionnaire to determine the inputs required for setting up the ANP model (Appendix F). The researcher then customized the ANP model specifically to the requirements of the user. For reasons of simplification, the generic model, developed and described in the previous chapter, was adjusted to the user-specific inputs. As a next step of this case study, an interview with the expert was conducted to directly carry out comparisons within the ANP software model. The following two sections first describe the ANP input and process, and then the output of this case study.

\section{Case Study: ANP Input and Process}

With the help of the questionnaire, the critical product selection model was set up in the SuperDecisions software. The decision-maker then compared products pairwise with respect to the selected criteria to identify the key products of his company. Due to confidentiality reasons, the products are subsequently referred as to "Product A" and "Product B." The user chose "Dissatisfied customers" and "Loss of revenue" as

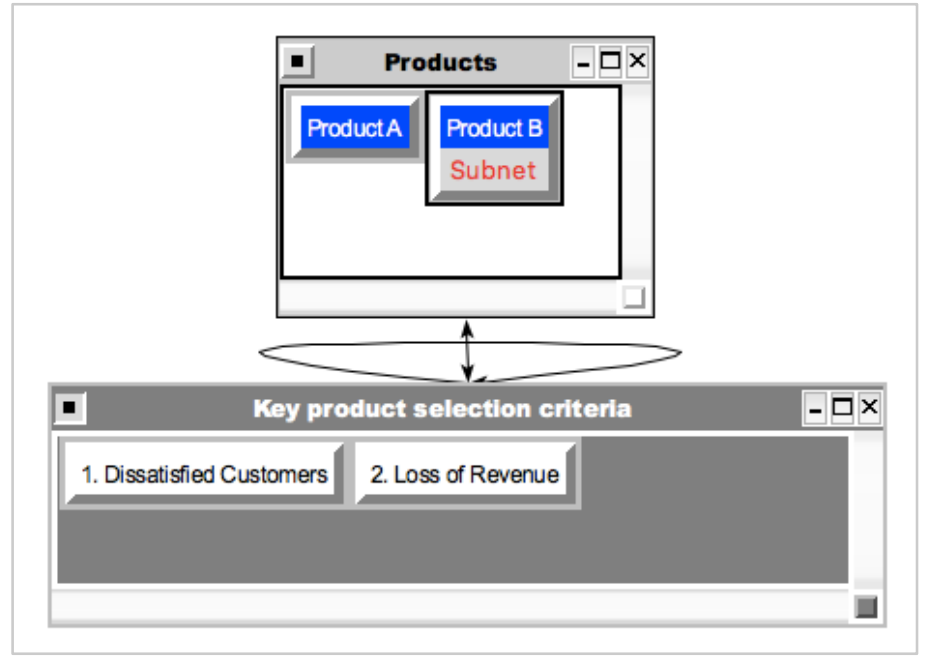

Figure 26: Screenshot of "Key Product Selection" Network (Case Study) criteria to pairwise compare his products.

Figure 26 shows a screenshot of the ANP model developed in the SuperDecisions application. The arrows on the software interface demonstrate the relationships between cluster elements. In 
this specific case, there is an inner dependence between the two selection criteria. This can be explained by the influence of dissatisfied customers on potential future sales. When the ANP model was set up in SuperDecisions, the expert was asked to conduct pairwise comparisons with the result that Product B obtained higher priorities than Product $A$, with $68.3 \%$ versus $31.7 \%$ priority respectively. Thus, the case study expert decided that an assessment of disruption recovery strategies should only be employed for Product B.

The user then proceeded with the second ANP model to find an optimal strategy to mitigate supply chain disruptions for his Product B. He chose to compare two strategies, based on their usefulness for his business. The strategies were "Build a supplier network" and "Establish a technological substitution." Again, the BOCR-ANP model was set up specifically to the inputs determined through the questionnaire. To enhance the readers understanding, all necessary network structures including their inputs and relationships between elements will be described in detail in the following paragraphs.

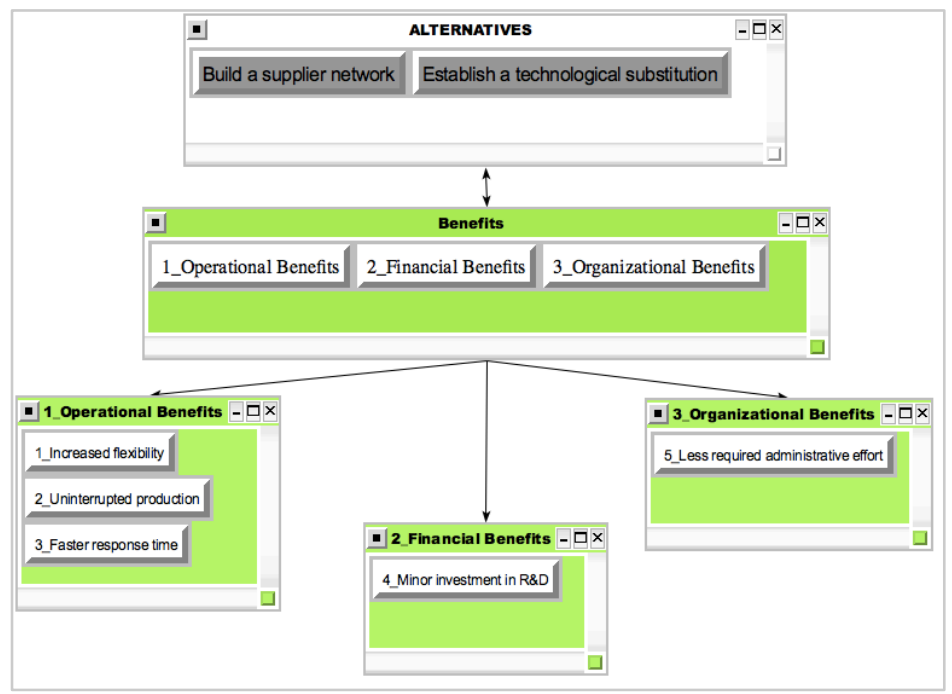

Figure 27: Screenshot of Benefits Merit (Case Study)
Figure 27 shows the control criteria network of "Benefits." The model consists of three clusters for operational, financial, and organizational benefits. The operational benefits cluster contains the nodes increased 
flexibility, uninterrupted production, and faster response time. Financial benefits are described trough a "Minor investment in R\&D." "Less required administrative effort" is the main criterion for organizational benefits.

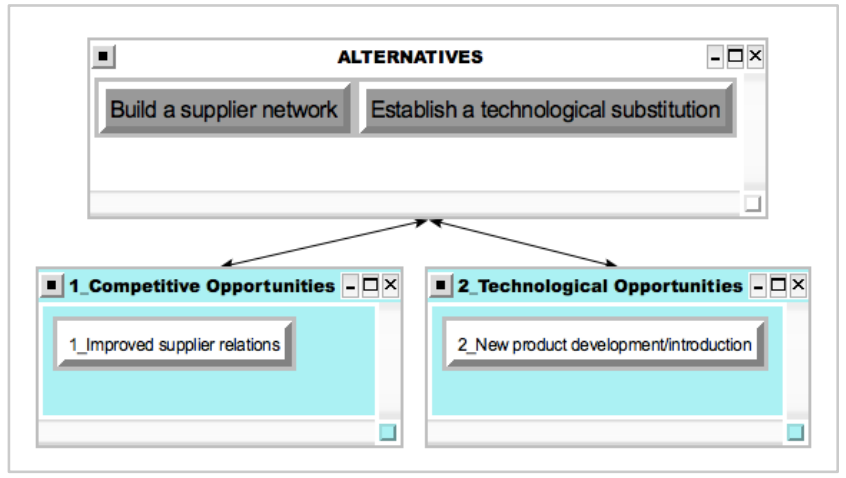

Figure 28: Screenshot of Opportunities Merit (Case Study)

For the opportunities merit, the expert decided on a network with a cluster for competitive and technological opportunities. As illustrated in Figure 28, criteria are "Improved supplier relations" and "New product development" respectively.

Figure 29 shows the costs merit with three criteria clusters. The node "Price per unit increases" describes the first cluster, "Costs of goods sold." The second cluster, "Operating expenses," contains the criteria "Research and Development" and "Administrative expenses." "Recovery cost" and "Unavailability cost" are criteria for the "Disaster Recovery Cost" cluster.

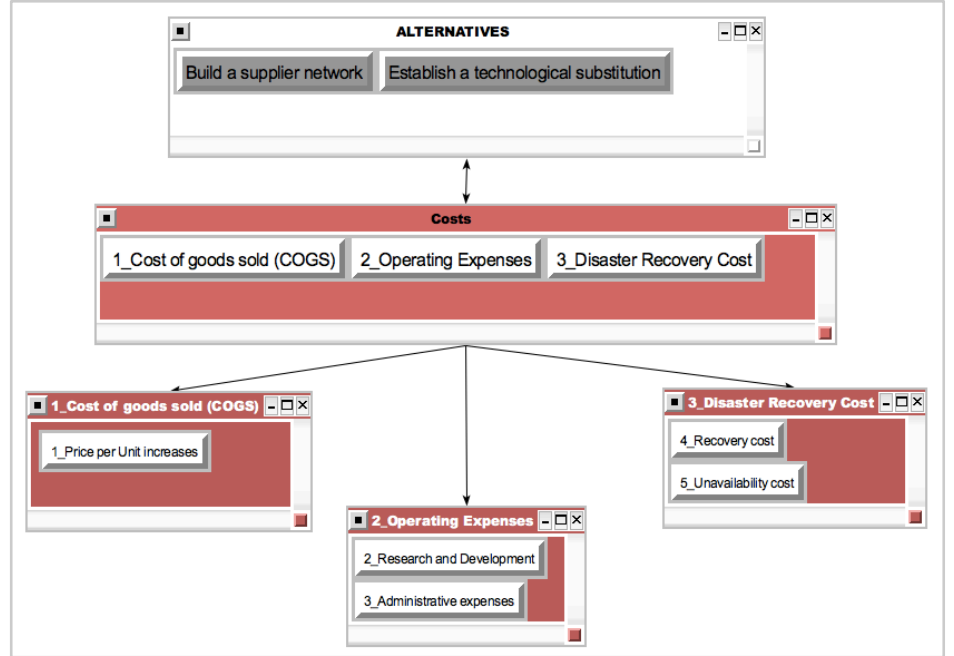

Figure 29: Screenshot of Costs Merit (Case Study)
As shown in Figure 30, the risks merit contains two clusters for external and internal risks with the nodes "Dissatisfied customers due to product unavailability" and "Financial losses." The BOCR merits in this case 
study display a relatively simple network structure. Thus, the two alternative strategies were input as a cluster directly to each of the BOCR merit networks.

With this ANP model set

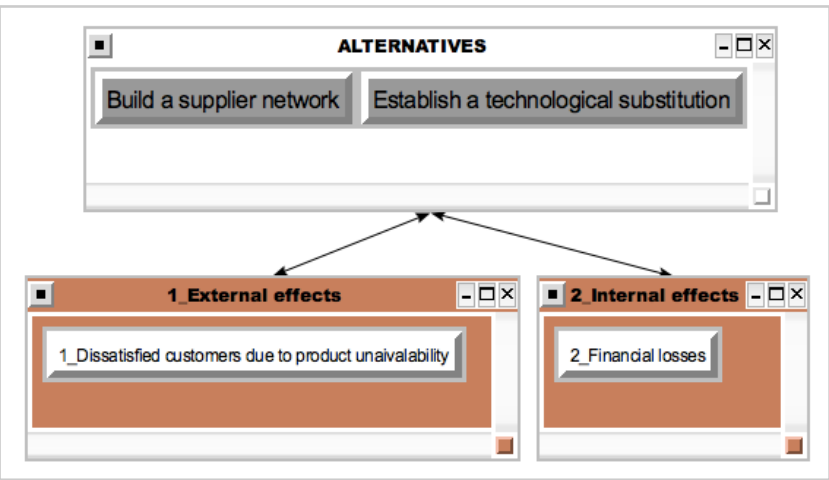

Figure 30: Screenshot of Risks Merit (Case Study) up accordingly to the user's input, the expert was able to carry out pairwise comparisons in each of the BOCR merit networks. To remind the reader, in the benefits and opportunities networks, the decision-maker compared elements to find the most beneficial or opportune disruption mitigation strategy for Product $B$. The goal of costs and risks networks, however, was to identify the most costly or risky choice. After the expert expressed his judgments via pairwise comparisons in each of the BOCR merits, the supermatrices and limitmatrices were obtained in the SuperDecisions software. Appendix G provides details on the priorities of each criterion of the BOCR merits. In addition, the supermatrices and limitmatrices for the benefits, opportunities, costs, and risks nodes can be found in Appendix I.

As a note, the structure of the strategic criteria network was kept identical to the generic model described in the previous chapter. The expert rated the BOCR merits according to his judgment with respect to the strategic criteria. Details on the rating procedure can be found in Appendix $\mathrm{H}$.

\section{Case Study: ANP Output}

A final synthesis was run in the ANP software application applying two formulas (additive and multiplicative) to retrieve overall priorities for each alternative. Table 10 shows the final results, indicating that the "Build a supplier network" strategy represents 
the best overall alternative. The strategy "Establish a technological substitution" results in an overall negative priority when the additive formula is employed. This implies that the negative priorities of the costs and risks merits dominate the outcome over the positive benefits and opportunities merits. Thus, a technological substitution is not only less favorable when compared to the supplier network strategy, but appears to be a poor choice for Product B in general. When employing the multiplicative formula, which gives the best short-term outcome, the hypothesis that the "Supplier network" strategy is more favorable than the "Technological substitution" strategy is supported.

Table 10: Final Ranking of Disruption Mitigation Strategies for Product B

\begin{tabular}{|c|c|c|c|c|}
\hline Strategy selection for Product B & $\begin{array}{c}\text { Additive } \\
\text { Priorities } \\
\text { (normalized) }\end{array}$ & $\begin{array}{l}\text { rmula } \\
\text { Graphic }\end{array}$ & \multicolumn{2}{|c|}{$\begin{array}{l}\text { Multiplicative formula } \\
\text { Priorities } \\
\text { (normalized) Graphic }\end{array}$} \\
\hline Build a supplier network & 0.694115 & & 0.990296 & \\
\hline Establish a technological substitution & -0.305885 & & 0.009704 & \\
\hline
\end{tabular}

In order to validate the results obtained by the BOCR-ANP model, the researcher performed a sensitivity analysis for each merit with the ANP software. In general, the sensitivity analysis reveals how stable the highest ranked alternative is when input parameters are changed. Figure 31 shows the sensitivity graphs for each BOCR merit with red lines representing the supplier network strategy and blue lines representing the technological substitution strategy. In general, changing the priority for each merit might lead to a change in the ranking of alternatives. However, in this case study, the output remained stable for each of the four merits, proving that the "Supplier network" is the preferred choice over the "Technological substitution" tactic for Product B. 


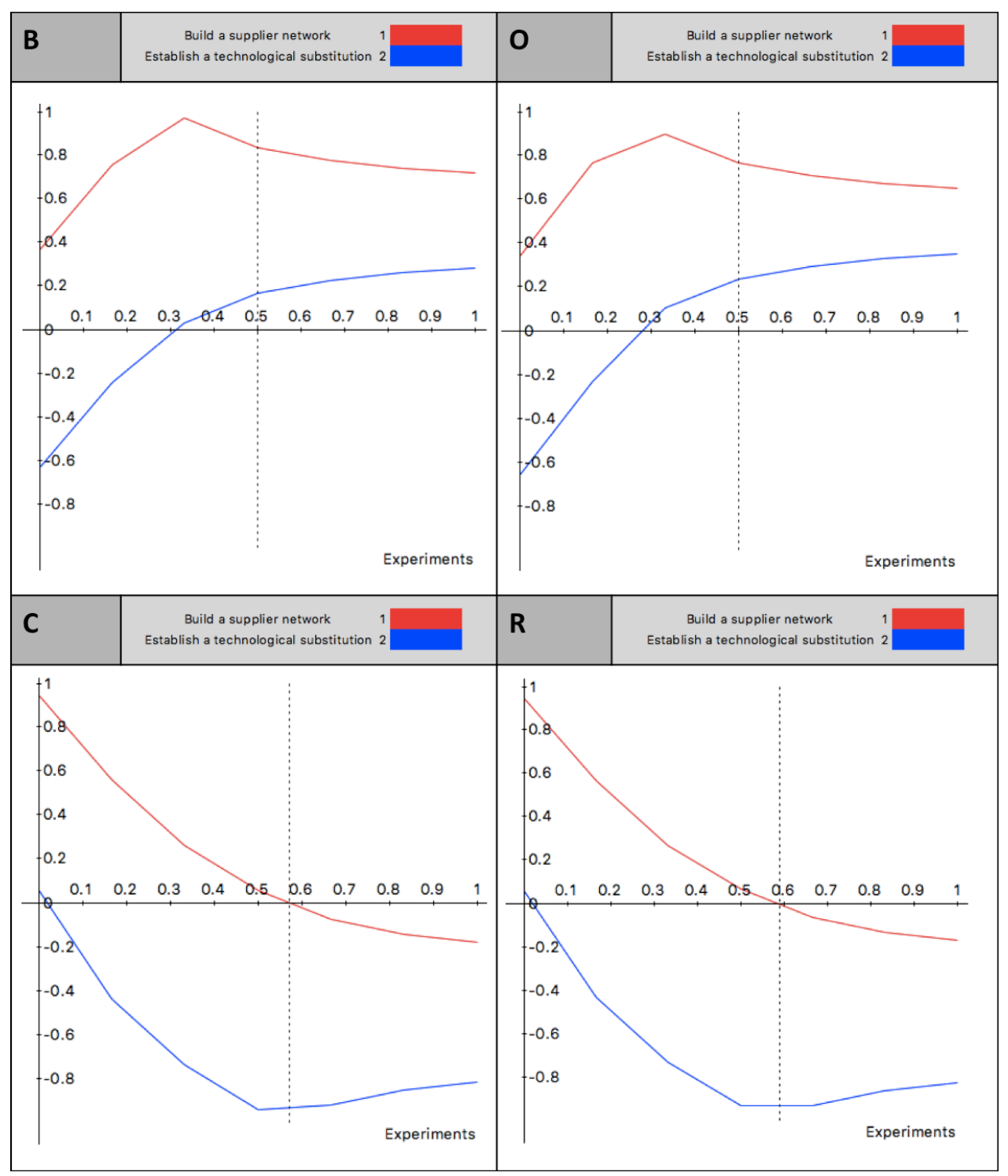

Figure 31: Sensitivity Analysis for each BOCR Merit

A thorough analysis of the benefits merit exposed that under a priority rating of $0.3(30 \%)$ the "Technological Substitution" strategy (blue line) results in a negative priority, which means that it is not beneficial to choose. A similar trend can be seen for the opportunities merit. Only when costs and risks are compared, the sensitivity graph indicates that the "Supplier network" (red line) obtains negative weights when priorities over $0.55(55 \%)$ are selected for each merit. The sensitivity analysis confirms the initial conclusion that the "Supplier network" strategy is the best overall strategy for Product 
B. In addition, the sensitivity analysis verifies the stability of the results obtained from input changes in the proposed BOCR-ANP model. When the final results of this case study were discussed with the expert, he confirmed that the supplier network strategy was the favorable strategy based on his expertise and professional decision-making.

\subsection{Discussion}

\section{Positive Attributes}

In general, the Analytic Network Process demonstrates a strong method for decision-making based on multiple criteria. It accounts for tangible and intangible factors when judgments are made in order to come to a conclusion without solely relying on just one measure or intuition. Additionally, the ANP provides a framework to justify in-

consistencies, which are a natural consequence of human decision-making. Compared to other multi-criteria decision-making (MCDM) approaches, the ANP is especially useful for organizations since it allows the reinforcement of management decisions with a mathematical justification (Taslicali \& Ercan, 2006). Another benefit is that ANP can be used in combination with other tools to simplify and carry out managerial decisionmaking based on the judgment of individual experts or a group of experts. With the help of ANP software, such as the freely accessible SuperDecisions application, the ANP method is relatively easy to apply to business problems. In conclusion, it can be said that the Analytic Network Process represents a powerful tool when making decisions in unstable, fast-changing environments such as BC/DR planning.

Referring to this research, the proposed methodology of employing the Analytic Network Process is unique in two aspects. First, in the field of BC/DR planning, there has been no tool developed to match critical products of a company with optimal dis- 
ruption mitigation strategies. For this extensive investigation, a multiple level network structure was required to combine two individual operating ANP models with the goal of identifying the optimal resilience strategy for the key products of a company. No comparable or similar approach has been found in any research papers or applications, by Saaty nor others. Furthermore, the proposed generic model in this thesis can be quickly adjusted according to the user input and is therefore ideal for organizations concerned about proactive BC/DR planning.

\section{Limitations of ANP Methodology}

The Analytic Network Process and its specialized linear form, the Analytic Hierarchy Process, are criticized in literature for some of their features. Widely discussed is the term of "Rank preservation and reversal" (Saaty \& Vargas, 2001). Axioms in decision theory state that the ranking of alternatives should not change when new alternatives are added or insignificant alternatives are eliminated. In particular, AHP is prone to rank reversal; however, Taslicali and Ercan (2006) state that this phenomenon is alleviated by the use of a network structure instead of a hierarchical structure. Moreover, inconsistencies could falsify results if not kept at an acceptable level. Fortunately, however, SuperDecisions software provides an application to monitor and reduce inconsistencies.

Another limitation that some researchers allege is the ability of decision-makers to structure the model in a way that their favorable outcome will obtain the highest priorities. It may therefore be implied that users who carry out the comparisons should not design the ANP framework. Another way to appease personal preference of single decision-makers is through gathering groups judgments for ANP instead of referring to the opinion of an individual. 
When comparisons are made, Saaty's fundamental scale of judgment is employed to assign a qualitative opinion to a scale from one to nine. Using a limited set of integers to make comparisons may not be an effective approach when modeling complex problems. One way to address this issue is the use of "Fuzzy Logic" to model human judgments. Fuzzy logic was not used in this research; however, more information on the theory of fuzzy logic can be found by Zadeh (1976) and could be applied in future work.

Utilizing a specific type of ANP software led to a couple of disadvantages. One limitation of SuperDecisions is that it does not include an instrument to directly gather group judgments. Data gathering (questionnaires and interviews) and statistical methods are required to process large groups of data (Saaty \& Vargas, 2001) before being entered into the software application. Another limitation of the SuperDecisions software was found in the verification of the proposed ANP model. In general, after results are synthesized the performance of a sensitivity analysis is recommended for each BOCR node in order to validate the stability of the ranking. For this purpose, the priorities placed on each BOCR merit (referred to earlier as b, o, c, and r) must be varied, and hence the ranking of alternatives may change; however, this can only be done by the SuperDecisions software if the additive formula is selected. For the multiplicative formula, the priorities placed on each BOCR merit (b, o, c, and $r$ ) cancel out. As a result, it is questionable how valuable the utilization of the multiplicative formula is. As a general approach, the decision-maker should always use both formulas to acquire reliable results. 


\section{Requirements for the Success of the Proposed Model}

The goal of developing a generic model was to include criteria and alternatives for as many scenarios as possible, so that in the best case little to no adjustment will be required. The intention is to minimize the effort for future users. Therefore, the researcher chose a set of elements (criteria, subcriteria and alternatives) to apply to the generic ANP model in order to identify key products and match optimal disruption mitigation strategies. The reader should keep in mind that each model needs to be adjusted and judgments must be entered individually before conclusions can be drawn. In addition, the network structure has to be set up correctly. Therefore, it is absolutely necessary that users are knowledgeable about the working mechanics of the ANP and know how the software application is utilized.

Another requirement to ensure quality results is the determination of threshold values used throughout the decision-making procedure. In the first product selection ANP model, a determinant value must be set to categorize products based on their importance for the company. As a result, the succeeding ANP model that evaluates disruption mitigation strategies is then set up only for critical products. Additionally, the user defines critical measures for the control decision networks. Only criteria with major influence on each BOCR network will be linked to a decision network. As a general rule, the decision maker should exclude criteria and subcriteria with less than $3 \%$ of the total priority from being control criteria (Saaty, 2009).

The effectiveness of the proactive decision-making model is dependent on the users' input and judgments. Again, this supports the concern that the decision-maker should be knowledgeable about the ANP methodology. For the case study introduced in this thesis, one industry expert was exposed to the proposed ANP model. After he 
determined the inputs, the model was adjusted accordingly. Judgments were then directly entered into the software application. Results obtained with the proposed ANP method were confirmed according to the user's expertise. Hence, it can be concluded that the case study in this research provides a reasonable approach to testing and validating the proposed method. However, the results could change if a panel of decisionmakers with different backgrounds and specialization fields were involved and a consensus on judgments were to be required. Although group decision-making would lead to the most accurate and predictable results, doing so ultimately depends on the company's willingness to invest resources and training required to employ the proposed BC/DR planning tool. 


\section{CONCLUSIONS AND FUTURE WORK}

The objective of this research was to develop a framework to identify critical products of a company and then match these products with optimal disruption mitigation strategies. To support the decision process in BC/DR planning, a multiple level Analytic Network Process model was generated to combine two separate but consecutive parts of Disaster Recovery Planning for supply chains in one tool. Using the model described in this thesis, organizations will be able to evaluate their product importance according to monetary and non-monetary criteria. Additionally, they will identify ideal strategies for disruption mitigation of their supply chains based on an assessment of benefits, opportunities, costs, and risks. The structure and all inputs of the ANP can be adjusted to target it specifically to the user's needs. After entering the inputs into the system, results will be obtained by ANP software. In conclusion, the proposed methodology provides an extremely helpful tool for organizations to proactively plan the mitigation of supply chain disruptions.

Comparing the proposed model with previous research performed in the field of BC/DR planning, it can be said that this research demonstrates a unique approach. First, no tool has been developed before to combine parts of the Business Impact Analysis with the evaluation of resilience strategies. In addition, the proposed model is a novel approach which combines two separate ANP models together into one detailed multiple level ANP model. Moreover, analysis of disruption mitigation strategies is based on a thorough evaluation of the strategies' benefits, opportunities, costs, and risks. ANP offers a solution to extend a simple network structure to a comprehensive model, including a BOCR analysis. Since this research framework results in a fairly 
complex ANP model, a specific ANP decision-making software called SuperDecisions was utilized.

In order to test the functionality and effectiveness of the thesis proposal, the author developed a generic model with predetermined criteria, subcriteria, and alternatives in SuperDecisions. The model was then validated using data from a semiconductor company (Company $\mathrm{XYZ}$ ). An analyst from Company $\mathrm{XYZ}$, who has been a BC/DR expert for several years, gave input and carried out the comparisons required for the ANP. Synthesis of the first ANP model led to a conclusion that according to his input one key product should be matched with an optimal disruption mitigation strategy. For his critical product, two common supply chain disruption mitigation strategies ("Supplier network" and "Technological substitution") were then evaluated based on their benefits, opportunities, costs, and risks. After the user pairwise compared criteria and alternatives within the software application, the results were calculated. The strategy of establishing a supplier network obtained a higher priority than the strategy of investing into a technological substitution. In order to validate these results, a sensitivity analysis was performed for all merits of the model with the conclusion that the supplier network strategy would in this case study always be preferable over the technological substitution alternative.

After final outcomes of this case study were obtained, Company's XYZ expert was interviewed about his opinions on the effectiveness and applicability of the proposed method. The highest ranked strategy of the ANP model was indeed his preferred choice when asked to make a decision based on his intuition. This demonstrates that the proposed framework provides a valuable approach to identify, and more importantly, reinforce BC/DR planning decisions based on a mathematical justification. 
As mentioned before, the generic model was adjusted to the expert's inputs for the case study. To further validate and test the usefulness and effectiveness of the proposed framework, multiple case studies involving various companies from different industries and multiple decision-makers should be implemented. This would provide an insight to whether the proposed method is reliable in yielding valid and consistent results. Additionally, the question of how applicable and effective the proposed method is for users can only be answered if tested adequately in various environments.

In general, there are opportunities for improvement. First, consulting groups instead of individuals could increase the plausibility of the results. For this purpose, another tool needs to be implemented to gather and prepare data sufficiently before entering it into the SuperDecisions software. As an example, Torabi et al. (2014) applied the Decision Making Trial and Evaluation Laboratory (DEMATEL) method to translate the consensus on judgments of an experienced group into a number from the fundamental scale of ANP. Moreover, ANP can be combined with other techniques applied to decision-making models to increase the reliability of outcomes. As described in the Discussion Chapter, one possibility would be the application of fuzzy logic, rather than using a fixed scale, in order to better simulate the way humans make decisions. Another opportunity to enhance this research is the application of resource allocation, which enables the researcher to distribute resources optimally amongst a set of alternatives. In this specific investigation, doing so could lead to a precise determination of budgets for disruption mitigation strategies.

Future work could include the research and application of other MCDM tools to challenge and validate outcomes and the effectiveness of the proposed ANP method. In addition, applying a multiple layer ANP model to solve a problem in BC/DR planning 
is only one example of how the proposed framework can be used. To date, ANP has been applied to several fields of decision-making, including political, social, technological, and economical/management environments. One specific example of extending the proposed application to another field of BC/DR planning would be the analysis of Information Technology (IT) disaster recovery planning. In today's digitalized world, organizations need to decide how to protect their businesses from software and hardware interruptions and data loss. A thorough assessment of benefits, opportunities, costs, and risks might be a valuable approach for organizations when deciding whether to invest in IT resilience strategies.

In addition, the proposed framework could be applied to more topics of general public interest, such as humanitarian aid and disaster relief. A tool to evaluate various mitigation strategies based on a monetary and non-monetary assessment could be especially helpful for non-governmental and disaster relief agencies. Supporting decisions involving social and political aspects with a tool that provides mathematical justification might lead to improvements in humanitarian disaster planning.

Overall, this thesis helps to expand the knowledge of applicable solutions in BC/DR planning for organizations. The proposed framework is a unique approach of a modifiable ANP model to combine the identification of key products with the matching of ideal supply chain disruption mitigation strategies. Future research could include the expansion to other fields, such as human disaster relief, where reliable planning tools are crucial to mitigate the devastating effects of disasters. 


\section{REFERENCES}

Abe, M., \& Ye, L. (2013). Building Resilient Supply Chains against Natural Disasters: The Cases of Japan and Thailand. Global Business Review, 14(4), 567-586. doi:10.1177/0972150913501606

Chopra, S., \& Sodhi, M. S. (2004). Managing risk to avoid supply-chain breakdown. MIT Sloan Management Review, 46(46109), 53-61.

Chung, S. H., Lee, a. H. I., \& Pearn, W. L. (2005). Analytic network process (ANP) approach for product mix planning in semiconductor fabricator. International Journal of Production Economics, 96, 15-36. doi:10.1016/j.ijpe.2004.02.006

Evans, N., \& Elphick, S. (2005). Models of crisis management: An evaluation of their value for Strategic Planning in the International Travel Industry. The International Journal of Tourism Research, 7(3), 135.

Hewlett-Packard Development Company L.P. (2007). Impact on U. S. Small Business of Natural \& Man-Made Disasters. Retrieved from www.webwizebackup.com/impactofDisaster.pdf

International Organization for Standardization. (2012). ISO 22301:2012. International Organization for Standardization.

Lockamy III, A. (2014). Assessing disaster risks in supply chains. Industrial Management \& Data Systems, 114, 755-777. doi:10.1108/IMDS-11-2013-0477

Matsuo, H. (2014). Implications of the Tohoku earthquake for Toyota's coordination mechanism: Supply chain disruption of automotive semiconductors. International Journal of Production Economics, 1-11. doi:10.1016/j.ijpe.2014.07.010

Munich Re. (2015). Natural disasters 2014 (p. 2).

Saaty, T. L. (2004). Fundamentals of the analytic network process - Dependence and feedback in decision-making with a single network. Journal of Systems Science and Systems Engineering, 13(2), 129-157. doi:10.1007/s11518-006-0158-y 
Saaty, T. L. (2009). Theory and Applications of the Analytic Network Process: Decision Making with Benefits, Opportunities, Costs, and Risks (pp. 1-352). Pittsburgh, PA: RWS Publications.

Saaty, T. L., \& Vargas, L. G. (2001). Models, Methods, Concepts \& Applications of the Analytic Hierarchy Process (Second edition). New York: Springer International Publishing. doi:10.1007/978-1-4614-3597-6

Saaty, T. L., \& Vargas, L. G. (2013). Decision Making with the Analytic Network Process. Economic, Political, Social and Technological Applications with Benefits, Opportunities, Costs and Risks. (Second Edi.). New York: Springer International Publishing. Retrieved from http://search.ebscohost.com.ezproxy.liv.ac.uk/login.aspx?direct=true $\& \mathrm{db}=\mathrm{cat} 0000$ $3 a \& A N=$ lvp.b2803680\&site $=$ eds-live \&scope $=$ site

Sahebjamnia, N., Torabi, S. A., \& Mansouri, S. A. (2015). Integrated business continuity and disaster recovery planning: Towards organizational resilience. European Journal of Operational Research, 242(1), 261-273. doi:10.1016/j.ejor.2014.09.055

Sapci, S., \& Pouraghabagher, R. (2003). A systematic approach for selection of suppliers through an integration of Quality Function Deployment (QFD) and Analytical Hierarchy Process (AHP). In 8th International Symposium on Logistics (pp. 319326). Seville, Spain.

Taslicali, A. K., \& Ercan, S. (2006). The analytic hierarchy \& the analytic network processes in multicriteria decision-making: A comparative study. Journal of Aeronautics \& Space Technologies, 2(4), 55-65. Retrieved from http://search.ebscohost.com/login.aspx?direct=true\&profile=ehost\&scope=site\&au thtype=crawler \&jrnl=13040448\&AN=29406822\&h=15wa5keRdC9ufELEwaGErfjgt TekdlfYF8+0RGh+9Jk2S2MAxfxWiMo9cbA9KW/y/DKhxsrll9IYvRVeumAyog==\&c $\mathrm{rl}=\mathrm{C}$

Tomlin, B. (2006). On the Value of Mitigation Supply for Managing and Contingency Chain Disruption Strategies Risks. Management Science, 52(May), 639-657. 
Torabi, S. A., Rezaei Soufi, H., \& Sahebjamnia, N. (2014). A new framework for business impact analysis in business continuity management (with a case study). Safety Science, 68, 309-323. doi:10.1016/j.ssci.2014.04.017

Wieland, A., \& Wallenburg, C. M. (2012). Dealing with supply chain risks: Linking risk management practices and strategies to performance. International Journal of Physical Distribution \& Logistics Management, 42(10), 887-905.

World Continuity Congress. (2011). Risk analysis and Business Continuity Process Graphic. Retrieved from www.worldcontinuitycongress.com

Zadeh, L. (1976). A fuzzy-algorithmic approach to the definition of complex or imprecise concepts. International Journal of Man-Machine Studies, 8, 249-291. 
APPENDICES 
A) Matrices of Product Selection ANP Model

\section{Supermatrix}

\begin{tabular}{|c|c|c|c|c|c|c|c|c|c|c|c|c|c|c|c|}
\hline \multirow{2}{*}{\multicolumn{2}{|c|}{ Supermatrix }} & \multicolumn{4}{|c|}{ Alternatives } & \multicolumn{3}{|c|}{ Quantifiably Criteria } & \multicolumn{7}{|c|}{ Unquantifiable Criteria } \\
\hline & & \multirow{2}{*}{\begin{tabular}{|l} 
Product A \\
0.0000
\end{tabular}} & \multirow{2}{*}{ Product B } & \multirow{2}{*}{ Product C } & \multirow{2}{*}{ Product D } & \multirow{2}{*}{$\begin{array}{l}\begin{array}{l}\text { 1Loss of } \\
\text { revenue }\end{array} \\
\end{array}$} & \multirow{2}{*}{$\begin{array}{l}\text { 4Higher } \\
\text { insurance } \\
\text { cost } \\
00999\end{array}$} & \multirow{2}{*}{$\begin{array}{l}\text { 8Influence } \\
\text { on human } \\
\text { resources }\end{array}$} & \multirow{2}{*}{\begin{tabular}{|l|}
$\begin{array}{l}\text { 2Loss of } \\
\text { interested } \\
\text { parties }\end{array}$ \\
0.0797 \\
\end{tabular}} & \multirow{2}{*}{$\begin{array}{l}\begin{array}{l}\text { 3Defection } \\
\text { of customers }\end{array} \\
0.7500\end{array}$} & \multirow{2}{*}{$\begin{array}{l}\text { 5Degree of } \\
\text { damage on } \\
\text { company's } \\
\text { image and } \\
\text { reputation } \\
0.0467\end{array}$} & \multirow{2}{*}{$\begin{array}{l}\begin{array}{l}6 \text { Influence } \\
\text { on markets }\end{array} \\
0.1294\end{array}$} & \multirow{2}{*}{$\begin{array}{l}7 \text { Importance } \\
\text { of product } \\
\text { for the } \\
\text { company } \\
0.7368\end{array}$} & \multirow{2}{*}{ 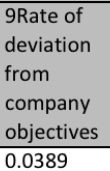 } & \multirow{2}{*}{$\begin{array}{l}\text { 10Loss of } \\
\text { technologica } \\
\text { level of } \\
\text { company } \\
0.1167\end{array}$} \\
\hline \begin{tabular}{|l} 
Alternatives \\
\end{tabular} & Product A & & & & & & & & & & & & & & \\
\hline & Product B & 0.0000 & 0.0000 & 0.0000 & 0.0000 & 0.0582 & 0.5879 & 0.0935 & 0.1268 & 0.0833 & 0.2456 & 0.0487 & 0.0478 & 0.2456 & 0.0825 \\
\hline & Product C & 0.0000 & 0.0000 & 0.0000 & 0.0000 & 0.1079 & 0.0544 & 0.7157 & 0.0523 & 0.0833 & 0.0171 & 0.6815 & 0.0896 & 0.0311 & 0.7425 \\
\hline & Product D & 0.0000 & 0.0000 & 0.0000 & 0.0000 & 0.2142 & 0.2578 & 0.0845 & 0.7412 & 0.0833 & 0.0239 & 0.1404 & 0.1258 & 0.0178 & 0.0583 \\
\hline \multirow[t]{2}{*}{$\begin{array}{c}\text { Quantifiably } \\
\text { Criteria }\end{array}$} & $\begin{array}{l}\text { Loss of } \\
\text { revenue }\end{array}$ & 0.1905 & 0.1804 & 0.2072 & 0.2552 & 0.0000 & 0.0000 & 0.0000 & 0.0000 & 0.0000 & 0.3333 & 0.0000 & 0.0000 & 0.3333 & 0.0000 \\
\hline & $\begin{array}{l}\text { 8Influence } \\
\text { on human } \\
\text { resources }\end{array}$ & 0.3810 & 0.0568 & 0.3289 & 0.3726 & 0.0000 & 0.0000 & 0.0000 & 0.0000 & 0.0000 & 0.0000 & 0.0000 & 0.0000 & 0.0000 & 0.0000 \\
\hline \multirow[t]{7}{*}{$\begin{array}{c}\text { Unquantifiab } \\
\text { le Criteria }\end{array}$} & \begin{tabular}{|l|} 
2Loss of \\
interested \\
parties
\end{tabular} & 0.0360 & 0.0528 & 0.0404 & 0.1755 & 0.0000 & 0.0000 & 0.0000 & 0.0000 & 0.0000 & 0.0667 & 0.0000 & 0.0000 & 0.3333 & 0.0000 \\
\hline & $\begin{array}{l}\text { 3Defection } \\
\text { of customers }\end{array}$ & 0.0673 & 0.0407 & 0.0185 & 0.0225 & 0.0000 & 0.0000 & 0.0000 & 0.0000 & 0.0000 & 0.2667 & 0.0000 & 0.0000 & 0.0000 & 0.0000 \\
\hline & $\begin{array}{l}\text { 5Degree of } \\
\text { damage on } \\
\text { company's } \\
\text { image and } \\
\text { reputation }\end{array}$ & 0.0747 & 0.0633 & 0.0171 & 0.0225 & 0.0000 & 0.0000 & 0.0000 & 0.0000 & 0.0000 & 0.0000 & 0.0000 & 0.0000 & 0.0000 & 0.0000 \\
\hline & $\begin{array}{l}\text { 6Influence } \\
\text { on markets }\end{array}$ & 0.0521 & 0.0303 & 0.0183 & 0.0642 & 0.0000 & 0.0000 & 0.0000 & 0.0000 & 0.0000 & 0.0000 & 0.0000 & 0.0000 & 0.0000 & 0.0000 \\
\hline & $\begin{array}{l}7 \text { Importance } \\
\text { of product } \\
\text { for the } \\
\text { company }\end{array}$ & 0.0336 & 0.0885 & 0.0259 & 0.0156 & 0.0000 & 0.0000 & 0.0000 & 0.0000 & 0.0000 & 0.0000 & 0.0000 & 0.0000 & 0.0000 & 0.0000 \\
\hline & $\begin{array}{l}\text { 9Rate of } \\
\text { deviation } \\
\text { from } \\
\text { company } \\
\text { objectives }\end{array}$ & 0.0331 & 0.0217 & 0.0259 & 0.0175 & 0.0000 & 0.0000 & 0.0000 & 0.0000 & 0.0000 & 0.0000 & 0.0000 & 0.0000 & 0.0000 & 0.0000 \\
\hline & $\begin{array}{l}\text { 10Loss of } \\
\text { technological } \\
\text { level of } \\
\text { company }\end{array}$ & 0.0365 & 0.0360 & 0.1873 & 0.0155 & 0.0000 & 0.0000 & 0.0000 & 0.0000 & 0.0000 & 0.0000 & 0.0000 & 0.0000 & 0.0000 & 0.0000 \\
\hline
\end{tabular}




\section{Limitmatrix}

\begin{tabular}{|c|c|c|c|c|c|c|c|c|c|c|c|c|c|c|c|}
\hline \multirow{2}{*}{\multicolumn{2}{|c|}{ Limitmatrix }} & \multicolumn{4}{|c|}{ Alternatives } & \multicolumn{3}{|c|}{ Quantifiable Criteria } & \multicolumn{7}{|c|}{ Unquantifiable Criteria } \\
\hline & & \multirow{2}{*}{\begin{tabular}{|l} 
Product A \\
0.1358
\end{tabular}} & Product B & Product C & Product D & $\begin{array}{l}\text { 1Loss of } \\
\text { revenue }\end{array}$ & $\begin{array}{l}\text { 4Higher } \\
\text { insurance } \\
\text { cost }\end{array}$ & $\begin{array}{l}\text { 8Influence } \\
\text { on human } \\
\text { resources }\end{array}$ & $\begin{array}{l}2 \text { Loss of } \\
\text { interested } \\
\text { parties }\end{array}$ & \multirow{2}{*}{$\begin{array}{l}\text { 3Defection } \\
\text { of customers }\end{array}$} & \multirow{2}{*}{$\begin{array}{l}\text { 5Degree of } \\
\text { damage on } \\
\text { company's } \\
\text { image and } \\
\text { reputation }\end{array}$} & \multirow{2}{*}{$\begin{array}{l}\begin{array}{l}\text { 6Influence } \\
\text { on markets }\end{array} \\
0.1358\end{array}$} & \multirow{2}{*}{$\begin{array}{l}71 \text { mportance } \\
\text { of product } \\
\text { for the } \\
\text { company } \\
0.1358\end{array}$} & \multirow{2}{*}{$\begin{array}{l}\text { 9Rate of } \\
\text { deviation } \\
\text { from } \\
\text { company } \\
\text { objectives } \\
0.1358\end{array}$} & \multirow{2}{*}{$\begin{array}{l}\text { 10Loss of } \\
\text { technological } \\
\text { level of } \\
\text { company } \\
0.1358\end{array}$} \\
\hline \begin{tabular}{|l|} 
Alternatives \\
\end{tabular} & Product A & & 0.1358 & 0.1358 & 0.1358 & 0.1358 & 0.1358 & 0.1358 & 0.1358 & & & & & & \\
\hline & Product B & 0.0853 & 0.0853 & 0.0853 & 0.0853 & 0.0853 & 0.0853 & 0.0853 & 0.0853 & 0.0853 & 0.0853 & 0.0853 & 0.0853 & 0.0853 & 0.0853 \\
\hline & Product C & 0.1731 & 0.1731 & 0.1731 & 0.1731 & 0.1731 & 0.1731 & 0.1731 & 0.1731 & 0.1731 & 0.1731 & 0.1731 & 0.1731 & 0.1731 & 0.1731 \\
\hline & Product D & 0.0948 & 0.0948 & 0.0948 & 0.0948 & 0.0948 & 0.0948 & 0.0948 & 0.0948 & 0.0948 & 0.0948 & 0.0948 & 0.0948 & 0.0948 & 0.0948 \\
\hline \multirow[t]{3}{*}{$\begin{array}{l}\text { Quantifiably } \\
\text { Criteria }\end{array}$} & $\begin{array}{l}\text { Loss of } \\
\text { revenue }\end{array}$ & 0.1124 & 0.1124 & 0.1124 & 0.1124 & 0.1124 & 0.1124 & 0.1124 & 0.1124 & 0.1124 & 0.1124 & 0.1124 & 0.1124 & 0.1124 & 0.1124 \\
\hline & $\begin{array}{l}4 \mathrm{Higher} \\
\text { insurance } \\
\text { cost }\end{array}$ & 0.0758 & 0.0758 & 0.0758 & 0.0758 & 0.0758 & 0.0758 & 0.0758 & 0.0758 & 0.0758 & 0.0758 & 0.0758 & 0.0758 & 0.0758 & 0.0758 \\
\hline & $\begin{array}{l}\text { 8Influence } \\
\text { on human } \\
\text { resources }\end{array}$ & 0.1488 & 0.1488 & 0.1488 & 0.1488 & 0.1488 & 0.1488 & 0.1488 & 0.1488 & 0.1488 & 0.1488 & 0.1488 & 0.1488 & 0.1488 & 0.1488 \\
\hline \multirow[t]{7}{*}{$\begin{array}{c}\text { Unquantifiab } \\
\text { le Criteria }\end{array}$} & \begin{tabular}{|l|} 
2Loss of \\
interested \\
parties
\end{tabular} & 0.0386 & 0.0386 & 0.0386 & 0.0386 & 0.0386 & 0.0386 & 0.0386 & 0.0386 & 0.0386 & 0.0386 & 0.0386 & 0.0386 & 0.0386 & 0.0386 \\
\hline & $\begin{array}{l}\text { 3Defection } \\
\text { of customers }\end{array}$ & 0.0234 & 0.0234 & 0.0234 & 0.0234 & 0.0234 & 0.0234 & 0.0234 & 0.0234 & 0.0234 & 0.0234 & 0.0234 & 0.0234 & 0.0234 & 0.0234 \\
\hline & $\begin{array}{l}\text { 5Degree of } \\
\text { damage on } \\
\text { company's } \\
\text { image and } \\
\text { reputation }\end{array}$ & 0.0206 & 0.0206 & 0.0206 & 0.0206 & 0.0206 & 0.0206 & 0.0206 & 0.0206 & 0.0206 & 0.0206 & 0.0206 & 0.0206 & 0.0206 & 0.0206 \\
\hline & $\begin{array}{l}\text { 6Influence } \\
\text { on markets }\end{array}$ & 0.0189 & 0.0189 & 0.0189 & 0.0189 & 0.0189 & 0.0189 & 0.0189 & 0.0189 & 0.0189 & 0.0189 & 0.0189 & 0.0189 & 0.0189 & 0.0189 \\
\hline & $\begin{array}{l}\text { 7Importance } \\
\text { of product } \\
\text { for the } \\
\text { company }\end{array}$ & 0.0181 & 0.0181 & 0.0181 & 0.0181 & 0.0181 & 0.0181 & 0.0181 & 0.0181 & 0.0181 & 0.0181 & 0.0181 & 0.0181 & 0.0181 & 0.0181 \\
\hline & $\begin{array}{l}9 \text { Rate of } \\
\text { deviation } \\
\text { from } \\
\text { company } \\
\text { objectives }\end{array}$ & 0.0125 & 0.0125 & 0.0125 & 0.0125 & 0.0125 & 0.0125 & 0.0125 & 0.0125 & 0.0125 & 0.0125 & 0.0125 & 0.0125 & 0.0125 & 0.0125 \\
\hline & $\begin{array}{l}\text { 10Loss of } \\
\text { technological } \\
\text { level of } \\
\text { company }\end{array}$ & 0.0419 & 0.0419 & 0.0419 & 0.0419 & 0.0419 & 0.0419 & 0.0419 & 0.0419 & 0.0419 & 0.0419 & 0.0419 & 0.0419 & 0.0419 & 0.0419 \\
\hline
\end{tabular}


B) Limitmatrices for Benefits, Opportunities, Costs, and Risks

\begin{tabular}{|c|c|c|c|c|c|}
\hline \multirow{2}{*}{\multicolumn{2}{|c|}{ Limitmatrix Benefits }} & \multicolumn{3}{|c|}{ Control Criteria } & \multirow{2}{*}{\begin{tabular}{|c|} 
Control Criteria Goal \\
Goal: Find Benefit Control Criteria \\
\end{tabular}} \\
\hline & & 10perational Benefits & 2Financial Benefits & 30rganizational Benefits & \\
\hline \multirow{3}{*}{ Control Criteria } & 10perational Benefits & 0.0000 & 0.0000 & 0.0000 & 0.3643 \\
\hline & 2Financial Benefits & 0.0000 & 0.0000 & 0.0000 & 0.5368 \\
\hline & 3Organizational Benefits & 0.0000 & 0.0000 & 0.0000 & 0.0989 \\
\hline Control Criteria Goal & Goal: Find Benefit Control Criteria & 0.0000 & 0.0000 & 0.0000 & 0.0000 \\
\hline
\end{tabular}

\begin{tabular}{|c|c|c|c|c|}
\hline \multirow{2}{*}{\multicolumn{2}{|c|}{ Limitmatrix Opportunities }} & \multicolumn{2}{|l|}{ Control Criteria } & \multirow{2}{*}{\begin{tabular}{|l|} 
Control Criteria Goal \\
Goal: Find Opportunity Control Criteria
\end{tabular}} \\
\hline & & 1Competitive Opportunities & 2Technological Opportunities & \\
\hline \multirow[t]{2}{*}{ Control Criteria } & 1Competitive Opportunities & 0.0000 & 0.0000 & 0.3333 \\
\hline & 2Technological Opportunities & 0.0000 & 0.0000 & 0.6667 \\
\hline Control Criteria Goal & Goal: Find Opportunity Control Criteria & 0.0000 & 0.0000 & 0.0000 \\
\hline
\end{tabular}

\begin{tabular}{|c|c|c|c|c|c|}
\hline \multirow{2}{*}{\multicolumn{2}{|c|}{ Limitmatrix Costs }} & \multicolumn{3}{|c|}{ Control Criteria } & \multirow{2}{*}{\begin{tabular}{|c|} 
Control Criteria Goal \\
Goal: Find Cost Control Criteria \\
\end{tabular}} \\
\hline & & 1Cost of goods sold (COGS) & 2Operating Expenses & 3Disaster Recovery Cost & \\
\hline \multirow[t]{3}{*}{ Control Criteria } & 1Cost of goods sold (COGS) & 0.0000 & 0.0000 & 0.0000 & 0.1626 \\
\hline & 20perating Expenses & 0.0000 & 0.0000 & 0.0000 & 0.1088 \\
\hline & 3Disaster Recovery Cost & 0.0000 & 0.0000 & 0.0000 & 0.7286 \\
\hline Control Criteria Goal & Goal: Find Cost Control Criteria & 0.0000 & 0.0000 & 0.0000 & 0.0000 \\
\hline
\end{tabular}

\begin{tabular}{|l|l|ll|l|}
\hline \multicolumn{2}{|c|}{ Limitmatrix Risks } & Control Criteria & Control Criteria Goal \\
\cline { 3 - 5 } \multicolumn{2}{l|}{} & 1External effects & 2Internal Effects & Goal: Find Risk Control Criteria \\
\hline Control Criteria & 1External effects & 0.0000 & 0.0000 & 0.8000 \\
& 2Internal Effects & 0.0000 & 0.0000 & 0.2000 \\
\hline Control Criteria Goal & Goal: Find Risk Control Criteria & 0.0000 & 0.0000 & 0.0000 \\
\hline
\end{tabular}


C) Overview of Control Criteria and Decision Networks for each BOCR Merit

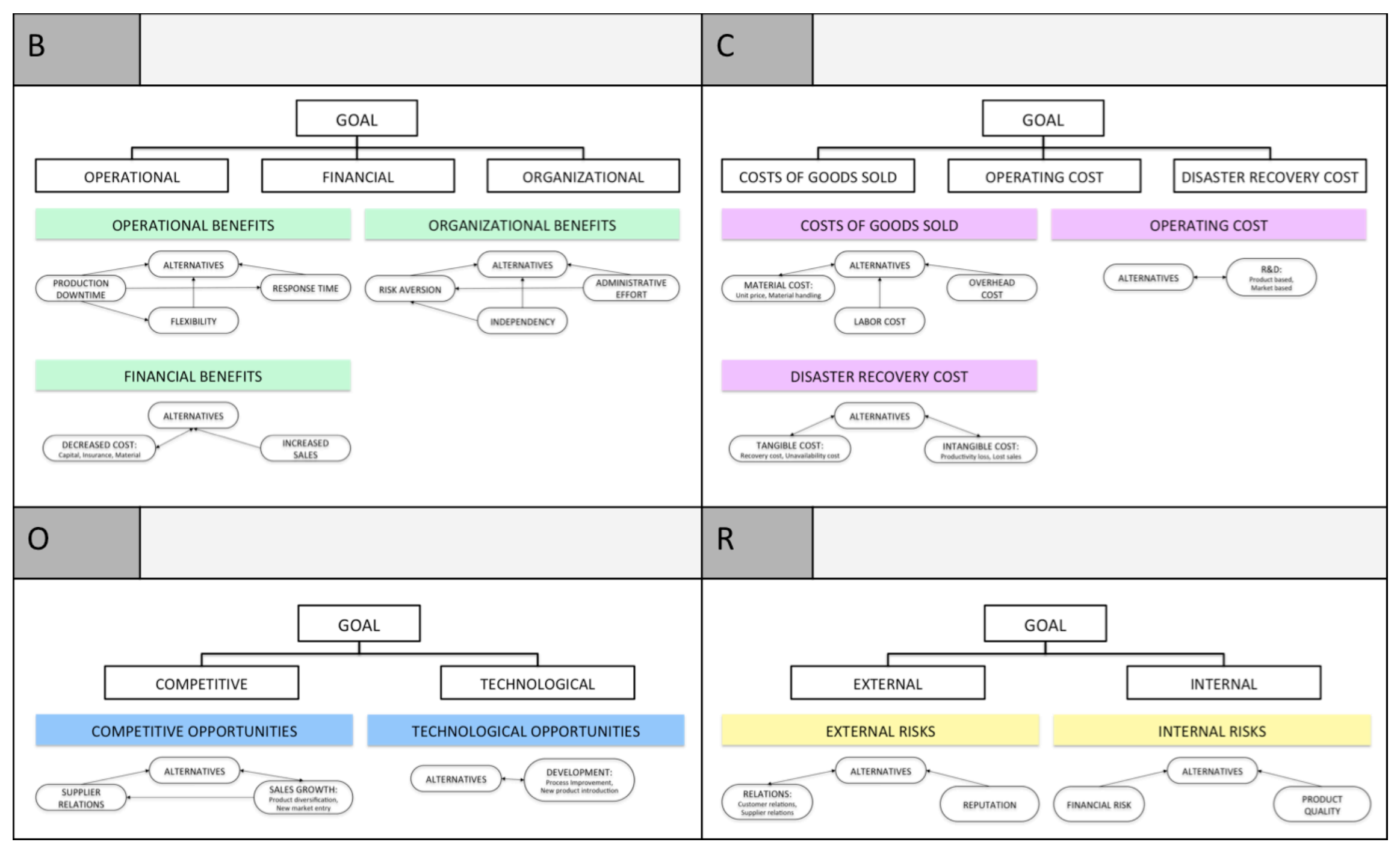




\section{D) Limitmatrices for Decision Networks}

\section{Benefits decision networks}

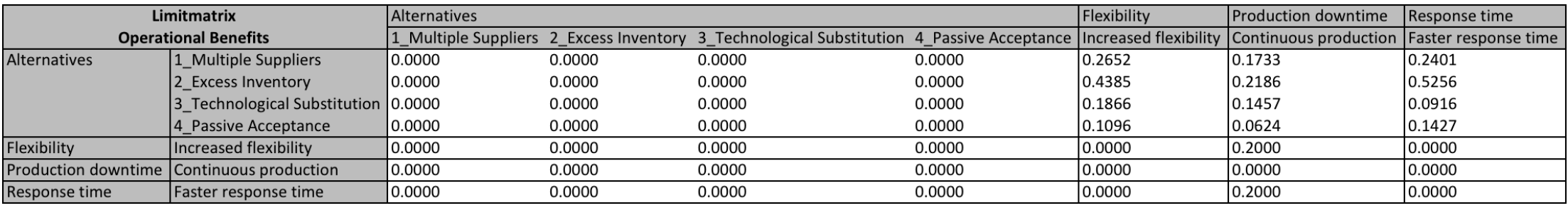

\begin{tabular}{|c|c|c|c|c|c|c|c|c|c|}
\hline \multirow{2}{*}{\multicolumn{2}{|c|}{$\begin{array}{l}\text { Limitmatrix } \\
\text { Financial Benefits }\end{array}$}} & \multicolumn{4}{|c|}{ Alternatives } & \multicolumn{3}{|l|}{ Cost } & \multirow{2}{*}{$\begin{array}{l}\text { Revenue } \\
\text { 4Increased sales }\end{array}$} \\
\hline & & 1_Multiple Suppliers & 2_Excess Inventory & 3_Technological Substitution & 4_Passive Acceptance & $\begin{array}{l}\text { 1Low } \\
\text { investment/capital cost }\end{array}$ & 2Lower insurance cost & $\begin{array}{l}\text { 3Lower } \\
\text { product/purchasing } \\
\text { cost }\end{array}$ & \\
\hline \multirow[t]{4}{*}{ Alternatives } & 1_Multiple Suppliers & 0.0832 & 0.0832 & 0.0832 & 0.0832 & 0.0832 & 0.0832 & 0.0832 & 0.0832 \\
\hline & 2_Excess Inventory & 0.1475 & 0.1475 & 0.1475 & 0.1475 & 0.1475 & 0.1475 & 0.1475 & 0.1475 \\
\hline & 3_Technological Substitution & 0.0782 & 0.0782 & 0.0782 & 0.0782 & 0.0782 & 0.0782 & 0.0782 & 0.0782 \\
\hline & 4_Passive Acceptance & 0.1911 & 0.1911 & 0.1911 & 0.1911 & 0.1911 & 0.1911 & 0.1911 & 0.1911 \\
\hline \multirow[t]{3}{*}{ Cost } & 1Low investment/capital cost & 0.2577 & 0.2577 & 0.2577 & 0.2577 & 0.2577 & 0.2577 & 0.2577 & 0.2577 \\
\hline & 2Lower insurance cost & 0.1435 & 0.1435 & 0.1435 & 0.1435 & 0.1435 & 0.1435 & 0.1435 & 0.1435 \\
\hline & 3Lower product/purchasing co & 0.0988 & 0.0988 & 0.0988 & 0.0988 & 0.0988 & 0.0988 & 0.0988 & 0.0988 \\
\hline Revenue & 4Increased sales & 0.0000 & 0.0000 & 0.0000 & 0.0000 & 0.0000 & 0.0000 & 0.0000 & 0.0000 \\
\hline
\end{tabular}

\begin{tabular}{|c|c|c|c|c|c|c|c|c|}
\hline \multirow{2}{*}{\multicolumn{2}{|c|}{$\begin{array}{l}\text { Limitmatrix } \\
\text { Organizational Benefits }\end{array}$}} & \multicolumn{4}{|c|}{ Alternatives } & \multirow{2}{*}{\begin{tabular}{|l|} 
Risk aversion/Security \\
1Low risks/High security \\
\end{tabular}} & \multirow{2}{*}{\begin{tabular}{|l|} 
Independency \\
2Higher independency \\
from specific supplier
\end{tabular}} & \multirow{2}{*}{\begin{tabular}{|l|} 
Administrative activity \\
3Required administrative \\
effort
\end{tabular}} \\
\hline & & 1_Multiple Suppliers & 2_Excess Inventory & 3_Technological Substitution & 4_Passive Acceptance & & & \\
\hline \multirow[t]{4}{*}{ Alternatives } & 1_Multiple Suppliers & 0.0000 & 0.0000 & 0.0000 & 0.0000 & 0.1753 & 0.1712 & 0.1320 \\
\hline & 2_Excess Inventory & 0.0000 & 0.0000 & 0.0000 & 0.0000 & 0.0609 & 0.0767 & 0.0502 \\
\hline & 3_Technological Substitution & 0.0000 & 0.0000 & 0.0000 & 0.0000 & 0.4059 & 0.2035 & 0.2395 \\
\hline & 4_Passive Acceptance & 0.0000 & 0.0000 & 0.0000 & 0.0000 & 0.3579 & 0.2153 & 0.2449 \\
\hline Risk aversion/Security & 1Low risks/High security & 0.0000 & 0.0000 & 0.0000 & 0.0000 & 0.0000 & 0.3333 & 0.3333 \\
\hline Independency & $2 \mathrm{Higher}$ independency from specific supplier & 0.0000 & 0.0000 & 0.0000 & 0.0000 & 0.0000 & 0.0000 & 0.0000 \\
\hline Administrative activity & 3Required administrative effort & 0.0000 & 0.0000 & 0.0000 & 0.0000 & 0.0000 & 0.0000 & 0.0000 \\
\hline
\end{tabular}




\section{Opportunities decision networks}

\begin{tabular}{|c|c|c|c|c|c|c|c|c|}
\hline \multirow{2}{*}{\multicolumn{2}{|c|}{$\begin{array}{c}\text { Limitmatrix } \\
\text { Competitive Opportunities }\end{array}$}} & \multicolumn{4}{|l|}{ Alternatives } & \multirow{3}{*}{\begin{tabular}{|l|} 
Relations \\
1 Improved supplier relations \\
0.0781 \\
\end{tabular}} & \multicolumn{2}{|c|}{ Sales growth } \\
\hline & & \multirow{2}{*}{ 1_Multiple Suppliers } & \multirow{2}{*}{$\begin{array}{l}\text { 2_Excess Inventory } \\
0.0781\end{array}$} & \multirow{2}{*}{$\begin{array}{l}\text { 3_Technological Substitution } \\
0.0781\end{array}$} & \multirow{2}{*}{$\begin{array}{l}\text { 4_Passive Acceptance } \\
0.0781\end{array}$} & & \multirow{2}{*}{\begin{tabular}{|l|} 
2Product diversification \\
0.0781
\end{tabular}} & \multirow{2}{*}{$\begin{array}{l}\text { 3Entry into new market } \\
0.0781\end{array}$} \\
\hline \begin{tabular}{|l|} 
Alternatives \\
\end{tabular} & 1_Multiple Suppliers & & & & & & & \\
\hline & 2_Excess Inventory & 0.0858 & 0.0858 & 0.0858 & 0.0858 & 0.0858 & 0.0858 & 0.0858 \\
\hline & 3_Technological Substitution & 0.2640 & 0.2640 & 0.2640 & 0.2640 & 0.2640 & 0.2640 & 0.2640 \\
\hline & 4_Passive Acceptance & 0.0266 & 0.0266 & 0.0266 & 0.0266 & 0.0266 & 0.0266 & 0.0266 \\
\hline Relations & 1Improved supplier relations & 0.0910 & 0.0910 & 0.0910 & 0.0910 & 0.0910 & 0.0910 & 0.0910 \\
\hline \multirow[t]{2}{*}{ Sales growth } & 2Product diversification & 0.2725 & 0.2725 & 0.2725 & 0.2725 & 0.2725 & 0.2725 & 0.2725 \\
\hline & 3Entry into new market & 0.1820 & 0.1820 & 0.1820 & 0.1820 & 0.1820 & 0.1820 & 0.1820 \\
\hline
\end{tabular}

\begin{tabular}{|c|c|c|c|c|c|c|c|}
\hline & \multirow[b]{2}{*}{$\begin{array}{l}\text { Limitmatrix } \\
\text { Technological Opportunities }\end{array}$} & \multicolumn{4}{|l|}{ Alternatives } & \multicolumn{2}{|c|}{ Development/Improvement } \\
\hline & & 1 Multiple Suppliers & 2 Excess Inventory & 3 Technological Substitution & 4 Passive Acceptance & $\begin{array}{l}\text { 1Improved processes } \\
\text { through skipping steps }\end{array}$ & $\begin{array}{l}\text { 2New Product } \\
\text { Introduction(NPI) }\end{array}$ \\
\hline \multirow[t]{4}{*}{ Alternatives } & 1_Multiple Suppliers & 0.1178 & 0.1178 & 0.1178 & 0.1178 & 0.1178 & 0.1178 \\
\hline & 2_Excess Inventory & 0.0462 & 0.0462 & 0.0462 & 0.0462 & 0.0462 & 0.0462 \\
\hline & 3_Technological Substitution & 0.3018 & 0.3018 & 0.3018 & 0.3018 & 0.3018 & 0.3018 \\
\hline & 4_Passive Acceptance & 0.0342 & 0.0342 & 0.0342 & 0.0342 & 0.0342 & 0.0342 \\
\hline \multirow{2}{*}{$\begin{array}{l}\text { Development/ } \\
\text { Improvement }\end{array}$} & 1Improved processes through skipping steps & 0.1475 & 0.1475 & 0.1475 & 0.1475 & 0.1475 & 0.1475 \\
\hline & 2New Product Introduction(NPI) & 0.3525 & 0.3525 & 0.3525 & 0.3525 & 0.3525 & 0.3525 \\
\hline
\end{tabular}

\section{Costs decision networks}

\begin{tabular}{|c|c|c|c|c|c|c|c|c|c|}
\hline \multirow{2}{*}{\multicolumn{2}{|c|}{$\begin{array}{l}\text { Limitmatrix } \\
\text { Costs of Goods Sold }\end{array}$}} & \multicolumn{4}{|c|}{ Alternatives } & \multirow{2}{*}{$\begin{array}{l}\text { Labor cost } \\
\text { 3Increased labor intensity }\end{array}$} & \multicolumn{2}{|c|}{ Material cost } & \multirow{2}{*}{\begin{tabular}{|l|} 
Overhead cost \\
$\begin{array}{l}4 \text { Increased administrative } \\
\text { effort }\end{array}$ \\
\end{tabular}} \\
\hline & & $\begin{array}{l}\text { 1_Multiple } \\
\text { Suppliers }\end{array}$ & $\begin{array}{l}\text { 2_Excess } \\
\text { Inventory }\end{array}$ & $\begin{array}{l}\text { 3_Technological } \\
\text { Substitution }\end{array}$ & $\begin{array}{l}\text { 4_Passive } \\
\text { Acceptance }\end{array}$ & & $\begin{array}{l}\text { 1Price/Unit rises due to } \\
\text { lower order quantity }\end{array}$ & $\begin{array}{l}\text { 2Material handling } \\
\text { increases }\end{array}$ & \\
\hline \multirow[t]{4}{*}{ Alternatives } & 1_Multiple Suppliers & 0.1250 & 0.1250 & 0.1250 & 0.1250 & 0.1250 & 0.1250 & 0.1250 & 0.1250 \\
\hline & 2_Excess Inventory & 0.1250 & 0.1250 & 0.1250 & 0.1250 & 0.1250 & 0.1250 & 0.1250 & 0.1250 \\
\hline & 3_Technological Substitution & 0.1250 & 0.1250 & 0.1250 & 0.1250 & 0.1250 & 0.1250 & 0.1250 & 0.1250 \\
\hline & 4_Passive Acceptance & 0.1250 & 0.1250 & 0.1250 & 0.1250 & 0.1250 & 0.1250 & 0.1250 & 0.1250 \\
\hline Labor cost & 3Increased labor intensity & 0.0000 & 0.0000 & 0.0000 & 0.0000 & 0.0000 & 0.0000 & 0.0000 & 0.0000 \\
\hline \multirow[t]{2}{*}{ Material cost } & 1Price/Unit rises due to lower order quantity & 0.2500 & 0.2500 & 0.2500 & 0.2500 & 0.2500 & 0.2500 & 0.2500 & 0.2500 \\
\hline & 2Material handling increases & 0.2500 & 0.2500 & 0.2500 & 0.2500 & 0.2500 & 0.2500 & 0.2500 & 0.2500 \\
\hline Overhead cost & 4Increased administrative effort & 0.0000 & 0.0000 & 0.0000 & 0.0000 & 0.0000 & 0.0000 & 0.0000 & 0.0000 \\
\hline
\end{tabular}




\begin{tabular}{|c|c|c|c|c|c|c|c|}
\hline \multirow{2}{*}{\multicolumn{2}{|c|}{$\begin{array}{c}\text { Limitmatrix } \\
\text { Operational Expenses }\end{array}$}} & \multicolumn{4}{|c|}{ Alternatives } & \multicolumn{2}{|c|}{$R \& D$} \\
\hline & & 1_Multiple Suppliers & \multirow{2}{*}{$\begin{array}{l}\text { 2_Excess Inventory } \\
0.0536\end{array}$} & \multirow{2}{*}{$\begin{array}{l}\text { 3_Technological Substitution } \\
0.0536\end{array}$} & \multirow{2}{*}{$\begin{array}{l}\text { 4_Passive Acceptance } \\
0.0536\end{array}$} & \multirow{2}{*}{\begin{tabular}{|r|} 
1Product-based R\&D \\
0.053619
\end{tabular}} & \multirow{2}{*}{$\begin{array}{r}\text { 2Market-based R\&D } \\
0.053619\end{array}$} \\
\hline Alternatives & 1_Multiple Suppliers & 0.0536 & & & & & \\
\hline & 2 Excess Inventory & 0.0364 & 0.0364 & 0.0364 & 0.0364 & 0.036366 & 0.036366 \\
\hline & 3_Technological Substitution & 0.3736 & 0.3736 & 0.3736 & 0.3736 & 0.373648 & 0.373648 \\
\hline & 4_Passive Acceptance & 0.0364 & 0.0364 & 0.0364 & 0.0364 & 0.036367 & 0.036367 \\
\hline R\&D & 1Product-based R\&D & 0.1415 & 0.1415 & 0.1415 & 0.1415 & 0.141536 & 0.141536 \\
\hline & 2Market-based R\&D & 0.3585 & 0.3585 & 0.3585 & 0.3585 & 0.358464 & 0.358464 \\
\hline
\end{tabular}

\begin{tabular}{|c|c|c|c|c|c|c|c|c|c|}
\hline \multirow{2}{*}{\multicolumn{2}{|c|}{$\begin{array}{c}\text { Limitmatrix } \\
\text { Disaster Recovery Costs }\end{array}$}} & \multicolumn{4}{|c|}{ Alternatives } & \multicolumn{2}{|c|}{ Intangible cost } & \multicolumn{2}{|c|}{ Tangible cost } \\
\hline & & 1_Multiple Suppliers & 2_Excess Inventory & 3_Technological Substitution & 4_Passive Acceptance & 3Productivity loss & 4Lost sales & 1Recovery cost & 2Unavailability cost \\
\hline \multirow[t]{4}{*}{ Alternatives } & 1_Multiple Suppliers & 0.0410 & 0.0410 & 0.0410 & 0.0410 & 0.041026 & 0.041026 & 0.041026 & 0.041026 \\
\hline & 2_Excess Inventory & 0.0491 & 0.0491 & 0.0491 & 0.0491 & 0.049143 & 0.049143 & 0.049143 & 0.049143 \\
\hline & 3_Technological Substitution & 0.0415 & 0.0415 & 0.0415 & 0.0415 & 0.041544 & 0.041544 & 0.041544 & 0.041544 \\
\hline & 4_Passive Acceptance & 0.3683 & 0.3683 & 0.3683 & 0.3683 & 0.368287 & 0.368287 & 0.368287 & 0.368287 \\
\hline \multirow[t]{2}{*}{ Intangible cost } & 3Productivity loss & 0.0492 & 0.0492 & 0.0492 & 0.0492 & 0.049181 & 0.049181 & 0.049181 & 0.049181 \\
\hline & 4Lost sales & 0.0758 & 0.0758 & 0.0758 & 0.0758 & 0.075819 & 0.075819 & 0.075819 & 0.075819 \\
\hline \multirow[t]{2}{*}{ Tangible cost } & 1Recovery cost & 0.1840 & 0.1840 & 0.1840 & 0.1840 & 0.184018 & 0.184018 & 0.184018 & 0.184018 \\
\hline & 2Unavailability cost & 0.1910 & 0.1910 & 0.1910 & 0.1910 & 0.190982 & 0.190982 & 0.190982 & 0.190982 \\
\hline
\end{tabular}

\section{Risks decision networks}

\begin{tabular}{|c|c|c|c|c|c|c|c|c|}
\hline \multirow{2}{*}{\multicolumn{2}{|c|}{$\begin{array}{l}\text { Limitmatrix } \\
\text { External Risks }\end{array}$}} & \multicolumn{4}{|c|}{ Alternatives } & \multicolumn{2}{|c|}{ Relations } & \multirow{2}{*}{\begin{tabular}{|l|}
\multicolumn{1}{|c|}{ Reputation } \\
3Lasting negative impact on \\
reputation
\end{tabular}} \\
\hline & & 1 Multiple Suppliers & 2 Excess Inventory & 3 Technological Substitution & 4. Passive Acceptance & $\begin{array}{l}\text { 1Damaged customer } \\
\text { relations }\end{array}$ & $\begin{array}{l}\text { 2Damaged supplier } \\
\text { relations }\end{array}$ & \\
\hline \multirow[t]{4}{*}{ Alternatives } & 1_Multiple Suppliers & 0.0864 & 0.0864 & 0.0864 & 0.0864 & 0.0864 & 0.0864 & 0.0864 \\
\hline & 2_Excess Inventory & 0.0683 & 0.0683 & 0.0683 & 0.0683 & 0.0683 & 0.0683 & 0.0683 \\
\hline & 3_Technological Substitution & 0.1286 & 0.1286 & 0.1286 & 0.1286 & 0.1286 & 0.1286 & 0.1286 \\
\hline & 4_Passive Acceptance & 0.2167 & 0.2167 & 0.2167 & 0.2167 & 0.2167 & 0.2167 & 0.2167 \\
\hline \multirow[t]{2}{*}{ Relations } & 1Damaged customer relations & 0.2784 & 0.2784 & 0.2784 & 0.2784 & 0.2784 & 0.2784 & 0.2784 \\
\hline & 2Damaged supplier relations & 0.2216 & 0.2216 & 0.2216 & 0.2216 & 0.2216 & 0.2216 & 0.2216 \\
\hline Reputation & 3Lasting negative impact on reputation & 0.0000 & 0.0000 & 0.0000 & 0.0000 & 0.0000 & 0.0000 & 0.0000 \\
\hline
\end{tabular}

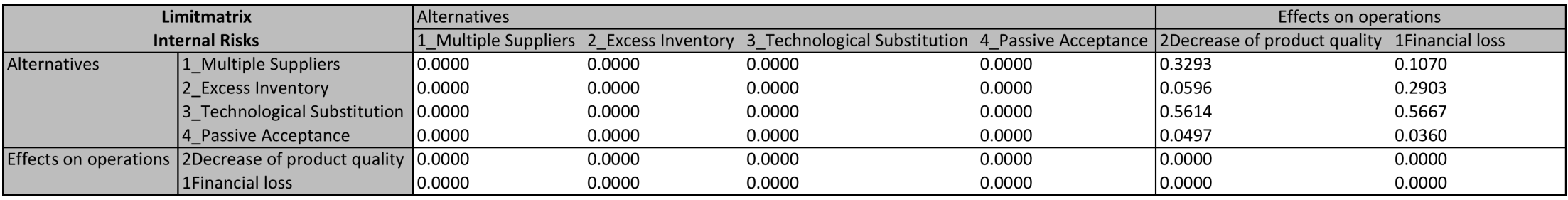


E) Table of Rating Standards used for BOCR-ANP Model

\begin{tabular}{|l|l|l|l|r|}
\hline Category name 1 & Category name 2 & Category name 3 & Category name 4 & Numerical value \\
\hline High influence & Increase & Improvement & Positive influence & 0.71075 \\
\hline Medium influence & Stable & Stable & Neutral & 0.24307 \\
\hline Low influence & Decrease & Degradation & Negative influence & 0.04618 \\
\hline No influence & No influence & No influence & No influence & 0.00000 \\
\hline
\end{tabular}


F) Case Study: ANP Input Questionnaire

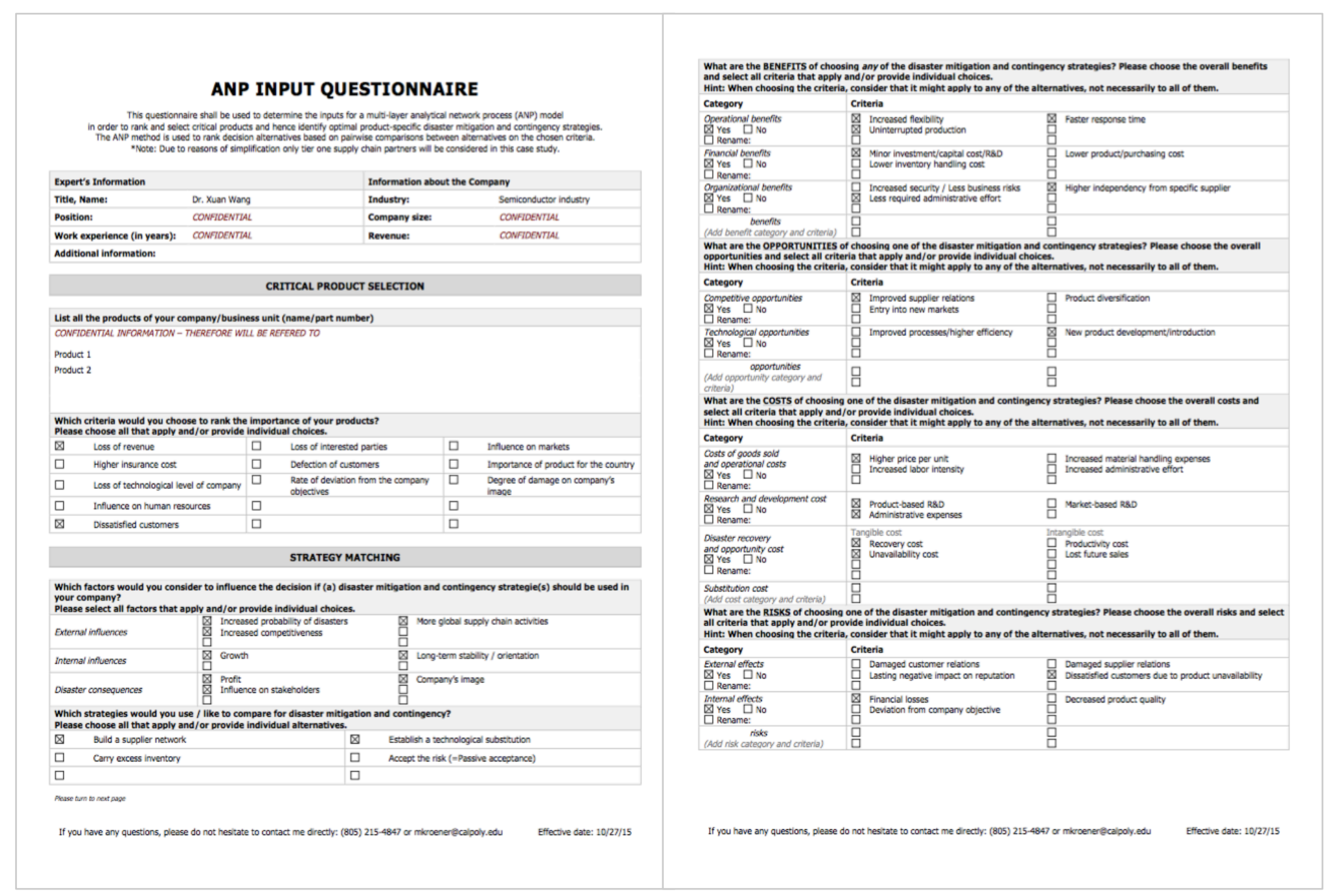


G) Case Study: Priorities per BOCR Merit

\begin{tabular}{llll}
\hline Merit & Criteria & Subcriteria & Local priorities \\
\hline Benefits & Operational benefits & Increased flexibility & 0.0948 \\
& & Uninterrupted production & 0.0163 \\
& Financial benefits & Minor investment in R\&D & 0.0098 \\
& Organizational benefits & Less required administrative effort & 0.7641 \\
Opportunities & Competitive opportunities & Improved supplier relations & 0.1149 \\
& & & 0.7500 \\
Technological opportuni- & New product development/introduction & 0.2500 \\
ties & & Price per unit increases & 0.5265 \\
& Costs of goods sold & & 0.2451 \\
& Operating expenses & Research and Development & 0.0817
\end{tabular}


H) Case Study: Rating of Strategic Criteria vs. BOCR Merits

\begin{tabular}{lcccc}
\hline Strategic criteria & \multicolumn{3}{c}{ Rating of highest ranked alternative } \\
& Benefits & Opportunities & Costs & Risks \\
\hline Increased probability of disasters (0.0190) & Low & No influence & Medium & Medium \\
Globalization (0.0066) & No influence & No influence & No influence & No influence \\
Competitive behavior (0.0273) & High & High & Medium & Medium \\
Growth/Long-term orientation (0.2664) & Medium & Medium & Medium & Medium \\
Profit (0.0586) & Increase & Increase & Stable & Stable \\
Image $(0.2718)$ & Stable & Stable & Stable & Stable \\
Stakeholders $(0.3503)$ & Negative & Negative & Negative & Negative \\
\hline Priorities & $\mathbf{0 . 2 7 4 4}$ & $\mathbf{0 . 2 7 4 4}$ & $\mathbf{0 . 2 2 6 3}$ & $\mathbf{0 . 2 2 6 3}$ \\
\hline
\end{tabular}


I) Case study: Super-/Limitmatrices for each BOCR Merit

\begin{tabular}{|c|c|c|c|c|c|c|c|c|c|c|c|}
\hline \multirow{2}{*}{\multicolumn{2}{|c|}{ Supermatrix }} & \multicolumn{3}{|c|}{ 1_Operational Benefits } & \multirow{2}{*}{\begin{tabular}{|l|} 
2_Financial \\
Benefits \\
$4 \_$Minor \\
investment in \\
R\&D \\
\end{tabular}} & \multirow{2}{*}{\begin{tabular}{|l} 
3_Organizationa \\
1 Benefits \\
5_Less required \\
administrative \\
effort \\
\end{tabular}} & \multicolumn{2}{|c|}{ ALTERNATIVES } & \multicolumn{3}{|c|}{ Benefits } \\
\hline & & \begin{tabular}{|l|} 
1_Increased \\
flexibility
\end{tabular} & $\begin{array}{l}\text { 2_Uninterrupte } \\
\text { d production }\end{array}$ & $\begin{array}{l}\text { 3_Faster response } \\
\text { time }\end{array}$ & & & \begin{tabular}{|l|} 
Build a \\
supplier \\
network
\end{tabular} & $\begin{array}{l}\text { Establish a } \\
\text { technological } \\
\text { substitution }\end{array}$ & \begin{tabular}{|l} 
1_Operational \\
Benefits
\end{tabular} & $\begin{array}{l}\text { 2_Financia } \\
\text { I Benefits }\end{array}$ & $\begin{array}{l}\text { 3_Organizationa } \\
\text { I Benefits }\end{array}$ \\
\hline \begin{tabular}{|l|} 
1_Operational \\
Benefits
\end{tabular} & \begin{tabular}{|l} 
1_Increased \\
flexibility \\
2_Uninterrupted \\
production \\
3_Faster response \\
time
\end{tabular} & 0 & $\begin{array}{l}0 \\
0 \\
0\end{array}$ & $\begin{array}{l}0 \\
0 \\
0\end{array}$ & 0 & 0 & 0 & $\begin{array}{l}0 \\
0 \\
0\end{array}$ & $\begin{array}{l}0.3919 \\
0.0675 \\
0.0407\end{array}$ & $\begin{array}{l}0 \\
0 \\
0\end{array}$ & $\begin{array}{l}0 \\
0 \\
0\end{array}$ \\
\hline \begin{tabular}{|l} 
2_Financial \\
Benefits
\end{tabular} & $\begin{array}{l}\text { 4_Minor } \\
\text { investment in R\&D }\end{array}$ & 0 & 0 & 0 & 0 & 0 & 0 & 0 & 0 & 0.5000 & 0 \\
\hline $\begin{array}{l}\text { 3_Organizationa } \\
\text { I Benefits }\end{array}$ & \begin{tabular}{|l} 
5_Less required \\
administrative \\
effort
\end{tabular} & 0 & 0 & 0 & 0 & 0 & 0 & 0 & 0 & 0 & 0.5000 \\
\hline ALTERNATIVES & \begin{tabular}{|l} 
Build a supplier \\
network \\
Establish a \\
technological \\
substitution
\end{tabular} & 0 & $\begin{array}{l}0 \\
0\end{array}$ & $\begin{array}{l}0 \\
0\end{array}$ & 0 & 0 & 0 & $\begin{array}{l}0 \\
0\end{array}$ & $\begin{array}{l}0.1000 \\
0.4000\end{array}$ & $\begin{array}{l}0.4167 \\
0.0833\end{array}$ & $\begin{array}{l}0.2500 \\
0.2500\end{array}$ \\
\hline Benefits & $\begin{array}{l}\text { 1_Operational } \\
\text { Benefits } \\
\text { 2_Financial } \\
\text { Benefits } \\
\text { 3_Organizational } \\
\text { Benefits }\end{array}$ & 0 & $\begin{array}{l}0 \\
0 \\
0\end{array}$ & $\begin{array}{l}0 \\
0\end{array}$ & $\left.\right|_{0} ^{0}$ & 0 & $\begin{array}{l}0.1210 \\
0.7641 \\
0.1149\end{array}$ & $\begin{array}{l}0.1210 \\
0.7641 \\
0.1149\end{array}$ & $\left.\right|_{0} ^{0}$ & $\begin{array}{l}0 \\
0 \\
0\end{array}$ & $\begin{array}{l}0 \\
0 \\
0\end{array}$ \\
\hline
\end{tabular}




\section{Limitmatrix for Benefits merit}

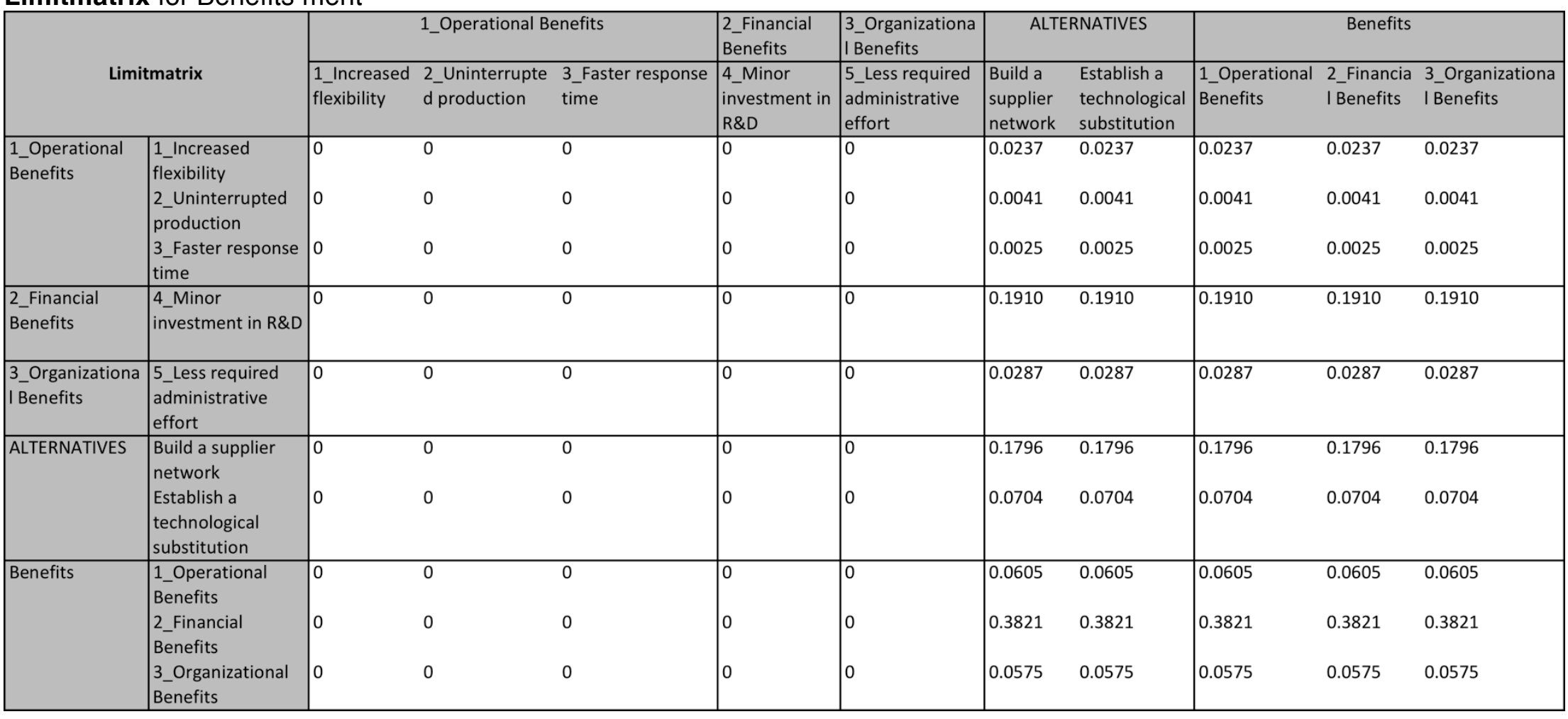




\section{Supermatrix for Opportunities merit}

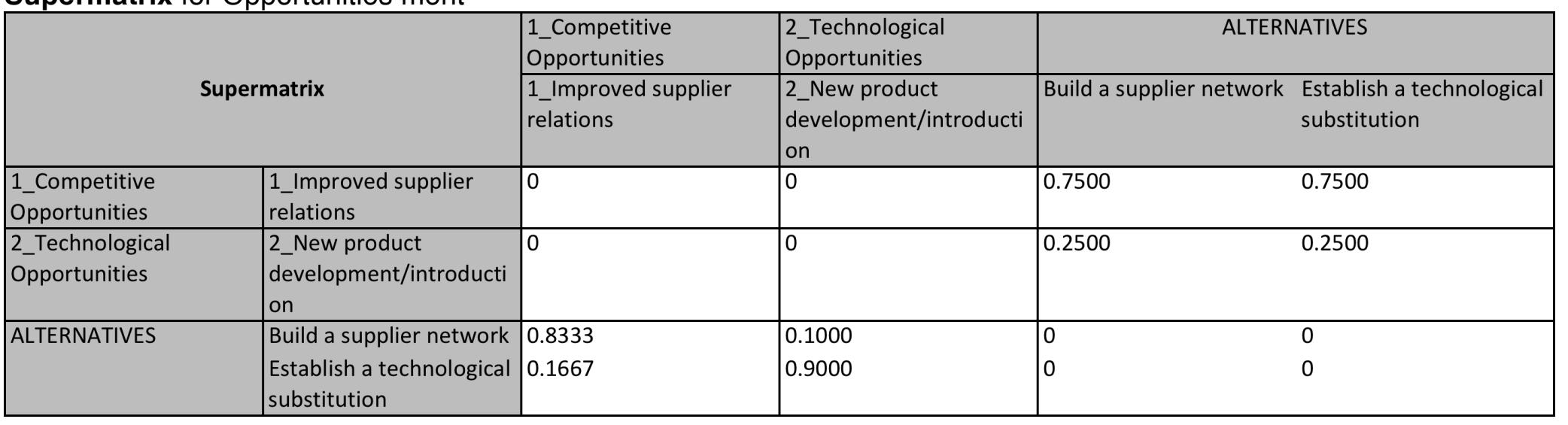

Limitmatrix for Opportunities merit

\begin{tabular}{|c|c|c|c|c|c|}
\hline & \multicolumn{2}{|c|}{ 2_Technological Opportunities } \\
\hline \multicolumn{2}{|c|}{ Limitmatrix } & $\begin{array}{l}\text { 1_Improved supplier } \\
\text { relations }\end{array}$ & $\begin{array}{l}\text { 2_New product } \\
\text { development/introduc } \\
\text { tion }\end{array}$ & $\begin{array}{l}\text { Build a supplier } \\
\text { network }\end{array}$ & $\begin{array}{l}\text { Establish a } \\
\text { technological } \\
\text { substitution }\end{array}$ \\
\hline $\begin{array}{l}\text { 1_Competitive } \\
\text { Opportunities }\end{array}$ & $\begin{array}{l}\text { 1_Improved supplier } \\
\text { relations }\end{array}$ & 0.3750 & 0.3750 & 0.3750 & 0.3750 \\
\hline $\begin{array}{l}\text { 2_Technological } \\
\text { Opportunities }\end{array}$ & $\begin{array}{l}\text { 2_New product } \\
\text { development/introduc } \\
\text { tion }\end{array}$ & 0.1250 & 0.1250 & 0.1250 & 0.1250 \\
\hline ALTERNATIVES & $\begin{array}{l}\text { Build a supplier } \\
\text { network } \\
\text { Establish a } \\
\text { technological } \\
\text { substitution }\end{array}$ & $\begin{array}{l}0.3250 \\
0.1750\end{array}$ & $\begin{array}{l}0.3250 \\
0.1750\end{array}$ & $\begin{array}{l}0.3250 \\
0.1750\end{array}$ & $\begin{array}{l}0.3250 \\
0.1750\end{array}$ \\
\hline
\end{tabular}


Supermatrix for Costs merit

\begin{tabular}{|c|c|c|c|c|c|c|c|c|c|c|c|}
\hline \multirow{2}{*}{\multicolumn{2}{|c|}{ Supermatrix }} & \multirow{2}{*}{\begin{tabular}{|l} 
1_Cost of goods \\
sold (COGS) \\
$\begin{array}{l}\text { 1_Price per Unit } \\
\text { increases }\end{array}$
\end{tabular}} & \multicolumn{2}{|c|}{ 2_Operating Expenses } & \multicolumn{2}{|c|}{ 3_Disaster Recovery Cost } & \multicolumn{2}{|c|}{ ALTERNATIVES } & \multicolumn{3}{|c|}{ Costs } \\
\hline & & & $\begin{array}{l}\text { 2_Research and } \\
\text { Development }\end{array}$ & $\begin{array}{l}\text { 3_Administrativ } \\
\text { e expenses }\end{array}$ & 4_Recovery cost & $\begin{array}{l}\text { 5_Unavailability } \\
\text { cost }\end{array}$ & $\begin{array}{l}\text { Build a supplier } \\
\text { network }\end{array}$ & $\begin{array}{l}\text { Establish a } \\
\text { technological } \\
\text { substitution }\end{array}$ & $\begin{array}{l}\text { 1_Cost of goods } \\
\text { sold (COGS) }\end{array}$ & $\begin{array}{l}\text { 2_Operating } \\
\text { Expenses }\end{array}$ & $\begin{array}{l}\text { 3_Disaster } \\
\text { Recovery Cost }\end{array}$ \\
\hline $\begin{array}{l}\text { 1_Cost of goods } \\
\text { sold (COGS) }\end{array}$ & $\begin{array}{l}\text { 1_Price per Unit } \\
\text { increases }\end{array}$ & 0 & 0 & 0 & 0 & 0 & 0 & 0 & 0.5000 & 0 & 0 \\
\hline $\begin{array}{l}\text { 2_Operating } \\
\text { Expenses }\end{array}$ & $\begin{array}{l}\text { 2_Research and } \\
\text { Development } \\
\text { 3_Administrative } \\
\text { expenses }\end{array}$ & 0 & 0 & 0 & 0 & $\begin{array}{l}0 \\
0\end{array}$ & 0 & $\begin{array}{l}0 \\
0\end{array}$ & 0 & $\begin{array}{l}0.3750 \\
0.1250\end{array}$ & $\begin{array}{l}0 \\
0\end{array}$ \\
\hline 3_Disaster & 4_Recovery cost & 0 & 0 & 0 & 0 & 0 & 0 & 0 & 0 & 0 & 0.1250 \\
\hline Recovery Cost & $\begin{array}{l}\text { 5_Unavailability } \\
\text { cost }\end{array}$ & 0 & 0 & 0 & 0 & 0 & 0 & 0 & 0 & 0 & 0.3750 \\
\hline \begin{tabular}{|l} 
ALTERNATIVES \\
\end{tabular} & $\begin{array}{l}\text { Build a supplier } \\
\text { network } \\
\text { Establish a } \\
\text { technological } \\
\text { substitution }\end{array}$ & 0 & 0 & 0 & $\int_{0}^{0}$ & $\begin{array}{l}0 \\
0\end{array}$ & 0 & $\begin{array}{l}0 \\
0\end{array}$ & $\begin{array}{l}0.0833 \\
0.4167\end{array}$ & $\begin{array}{l}0.1000 \\
0.4000\end{array}$ & $\begin{array}{l}0.1000 \\
0.4000\end{array}$ \\
\hline Costs & $\begin{array}{l}\text { 1_Cost of goods } \\
\text { sold (COGS) } \\
\text { 2_Operating } \\
\text { Expenses } \\
\text { 3_Disaster } \\
\text { Recovery Cost }\end{array}$ & 0 & 0 & $\begin{array}{l}0 \\
0\end{array}$ & $\begin{array}{l}0 \\
0 \\
0\end{array}$ & $\begin{array}{l}0 \\
0 \\
0\end{array}$ & $\begin{array}{l}0.2255 \\
0.6738 \\
0.1007\end{array}$ & $\begin{array}{l}0.5936 \\
0.2493 \\
0.1571\end{array}$ & $\begin{array}{l}0 \\
0 \\
0\end{array}$ & 0 & $\begin{array}{l}0 \\
0 \\
0\end{array}$ \\
\hline
\end{tabular}




\section{Limitmatrix for Costs merit}

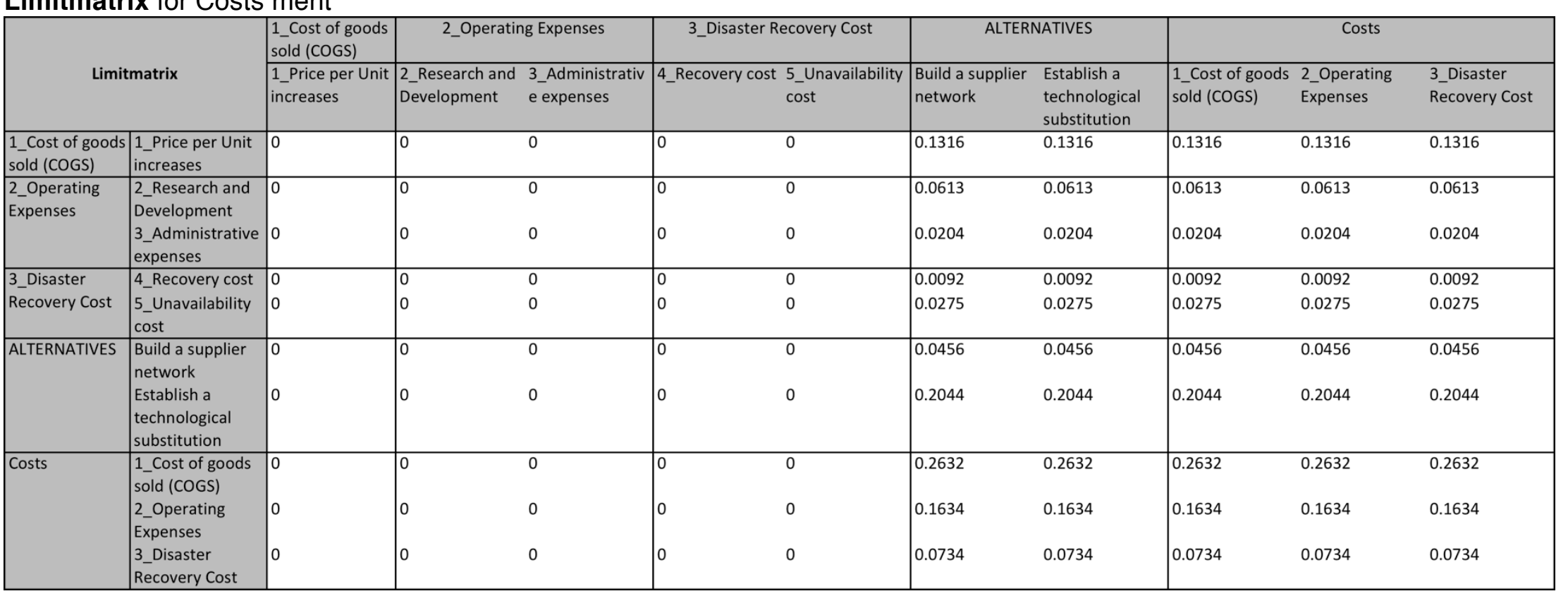


Supermatrix for Risks merit

\begin{tabular}{|l|l|l|l|ll|}
\hline \multicolumn{2}{|c|}{ Supermatrix } & 1_External effects & 2_Internal effects & \multicolumn{2}{c|}{ ALTERNATIVES } \\
\cline { 2 - 6 } & $\begin{array}{l}\text { 1_Dissatisfied } \\
\text { customers due to } \\
\text { product unaivalability }\end{array}$ & 2_Financial losses & $\begin{array}{l}\text { Build a supplier } \\
\text { network }\end{array}$ & $\begin{array}{l}\text { Establish a } \\
\text { technological } \\
\text { substitution }\end{array}$ \\
\hline 1_External effects & $\begin{array}{l}\text { 1_Dissatisfied } \\
\text { customers due to } \\
\text { product unaivalability }\end{array}$ & 0 & 0 & 0.1667 & 0.1667 \\
\hline 2_Internal effects & 2_Financial losses & 0 & 0 & 0.8333 & 0.8333 \\
\hline ALTERNATIVES & $\begin{array}{l}\text { Build a supplier } \\
\text { network } \\
\text { Establish a } \\
\text { technological } \\
\text { substitution }\end{array}$ & 0.2000 & 0.1667 & 0 & 0 \\
\hline
\end{tabular}

Limitmatrix for Risks merit

\begin{tabular}{|l|l|l|l|ll|}
\hline \multicolumn{2}{|c|}{ Limitmatrix } & 1_External effects & 2_Internal effects & \multicolumn{2}{|c|}{ ALTERNATIVES } \\
\cline { 2 - 6 } & $\begin{array}{l}\text { 1_Dissatisfied } \\
\text { customers due to } \\
\text { product unaivalability }\end{array}$ & 2_Financial losses & $\begin{array}{l}\text { Build a supplier } \\
\text { network }\end{array}$ & $\begin{array}{l}\text { Establish a } \\
\text { technological } \\
\text { substitution }\end{array}$ \\
\hline 1_External effects & $\begin{array}{l}\text { 1_Dissatisfied } \\
\text { customers due to } \\
\text { product unaivalability }\end{array}$ & 0.0833 & 0.0833 & 0.0833 & 0.0833 \\
\hline 2_Internal effects & 2_Financial losses & 0.4167 & 0.4167 & 0.4167 & 0.4167 \\
\hline ALTERNATIVES & $\begin{array}{l}\text { Build a supplier } \\
\text { network } \\
\text { Establish a } \\
\text { technological } \\
\text { substitution }\end{array}$ & 0.0861 & 0.0861 & 0.0861 & 0.0861 \\
& 0.4139 & 0.4139 & 0.4139 & 0.4139 \\
\hline
\end{tabular}

